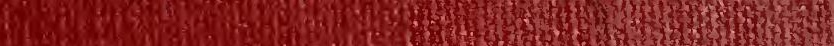
19.0.

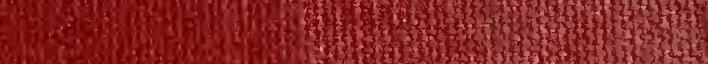
Von 1000 Whir Ho

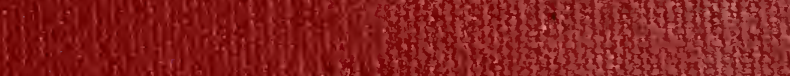
9.9.0. Q3 3 3. Liflow

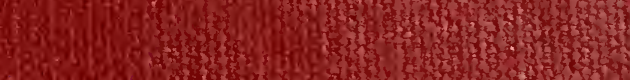

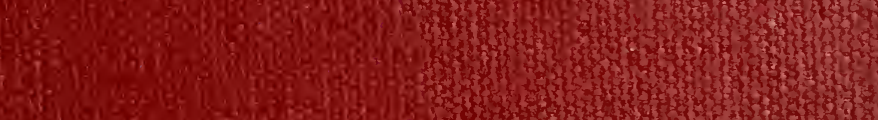
- 50 or P8: Ang Sign 6. Q कर 5y.j. (1)

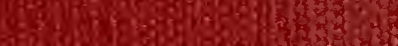

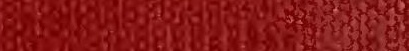
That

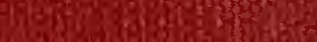
(4) 194.

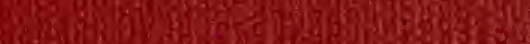

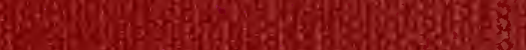

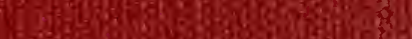
if 6ub bos.

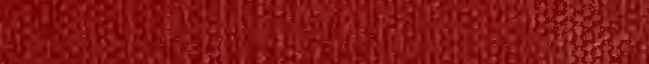
290

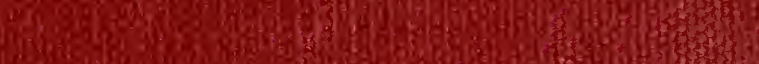

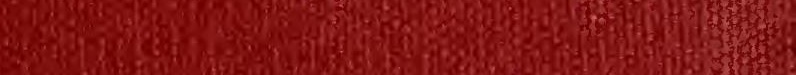
1892 Nas

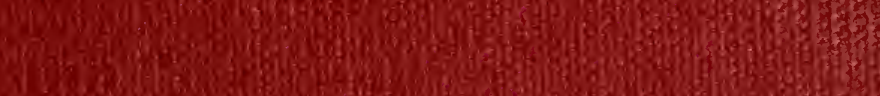

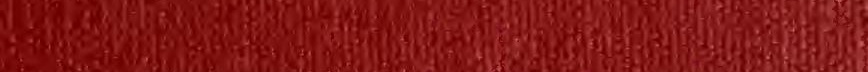
X. Wh

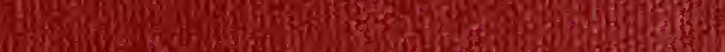

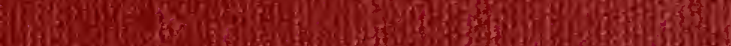
Mes -

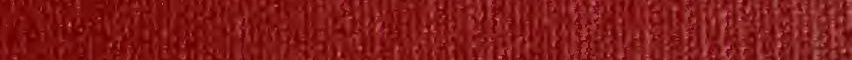
6horen 150. 6030. 


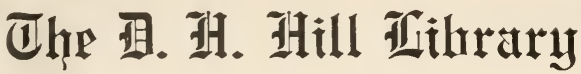

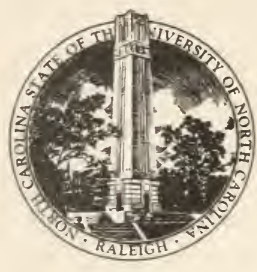

Wurth Carnlina State

QHH 43

$\operatorname{cog}$

$\operatorname{cop} \cdot 2$

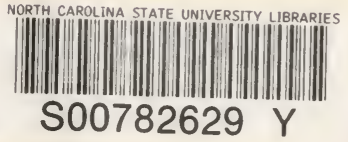


29452

This book is due on the date indicated below and is subject to a fine of FIVE CENTS a day thereafter.

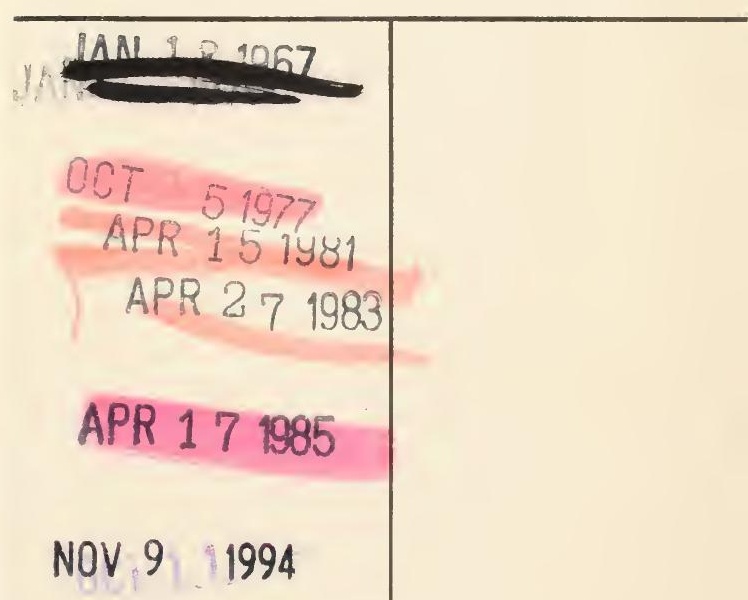



HORMONES AND HEREDITY 



\section{HORMONES AND HEREDITY}

A DISCUSSION OF THE EVOLUTION OF ADAPTATIONS AND THE EVOLUTION OF SPECIES

BY

J. T. CUNNINGHAM, M.A. (OxON), F.Z.S.

SOMETIME FELLOW OF UNIVERSITY COLLEGE, OXFORD LECTURER IN ZOOLOGY AT EAST LONION COLLEGE UNIVERSITY OF LONDON

NEW YORK

THE MACMILLAN COMPANY

$64 \& 66$ FIFTH AVENUE 
Printed in Great Britain 


\section{PREFACE}

My chief object in writing this volume was to discuss the relations of modern discoveries concerning hormones or internal secretions to the question of the evolution of adaptations, and on the other hand to the results of recent investigations of Mendelian heredity and mutations. I have frequently found, from verbal or written references to my opinions, that the evidence on these questions and my own conclusions from that evidence were either imperfectly known or misunderstood. This is not surprising in view of the fact that hitherto my only publications on the hormone theory have been a paper in a German periodical and a chapter in an elementary text-book. The present publication is by no means a thorough or complete exposition of the subject, it is merely an attempt to state the fundamental facts and conclusions, the importance of which it seems to me are not generally appreciated by biologists.

I have reviewed some of the chief of the recent discoveries concerning mutations, Mendelism, chromosomes, etc., but have not thought it necessary to repeat the illustrations which are contained in many of the volumes to which I have referred. I have made some Mendelian experiments myself, not always with results in agreement with the strict 
Mendelian doctrine, so that I am not venturing to criticise without experience. I have not hesitated to reprint the figure, published many years ago, of a Flounder showing the production of pigment under the influence of light, because I thought it was desirable that the reader should have before him this figure and those of an example of mutation in the Turbot for comparison when following the argument concerning mutation and recapitulation.

I take this opportunity of expressing my thanks to the Councils of the Royal Society and the Zoological Society for permission to reproduce the figures in the Plates. I also desire to thank Professor Dendy, F.R.S., of King's College for his sympathetic interest in the publication of the book, and Messrs. Constable and Co. for the care they have taken in its production.

J. T. CUNNINGHAM.

London, June 1921. 


\section{CONTENTS}

\section{INTRODUCTION}

HISTORICAL SURVEY OF THEORIES OR SUGGESTIONS OF CHEMICAL INFLUENCE IN HEREDITY . . . xi

\section{CHAPTER I}

CLASSIFICATION AND ADAPTATION .

\section{CHAP'TER II}

MENDELISM AND THE HEREDITY OF SEX

\section{CHAPTER III}

INFLUENCE OF HORMIONES ON DEVELOPMENT OF SOMATIC SEX-CHARACTERS

\section{CHAPTER IV}

ORIGIN OF SOMATIC SEX-CHARACTERS IN EVOLUTION .

\section{CHAPTER V}

MAMMALIAN SEXUAL CHARACTERS. EVIDENCF OPPOSED TO THE HORMONE THEORY . 
viii HORMONES AND HEREDITY

\section{CHAPTER VI}

ORIGIN OF NON-SEXUAL CHARACTERS: THE PHENOMENA

of mutation

PAGK

\section{CHAPTER VII}

METAMORPHOSIS AND RECAPITULATION

. 198

INDEX $\quad . \quad$. $\quad . \quad$. $\quad 243$

. 170 


\section{LIST OF PLATES}

Plate I. Recessive Pile Fowls . . . to face $p .47$

" II. Abnormal Specimen of Turbot . . . 206

" III. Flounder, showing Pigmentation of Lower

Side after Exposure to Liaht . • „ 212 



\section{INTRODUCTION}

HISTORICAL SURVEY OF THEORIES OR SUGGESTIONS OF CHEMICAL INFLUENCE IN HEREDITY

WeIsmans, strongly as he denied the possibility of the transmission of somatic modifications, admitted the possibility or even the fact of the simultaneous modification of soma and germ by external conditions such as temperature. Yves Delage ${ }^{1}$ in 1895, in discussing this question, pointed out how changes affecting the soma would produce an effect on the ovum (and presumably in a similar way on the sperm). He writes:-

' Ce qui empêche l'œuf de recevoir la modification reversible c'est qu'étant constitué autrement que les cellules différenciées de l'organisme il est influencé autrement qu'elles par les mêmes causes perturbatrices. Mais est-il impossible que malgré la différence de constitution physico-chimiques il soit influencé de la même façon ?'

The author's meaning would probably have been better expressed if he had written 'ce qui paraît empêcher.' By 'modification reversible' he means a change in the ovum which will produce in the next generation a somatic modification similar to that by which it was produced. It seems natural to think of the influence of the ovum on the body and of the body on the ovum as of similar kind but in opposite directions, but it must be remembered always that

1 Yves Delage, L'Hérédité (Paris, 1895), pp. 806-812. 
the development of the body from the ovum is not an influence at all but a direct conversion by celldivision and differentiation of the ovum into the body.

Delage argues that if the egg contains the substances characteristic of certain categories of cells of the organism it ought to be affected at the same time as those cells and by the same agents. He thinks that the egg only contains the substances or the arrangements characteristic of certain general functions (nervous, muscular, perhaps glandular of divers kinds) but without attribution to localised organs. In his view there is no representation of parts or of functions in the ovum, but a simple qualitative conformity of constitution between the egg and the categories of cells which in the body are charged with the accomplishment of the principal functions. Thus mutilations of organs formed of tissues occurring also elsewhere in the body cannot be hereditary, but if the organ affected contains the whole of a certain kind of tissue such as liver, spleen, kidney, then the blood undergoes a qualitative modification which reacts on the constitution of the egg.

Suppose the internal secretion of a gland (e.g. glucose for the liver, glycolytic ferment for the pancreas) is the physiological excitant for the gland. If the gland is removed in whole or in part the proportion of its internal secretion in the blood will be diminished. Then the gland, if the suppression is partial, will undergo a new diminution of activity. But in the egg the specific substance of the gland will also be less stimulated, and in the next generation a diminution of the gland may result. Thus Delage states Massin found that partial removal of the liver in rabbits had an inherited effect. In the case of excretory glands the contrary will be the case, 
for their removal causes increase in the blood of the exciting substances urea and uric acid.

The effects of disuse are similar to those of mutilations and of use vice versa. Delage, as seen above, does not consider that increase or decrease of particular muscles can be inherited, but only the muscular system in general. If, however, in consequence of the disuse of a group of muscles there was a general diminution of the inherited muscular system, the special group would remain diminished while the rest were developed by use in the individual: there would thus be a special heredity produced indirectly. With regard to general conditions of life, Delage states that there are only two of which we know anything-namely, climate and alimentation-and he merely suggests that temperature and food act at the same time on the cells of the body and on the similar substances in the egg.

H. M. Vernon (Variation in Animals and Plants, 1903, pp. 351 seq.) cites instances of the cumulative effects of changed conditions of life, and points out that they are not really instances of the inheritance of acquired characters, but merely of the germplasm and the body tissues being simultaneously affected. He then asks, Through what agency is the environment enabled to act on the germ-plasm ? And answers that the only conceivable one is a chemical influence through products of metabolism and specific internal secretions. He cites several cases of specific internal secretions, making one statement in particular which seems unintelligible, viz. that extirpation of the total kidney substance of a dog leads not to a diminished secretion of urine but to a largely increased secretion accompanied by a rapid wasting away which soon ends fatally. 
Whenever a changed environment acts upon the organism, therefore, it to some extent affects the normal excretions and secretions of some or all of the various tissues, and these react not only on the tissues themselves, but also to a less degree upon the determinants representing them in the germ-plasm. Thus the relative size of the brain has decreased in the tame rabbit. This may be due to disuse; the excretions and secretions of the nervous tissues would be diminished, and the corresponding determinants less stimulated. Another instance is afforded by pigmentation of the skin in man; which varies with the amount of light and heat from the sun to which the skin is exposed. Specific excretory products of pigment in the skin may stimulate the pigment determinants in the germ-plasm to increased vigour. But only those characters of which the corresponding tissues possess a specific secretion or excretion could become hereditary in this way. For instance, the brawny arm of the blacksmith could not be transmitted, as it is scarcely possible that the arm muscles can have a secretion different from that of the other muscles.

In 1904, P. Schiefferdecker ${ }^{1}$ made the definite suggestion that the presence of specific internal secretions could be very well used for the explanation of the inheritance of acquired characters. When particular parts of the body were changed, these modifications must change the mixture of materials in the blood by the substances secreted by the changed parts. Thereby would be found a connexion between the modified parts of the body and the germ-cells, the only connexion in existence. It is to

1 P. Schiefferdecker, Ueber Symbiose. S.B. d. Niederrhein. Gesellsch. zu Bonn. Sitzung der Medicinischen Sektion, 13 Juni 1904. 
be assumed, according to this author, that only a qualitative change in the nutritive fluid of the germcells could produce an effect : a quantitative change would only cause increased or decreased nourishment of the entire germ cells.

In my own volume on Sexual Dimorphism in the Animal Kingdom, published in 1900, I attempted to explain the limitation of secondary sexual characters not only to one sex, but usually to one period of the individual life, namely, that of sexual maturity; and in some cases, as in male Cervidae, to one season of the year in which alone the sexual organs are active. It had been known for centuries that the normal development of male sexual characters did not take place in castrated animals, but the exact nature of the influence of the male generative organs on that development was not known till a year or two later than 1900, when it was shown to be due to an internal secretion. My argument was that all selection theories failed to account for the limitation of secondary sexual characters in heredity, whereas the Lamarckian theory would explain them if the assumption were made that the effects of stimulation having been originally produced when the body and tissues were under the influence of the sexual organs in functional activity, these effects were only developed in heredity when the body was in the same condition.

About the year 1906, when preparing two special lectures in London University on the same subject, I became acquainted with the work of Starling and others on internal secretions or hormones, and saw at once that the hormone from the testes was the actual agent which constituted the "influence" assumed by me in 1900. In these lectures I 
elaborated a definite Lamarckian theory of the origin of Secondary Sexual Characters in relation to Hormones, extending the theory also to ordinary adaptive structures and characters which are not related to sex. Having met with many obstacles in endeavouring to get a paper founded on the original lectures published in England, I finally sent it to Professor Wilhelm Roux, the editor of the Archiv für Entwicklungsmechanik der Organismen, in which it was published in 1908.

In his volume on the Embryology of the Invertebrata, 1914 (Text-Book of Embryology, edited by Walter Heape, vol. i.), Professor E. W. MacBride in his general summary (chapter xviii.) puts forward suggestions concerning hormones without any reference to those who have discussed the subject previously. He considers the matter from the point of view of development, and after indicating the probability that hormones are given off by all the tissues of the body, gives instances of organs being formed in regeneration (eye of shrimp) or larvae (common sea-urchin) as the result of the presence of neighbouring organs, an influence which he thinks can only be due to a hormone given off by the organ already present. He then states that Professor Langley had pointed out to him in correspondence that if an animal changes its structure in response to a changed environment, the hormones produced by the altered organs will be changed. The altered hormones will circulate in the blood and bathe the growing and maturing genital cells. Sooner or later, he assumes, some of these hormones may become incorporated in the nuclear matter of the genital cells, and when these cells develop into embryos the hormones will be set free at the corresponding 
period of development at which they were originally formed, and reinforce the action of the environment. In this way MacBride attempts to explain recapitulation in development and the tendency to precocity in the development of ancestral structures. His idea that the hormones act by 'incorporation' in the genital cells is different from that of stimulation of determinants put forward by myself and others, but it is surprising that he should refer to unpublished suggestions of Professor Langley, and not to the publications of authors who had previously discussed the possible action of hormones in connexion with the heredity of somatic modifications.

Dr. J. G. Adami in 1918 published the Croonian Lectures, delivered by him in 1917 under the title 'Adaptation and Disease,' together with reprints of previous papers, in a volume entitled Medical Contributions to the Study of Evolution. In this work (footnote, p. 71) the author claims that he preceded Professor Y $\mathrm{Ves}_{\text {ves }}$ Delage by some two years in offering a physico-chemical hypothesis in place of determinants, and also asserts that 'the conclusions reached by him in 1901 regarding metabolites and, as we subsequently became accustomed to term them, hormones, and their influence on the germcells, have since been enunciated by Heape, Bourne, Cunningham, MacBride, and Dendy, although in each case without note of his (Adami's) earlier contribution.' These somewhat extensive claims deserve careful and impartial examination. The paper to which Dr. Adami refers was an Annual Address to the Brooklyn Medical Club, published in the New York Medical Journal and the British Medical Journal in 1901, and entitled 'On Theories of Inheritance, with special reference to Inheritance 
of Acquired Conditions in Man.' The belief that this paper had two years' priority over the volume of Delage entitled L'Hérédité appears to have arisen from the fact that Adami consulted the bibliographical list in Thomson's compilation, Heredity, 1908, where the date of Delage's work is given as 1903. But this was the second edition, the first having been published, as quoted above, in 1895, six years before the paper by Adami.

Next, with regard to the claim that Adami's views as stated in the paper to which he refers were essentially the same as those brought forward by myself and others many years later, we find on reading the paper that its author discussed merely the effect of toxins in disease upon the body-cells and the germ-cells, causing in the offspring either various forms of arrested and imperfect development or some degree of immunity. In the latter case he argues that the action of the toxin of the disease has been to set up certain molecular changes, certain alterations in the composition of the cell-substance, so that the latter responds in a different manner when again brought into contact with the toxin. Once this modification in the cell-substance is produced, the descendants of this cell retain the same properties, although not permanently. Inheritance of the acquired condition has to be granted, he says, in the case of the body-cells in such cases. But this is not the question: inheritance in the proper sense of the word means the transmission to individuals of the next generation.

On this point Adami says we must logically admit the action of the toxins on the germ-cells, and the individuals developed from these must, subject to the law of loss already noted, have the same properties. 
He admits that inherited immunity is rare, but says that it has occasionally been noted. Here we have again merely the same influence, chemical in this case, acting simultaneously on somatic cells and germcells, which is not the inheritance of acquired characters at all. Adami remarks that Weismann would make the somewhat subtle distinction that the toxins produce these results not by acting on the body-cells but by direct action on the germ-cells, that the inheritance is blastogenic not somatogenic, and calls this 'a sorry and almost Jesuitic play upon words.' On the contrary, it is the essential point, which Adami fails to appreciate. However, he goes further and refers to endogenous intoxication, to disturbed states of the constitution, due to disturbances in glandular activity or to excess of certain internal secretions. Such disturbances he says, acting on the germ-cells, would be truly somatogenic. In the case of gout he considers that defect in body metabolism has led to intoxication of the germ-cells, and the offspring show a peculiar liability to be the subjects of intoxications of the same order. Now, however important these views and conclusions may be from the medical point of view, in relation to the heredity of general physiological or pathological conditions, they throw no light on the problems considered by myself and other biologists-namely, the origin of species and of structural adaptations.

There is no mention anywhere in Adami's short paper of the evolution or heredity of structural characters or adaptations such as wing of Bird or Bat, lung of Frog, asymmetry of Flat-fish or of specific characters, still less of secondary sexual characters, which formed the basis of the hormone theory in my 1908 paper. He does not even consider the evolu- 
tion of the structural adaptations which enable man to maintain the erect position on the two hind-limbs. $\mathrm{He}$ does not consider the action of external stimulation, whether the direct action on epidermal or other external structures or the indirect action through stimulation of functional activity. All his examples of external agents are toxins produced by bacteria invading the body, except in the case of gout, for which he suggests no external cause at all.

Only once in the last part of the paper considered does Adami mention internal secretions. His actual words are: 'We recognise yearly more and more the existence of auto-intoxications, of disturbed states of the constitution due to disturbances in glandular activity or to excess of certain internal secretions or of the substances ordinarily neutralised by the same.' The only example he gives is that of gout. How remote this is from the discoveries concerning the specific action of hormones on the growth of the body or of special parts of the body, or on the function of glands, and from a definite hormone theory of heredity as proposed by myself, is sufficiently obvious. 


\section{CHAP'TER I}

\section{CLASSIFICATION AND ADAPTATION}

The study of the animals and plants now living on the earth naturally divides itself into two branches, the one being concerned with their structure and classification, the other with their living activities, their habits, life histories, and reproduction. Both branches are usually included under the terms Natural History, or Zoology, or Botany, and a work on any group of animals usually attempts to describe their structure, their classification, and their habits. But these two branches of biological science are obviously distinct in their methods and aims, and each has its own specialists. The pursuit, whose ultimate object is to distinguish the various kinds of organisms and show their true and not merely apparent relations to one another in structure and descent, requires large collections of specimens for comparison and reference : it can be carried on more successfully in the museum than among the animals or plants in their natural surroundings. This study, which may be called Taxonomics, deals, in fact, with organisms as dead specimens, and it emphasises especially the distinguishing characters of the ultimate subdivisions of the various tribes of animals and plants-namely, species and varieties. The investigation, on the other hand, of the different modes of life of animals or 
plants is based on a different mental conception of them : it regards them primarily as living active organisms, not as dead and preserved specimens, and it can only be carried on successfully by observing them in their natural conditions, in the wide spaces of nature, under the open sky.

The object of this kind of inquiry is to ascertain what are the uses of organs or structures, what they are for, as we say in colloquial language, to discover what are their functions and how these functions are useful or necessary to the life of the animals or plants to which they belong. For example, some Cuttle-fishes or Cephalopoda have eight arms or tentacles and others ten. The taxonomist notices the fact and distinguishes the two groups of Octopoda and Decapoda.

But it is also of interest to ascertain what is the use of the two additional arms in the Decapoda. They differ from the other arms in being much longer, and provided with sockets into which they can be retracted, and suckers on them are limited to the terminal region. In the majority of zoological books in which Cephalopoda are described, nothing is said of the use or function of these two special arms. Observation of the living animal in aquaria has shown that their function is to capture active prey such as prawns. They act as a kind of double lasso. Sepia, for instance, approaches gently and cautiously till it is within striking distance of a prawn, then the two long tentacles are suddenly and swiftly shot out from their sockets and the prawn is caught between the suckers at the ends of them. Another example is afforded by the masked crab (Corystes cassivelaunus). This 
species has unusually long and hairy antennae. These are usually tactile organs, but it has been found that the habit of Corystes is to bury itself deep in the sand with only the tips of the antennae at the surface, and the two are placed close together so as to form a tube, down which a current of water, produced by movements of certain appendages, passes to the gill chamber and provides for the respiration of the crab while it is buried to a depth of two or three inches. The results of the investigation of habits and functions may be called Bionomics. It may be aided by scientific institutions specially designed to supplement mere observation in the field, such as menageries, aquaria, vivaria, marine laboratories, the objects of which are to bring the living organism under closer and more accurate observation. The differences between the methods and results of these two branches of Biology may be illustrated by comparing a British Museum Catalogue with one of Darwin's studies, such as the 'Fertilisation of Orchids' or 'Earthworms.'

Other speculations in Biology are related to Taxonomics or Bionomics according as they deal with the structure of the dead organism or the action of the living. Anatomy and its more theoretical interpretation, morphology, are related to Taxonomics, physiology and its branches to Bionomics. In fact, the fundamental principles of physiology must be understood before the study of Bionomics can begin. We must know the essential nature of the process of respiration before we can appreciate the different modes of respiration in a whale and a fish, an aquatic insect and a crustacean. The more we know of the physiology of reproduction, 
the better we can understand the sexual and parental habits of different kinds of animals.

The two branches of biological study which we are contrasting cannot, however, be completely separated even by those whose studies are most specialised. In Bionomics it is necessary to distinguish the types which are observed, and often even the species, as may be illustrated by the fact that controversies occasionally arise among amateur and even professional fishermen on the question whether dog-fishes are viviparous or oviparous, the fact being that some species are the one and others the other, or the fact that the harmless slow-worm and ring-snake are dreaded and killed in the belief that they are venomous snakes. Taxonomics, on the other hand, must take account of the sex of its specimens, and the changes of structure that an individual undergoes in the course of its life, and of the different types that may be normally produced from the same parents, otherwise absurd errors are perpetrated. The young, the male, and the female of the same species have frequently been described under different names as distinct species or even genera. For example, the larva of marine crabs was formerly described as a distinct genus under the name of Zoaea, and in the earlier part of the nineteenth century a lively controversy on the question was carried on between a retired naval surgeon who hatched Zoaea from the eggs of crabs, and an eminent authority who was Professor at Oxford and a Fellow of the Royal Society, and who maintained that Zoaca was a mature and independent form. In the end taxonomy had to be altered so as to conform with the fact of develop- 
ment, and the name Zoaea disappeared altogether as that of an independent genus, persisting only as a convenient term for an important larval stage in the development of crabs.

These two kinds of study give us a knowledge of the animals now living. But we find it a universal rule that the individual animal is transitory, that the duration of life, though varying from a few weeks to more than a century, is limited, and that new individuals arise by reproduction, and we have no evidence that the series of successive generations has ever been interrupted; that is to say, the series in any given individual or species may come to an end; species may be exterminated, but we know of no instance of individuals coming into existence except by the process of reproduction or generation from pre-existing individuals. Further, we know from the evidence of fossil remains that the animals existing in former periods were very different from those existing now, and that many of the existing forms, such as man, mammals, birds, bony fishes, can only be traced back in the succession of stratified rocks to the later strata or to those about the middle of the series, evidence of their existence in the periods represented by the most ancient strata being entirely absent. Existing types then must have arisen by evolution, by changes occurring in the succession of generations.

These three facts-namely, the limited duration of individual life, the uninterrupted succession of generations, and the differences of the existing animals and plants from those of former geological periods whose remains are preserved in stratified rocks-are sufficient by themselves to prove that 
evolution has taken place, that the history of organisms has been a process of descent with modification. If the animals and plants whose remains are preserved as fossils, or at any rate forms closely related to these, were not the ancestors of existing forms, there are only two other possibilities: either the existing forms came into existence by new creations after the older forms became extinct, or the ancestors of existing forms, although they coexisted with the older forms, never left any fossil remains. Each of these suppositions is incredible.

In view of these plain facts and their logical conclusion it is curious to notice how Darwin in his Origin of Species constantly mingles together arguments to prove the proposition that evolution has occurred, that the structure and relations of existing animals can only be explained by descent with modification, with arguments and evidence in favour of natural selection as the explanation and cause of evolution. In the great controversy about evolution which his work aroused, the majority of the educated public were ultimately convinced of the truth of evolution by the belief that a sufficient cause of the process of change had been discovered, rather than by the logical conclusion that the organisms of a later period were the descendants of those of earlier periods. Even at the present day the theory of natural selection is constantly confused with the doctrine of evolution. The fact is that the investigation of the causes of evolution has been going on and has been making progress from the time of Darwin, and from times much earlier than his, down to the present day.

Bionomics show that every type must be adapted 
in structure to maintain its life under the conditions in which it lives, the primary requirements being food and oxygen. Every animal must be able to procure food either of various kinds or some special kind-either plants or other animals; it may be adapted to feed on plants or to catch insects or fish or animals similar to itself; its digestive organs must be adapted to the kind of food it takes; it must have respiratory organs adapted to breathe in air or water; it must produce eggs able to survive in particular conditions, and so on.

One of the most interesting results of the study of the facts of evolution is that each type of animal tends to multiply to such an extent as to occupy the whole earth and adapt itself to all possible conditions. In the Secondary period reptiles so adapted themselves: there were oceanic reptiles, flying reptiles, herbivorous reptiles, carnivorous reptiles. At the present day the Chelonia alone include oceanic, fresh-water, and terrestrial forms. Birds again have adapted themselves to oceanic conditions, to forests, plains, deserts, fresh waters. Mammals have repeated the process. The organs of locomotion in such cases show profound modifications, adapting them to their special functions. One thing to be explained is the origin of adaptations.

It is, however, necessary to distinguish between the adapted condition or structure of an organ and the process by which it became adapted in evolution; two ideas which are often confused. The eye would be equally adapted for seeing whether it had been created in its actual condition or gradually evolved. We have to distinguish here, as in other matters, between being and becoming, and, further, 
to distinguish between two kinds of becomingnamely, the development of the organ in the individual and its evolution in the course of descent. The word 'adaptation' is itself the cause of much fallacious reasoning and confusion of ideas, inasmuch as it suggests a process rather than a condition, and by biological writers is often used at one time to mean the former and at others the latter. We may take the mammary glands of mammals or organs adapted for the secretion of milk, whose only function is obviously the nourishment of the offspring. Here the function is certain whatever view we take of the origin of the organs, whether we believe they were created or evolved. But if we consider the flipper or paddle of a whale, we see that it is homologous with the fore-leg of a terrestrial mammal, and we are in the habit of saying that in the whale the fore-limb is modified into a paddle and has become adapted for aquatic locomotion. This, of course, assumes that it has become so adapted in the course of descent. But the pectoral fin of a fish is equally 'adapted' for aquatic locomotion, but it is certainly not the fore-leg of a terrestrial mammal adapted for that purpose. The original meaning of adaptation in animals and plants, of organic adaptation to use another term, is the relation of a mechanism to its action or of a tool to its work. A hammer is an adaptation for knocking in nails, and the woodpecker uses its head and beak in a similar way for making a hole in the bark of trees. The wings and the whole structure of a bird's body form a mechanism for producing one of the most difficult of mechanical results, namely, flight. Then, again, there are stationary conditions, 
such as colour and patterns, or scales and armour, which may be useful in the life of an animal or flower, but are not mechanisms of moving parts like a bird's wing, or secreting organs like mammary glands. Unless we choose or invent some new term, we must define adaptations apart from all questions of evolution as any structures or characters in an organism which can be shown either by their mere presence, or by their active function, to be either useful or necessary to the animal's existence. We must be on our guard against assuming that the word 'adaptation' implies any particular theory or conclusion concerning the method and process by which adaptations have arisen in the course of evolution. It is that method and process which we have to investigate.

On the other hand, when we look primarily at differences of structure we find that not only are there wide and distinct gaps between the larger categories, such as mammals and birds, with few or no intermediate forms, but the actual individuals most closely similar to one another naturally and inevitably fall into distinct groups which we call kinds or species. The conception of a species is difficult to define, and authorities are not agreed about it. Some, like Professor Huxley, state that a species is purely a mental conception, a generalised idea of a type to which actual individuals more or less closely conform. According to Huxley, you cannot lock the species 'horse' in a stable. Others regard the matter more objectively, and regard the species merely as the total number of individuals which possess a certain degree of resemblance, including, as mentioned above, all the forms which 
may be produced by the same parents, or which are merely stages in the life of the individual. There are cases in which the limits of species or the boundaries between them are indistinct, where there is a graduated series of differences through a wide range of structure, but these cases are the exception ; usually there are a vast majority of individuals which belong distinctly to one species or another, while intermediate forms are rare or absent. The problem then is, How did these distinct species arise ? How are we to explain their relations to one another in groups of species or genera; why are the genera grouped into families, families into orders, orders into classes, and so on ?

There are thus two main problems of evolution: first, how have animals become adapted to their conditions of life, how have their organs become adapted to the functions and actions they have to perform, or, at least, which they do perform ? The power of flight, for example, has been evolved by somewhat different modifications in several different types of animals not closely related to one another: in reptiles, in birds, and in mammals. We have no reason to believe that this faculty was ever universal, or that it existed in the original ancestors. How then was it evolved? The second great problem is, How is it that existing animals, and, as the evidence of the remains of extinct animals shows, these that existed at former periods of time also, are divided into the groups or types we call species, naturally classified into larger groups which are subdivisions of others still larger, and so on, in what we call the natural system of classification? The two problems which naturalists have to solve, and 
which for many recent generations they have been trying to solve, are the Origin of Species and the Origin of Adaptations.

Former generations of zoologists have assumed that these problems were the same. Lamarck maintained that the peculiarities of different animals were due to the fact that they had become adapted to modes of life different to those of their ancestors, and to those in which allied forms lived, the change of structure being due to the effect of the conditions of life and of the actions of the organs. He did not specially consider the differences of closely allied species, but the peculiarities of marked types such as the long neck of the giraffe, the antlers of stags, the trunk of the elephant, and so on; but he considered that the action of external conditions was the true cause of evolution, and assumed that in course of time the effects became hereditary.

Lamarck's views are expounded chiefly in his Philosophie Zoologique, first published in 1809, and an excellent edition of this work with biographical and critical introduction was published by Charles Martins in 1873. Although his conception of the mode in which structural changes were produced is of little importance to those now engaged in the investigation of the process of evolution, since it was naturally based on the physiological ideas of his time, many of which are now obsolete, for the sake of accuracy it is worth while to cite his principal propositions in his own words:-

'Il sera en effet évident que l'état ou nous voyons tous les animaux, est d'une part, le produit de la composition croissante de l'organisation, qui tend à former une gradation régulière, et de l'autre part 


\section{CLASSIFICATION AND ADAPTATION}

qu'il est celui des influences d'une multitude de circonstances très différentes qui tendent continuellement à détruire la régularité dans la gradation de la composition croissante de l'organisation.

'Ici il devient nécessaire de m'expliquer sur le sens que j'attache à ces expressions: Les circonstances influent sur la forme et l'organisation des animaux, c'est-à-dire qu'en devenant très différentes elles changent avec le temps et cette forme et l'organisation elle-même par des modifications proportionnées.

'Assurément si l'on prenait ces expressions à la lettre, on m'attribuerait une erreur; car quelles que puissent être les circonstances elles n'opèrent directement sur la forme et sur l'organisation des animaux aucune modification quelconque. Mais de grands changements dans les circonstances amènent pour les animaux de grands changements dans leurs besoins et de pareils changements dans les besoins en amènent nécessairement dans les actions. Or, si les nouveaux besoins deviennent constants ou très durables, les animaux prennent alors de nouvelles habitudes qui sont aussi durables que les besoins qui les ont fait naître. Il en sera résulté l'emploi de telle partie par préférence à celui de telle autre, et dans certains cas le défaut total d'emploi de telle partie qui est devenue inutile.'

The supposed effect of these changes of habit is definitely stated in the form of two 'laws' :-

\section{Première LoI}

'Dans tout animal qui n'a point dépassé le terme de ses développements l'emploi plus fréquent et soutenu d'un organe quelconque, fortifie peu à peu cet organe, le développe, l'agrandit et lui donne une 
puissance proportionnée à la durée de cet emploi ; tandis que le défaut constant d'usage de tel organe l'affaiblit insensiblement, le détériore, diminue progressivement ses facultés, et finit par le faire disparaître.

\section{Deuxième LoI}

' Tout ce que la nature a fait acquérir ou perdre aux individus par l'influence des circonstances ou leur race se trouve depuis longtemps exposée, et par conséquent, par l'influence de l'emploi prédominant de tel organe, ou par celle d'un défaut constant d'usage de telle partie, elle le conserve par la génération aux nouveaux individus qui en proviennent, pourvu que les changements acquis soient communs aux deux sexes, ou à ceux qui ont produits ces nouveaux individus.'

It will be seen that this last condition excludes the question of the origin of organs or characters confined to one sex, or secondary sexual characters. With regard to the expression 'emploi de telle partie,' the explanation which Lamarck gives of the evolution of horns and antlers is curious. He does not attempt to show how the use or employment of the head leads to the development of these outgrowths of bone and epidermic horn, but attributes their development in stags and bulls to an "interior sentiment in their fits of anger, which directs the fluids more strongly towards that part of their head.'

Lamarck's actual words (Phil. Zool., edit. 1873, p. 254) are: 'Dans leurs accès de colère qui sont fréquents surtout entre les mâles, leur sentiment intérieurs par ses efforts dirige plus fortement les 
fluides vers cette partie de leur tête, et il s'y fait une secrétion de matière cornée dans les uns (Bovidae) et de matière osseuse mélangée de matière cornée dans les autres (Cervidae), qui donne lieu à des protubérances solides : de là l'origine des cornes, et des bois, dont la plupart de ces animaux ont la tête armée.'

Darwin, on the other hand, definitely set before himself the problem of the origin of species, which the majority of naturalists, in spite of Lamarck and his predecessor Buffon, regarded as permanent and essentially immutable types established by the Creator at the beginning of the world. This principle of the persistence and fundamentally unchangeable nature of species was regarded as an article of religion, following necessarily from the divine inspiration of the Bible. This theological aspect of the subject is sufficiently curious when we consider it in relation to the history of biological knowledge, for Linnaeus at the beginning of the eighteenth century was the first naturalist who made a systematic attempt to define and classify the species of the whole organic world, and there are few species of which the limits and definition have not been altered since his time. In fact, at the present time there are very numerous groups, both in animals and plants, on the species of which scarcely any two experts are agreed.

In many cases a Linnaean species has been split up till it became, first, a genus, then a family, and, in some cases, an order. What one naturalist considers a species is considered by another a genus containing several species, and, vice versa, the species of one authority is described as merely a variety by another. 
The older naturalists might have said with truth: we do not know what the species are, but we are quite certain that whatever they are they have never undergone any change in their distinguishing characters. At the same time we know that whether we call related forms varieties or species or genera in different cases, we find, whatever organisms we study, whether plants or animals, definite types distinguished by special characters of form, colour, and structure, and that individuals of one species or type never give rise by generation to individuals of any other known species or type. We do not find wolves producing foxes, or bulldogs giving birth to greyhounds. As a general rule the distinguishing characters are inherited, and it is by no means easy even in domesticated animals and plants to obtain an exact and complete record of the descent of a new variety from the original form. Among species in a state of nature it is the exception to find two recognised species which can be crossed or hybridised. In the case of the horse and the ass, although mules are the hybrid offspring of the two, the mules themselves are sterile, and there are many similar cases, so that some naturalists have maintained that mutual infertility should be recognised as the test of separation in species.

Darwin founded his theory on the assumption that differences of species were differences of adaptation. His theory of natural selection is a theory of the origin of adaptations, and only a theory of the origin of species on the assumption that their distinguishing characters are adaptations to different modes and conditions of life, to different requirements. He pointed out that there is always a 


\section{CLASSIFICATION AND ADAPTATION}

considerable range of variation in the specific characters, that, as a rule, no two individuals are exactly alike, even when produced by the same two parents. The central principle of his theory was the survival of individuals possessing those variations which were most useful in the competition of species with species and of individual with individual. $\mathrm{He}$ thus explained adaptation to new conditions and divergence of several species from a common ancestor. Characters which were not obviously adaptive were explained either by correlation or by the supposition that they had a utility of which we were ignorant. Darwin also admitted the direct action of conditions as a subordinate factor.

Weismannism not only retained the principle of utility and selection, but made it the only principle, rejecting entirely the action of external conditions as a cause of congenital modifications, i.e. of characters whose development is predetermined in the fertilised ovum. It is to Weismann that we owe precise and definite conceptions, if not of the nature of heredity, at least of the details of the process. From him we learned to think of the ova or sperms, of the reproductive cells or 'gametes' of an individual, as cells which were from an early stage of development distinguished from the cells forming the organs and tissues; to regard the organism as consisting of soma on the one hand and gametes on the other, both derived from the original zygote cell, not the gametes from the soma. Weismann saw no possibility of changes induced by any sort of stimulation in the soma affecting the gametes in such a way as to be redeveloped in the soma of the next generation. He 
attributed variation partly to the union of gametes containing various determinants, which he termed amphimixis: this, however, would introduce nothing new. Then he proposed his theory of germinal selection, determinants growing and multiplying in competition, some perhaps disappearing altogether, though this does not satisfactorily account for entirely new characters. With Weismann, however, every species was a different adaptation, and natural selection was the deus ex machina; to quote his own words, Alles ist angepasst.

Romanes and other writers, on the other hand, had always maintained that in many cases the constant peculiarities of closely allied species had no known utility whatever, so that the problem presented by these characters was not explained by any theory of the origin of adaptations.

Mendelism, since 1900, has studied experimentally the transmission of definite characters, and maintains that the characters of species are of the same nature as the characters which segregate in Mendelian experiments. Such characters are not in any way related to external conditions, and cannot, therefore, be adaptive except by accident. Professor Bateson goes so far as to admit that such large variations or mutations offer more definite material to selection than minute variations too small to make any important difference in survival, but as regards species the important factor is the occurrence of mutations which are inherited and at once form a distinct definite difference between allied species which is not due to selection and has nothing to do with adaptation.

In a book entitled Problems of Genetics, 1913, 
Bateson describes several particular cases which show how impossible it is to find any relation at all between the diagnostic characters of certain species or local forms and their mode of life. One of these cases is that of the species of Colaptes, a genus of Woodpeckers in North America, of which a detailed study was published in the Bull. Am. Mus. Nat. Hist., 1892. The two forms specially considered are named $C$. auratus and $C$. cafer, and they differ in the following seven characters :-

C. auratus.

1. Quills yellow.

2. Male with black cheek stripe.

3. Adult female with no cheek stripe.

4. A scarlet nuchal crescent in both sexes.

5. Throat and fore-neck brown.

6. Top of head and hindneck grey.

7. General tone of plumage olivaceous.
C. cafer.

1. Quills red.

2. Male with red cheek stripe.

3. Adult female with usually brown chcek stripe.

4. No nuchal crescent in either sex.

5. Throat and fore-neck grey.

6. Top of head and hindneck brown.

7. General tone of plumage rufescent.

C. auratus occurs all over Canada, and the United States, from the north to Galveston; westwards it extends to Alaska and the Pacific coast to the northern border of British Columbia. C. cafer in comparatively pure form occupies Mexico, Arizona, California, part of Nevada, Utah, Oregon, and is bounded on the east by a line drawn from the Pacific south of Washington State, south and eastward 
through Colorado to the mouth of the Rio Grande on the Gulf of Mexico. Between the two areas thus roughly defined is a tract of country about 300 to 400 miles wide, which contains some normal birds of each type, but chiefly birds exhibiting irregular mixtures of the characters of both. Bateson remarks that some naturalists may be disposed once more to appeal to our ignorance, and suggest that if we only knew more we should find that the yellow quills, the black 'moustache,' and the red nuchal crescent specially adapt auratus to the conditions of the northern and eastern region, while the red quills, red moustache, and absence of crescent fit cafer to the conditions of the more southern and western territory. But, as the author we are quoting points out, when we think of the wide range of conditions in the country occupied by auratus, extending from Florida to the Arctic, it is impossible to believe that there is any common element in the conditions which demands a scarlet nuchal patch in auratus, while the equally varied conditions in the cafer area do not require that character. It may be added that the same objection is equally valid whether we apply it to the utility of such a character or to the supposition that the character has been caused by external conditions; in other words, whether we attempt to explain the facts by selection or by the Lamarckian principle.

Another case quoted by Bateson is that of the two common British Wasps, Vespa vulgaris and Vespa germanica. Both usually make subterranean nests, but of somewhat different materials. That of $V$. vulgaris is of a characteristic yellow colour, because made of rotten wood, while that of 
$V$. germanica is grey, from the weathered surface wood of palings or other exposed timber which is used in its construction. In characters the differences of the two forms are so slight as to be distinguishable only by the expert. $V$. vulgaris often has black spots on the tibiae, which are wanting in germanica. A horizontal yellow stripe on the thorax is enlarged downwards in the middle in germanica, not in vulgaris. There are distinct though slight differences in the genital appendages of the males in the two species. Here there are differences of habit, and slight but constant differences of structure; but it is impossible to find any relation between the former and the latter.

Mendelism in itself affords no evidence of the origin of new characters, since it deals only with the heredity of the characters which it finds usually in the varieties of cultivated animals and plants. But indirectly it draws the inference that new characters arose in the form in which they are found to be inherited, as complete units, and not by gradual, continuous increase, that specific characters are due to mutations, and that all evolution has been the result of similar hereditary factors, arising by some internal process in the divisions of reproductive cells, and not determined by external conditions. Some Mendelians maintain that if the mutations are not compatible with the existing conditions of life, the organism must either die or find new conditions in which it can live.

Bateson remarks (Mendel's Principles of Heredity, 1909, p. 288): 'Mendelism provides no fresh clue to the problem of adaptation except in so far as it is easier to believe that a definite integral change in 
attributes can make a perceptible difference to the prospect of success, than that an indefinite and impalpable change should entail such consequences.' Here the distinction between adaptive and nonadaptive characters is recognised, but both are emphatically attributed to the same origin.

The American evolutionist, T. H. Morgan, also a specialist in Mendelism, goes further, and maintains, not merely that mutations which happened to make a 'difference to the prospect of success' survived, or were selected, but that if a mutation arising from a change in the gametes was not compatible with the conditions of the animal's life at the time, it either died, or found other conditions, or adopted new habits which were adapted to the new character or structure. He takes Flat-fishes as an example, and suggests that having by mutation become asymmetrical, and having both eyes on one side, etc., the fish adopted the habit of lying on the ground on one side of its body. This is, of course, the exact opposite of the older conception: the structure of the animal has not been changed by new habits or conditions, but new habits and conditions have been sought and found in order to meet the requirements of the change of structure.

The present writer, on the other hand, believes that not only are adaptive characters distinct from non-adaptive specific characters, and from nonadaptive diagnostic characters in general, but that their origin and evolution are entirely distinct and different. There are two separate problems, the origin of adaptations and the origin of species, and the investigation of these two problems leads not to one explanation common to both, but to two entirely 
different explanations, to two different processes going on throughout the organic world and affecting every individual and every group in classification.

The Flat-fishes, now regarded not as merely a family but a sub-order of Teleosteans, afford a good example of the contrast between adaptive and non-adaptive diagnostic characters. For the whole group the adaptive characters are diagnostic, distinguishing it from other sub-orders. It is conceivable that different phyletic groups of fishes, that is fishes of different descent, might have been modified in the same way, as, for instance, grasshoppers and fleas have been adapted for leaping without being closely related to each other. It is generally held, however, that the Flat-fishes are of common descent. In this group the adaptive characters are diagnostic; that is to say, they distinguish the group from other sub-orders, though there are other non-adaptive characters which indicate the relationship to other groups and which are not adapted to the horizontal position of the original median plane of symmetry. The principal adaptive characters are: both eyes and the pigmentation on the side which is uppermost in the natural position, lower side without eyes and colourless; dorsal and ventral fins continuous and extending nearly the whole length of the dorsal and ventral edges; dorsal fin extending forwards on the head, not along the morphological median line, which is between the eyes, but between the more dorsal eye and the lower side of the body, in the same horizontal plane as the posterior part of the same fin. The 'adaptive' quality in these characters, as in other cases, does not necessarily consist in their utility 
to the animal, but in the definite relation between them and the external conditions. When the relation is one of function, the organ may be said to be useful: for example, the position of the two eyes is adaptive because they are on the upper side where alone light can reach them, the other side resting on the ground; and the adaptation is one of function, and therefore useful, because if the eyes were in their normal position one of them would be useless, being generally in contact with the ground or buried in it. Similarly with the extension of the dorsal and ventral fins, the undulations of which serve to move the fish gently along in a plane parallel to the ground. If the dorsal fin was not extended forward, the head would not be so well supported. But when we consider the pigmentation of the upper side and the normally white lower side, although the adaptation is equally obvious, the utility is by no means certain. To any naturalist who has observed these fishes in the living state the protective resemblance of the pigmentation of the upper side is very evident, especially because, as in many other fishes and amphibians, the intensity of the colour varies in harmony with the eolour of the ground on which the fish rests. But the utility of the white lower side is not so easy to prove. Would the fish be any worse off if the lower side were coloured like the upper? Probably it would not, although it has been maintained that the white lower side serves to render the fish less visible when seen against the sky by an enemy below it. Ambicolorate specimens oceur, and there is no evidence that their lives are less secure than those of normal specimens. The essential and universal quality of adaptation, then, is not 
utility, but relation to surroundings or to function or to habit. In this case colour is related to incidence of light, absence of colour to absence of light. Position of eyes is also related to light; they are situated where they can see, absent from the side which is shut off from light. The marginal fins are extended where their movements best support and move the body.

It is to be noted also that these adaptations of different organs of the body, eyes, fins, colour, are entirely independent of each other physiologically. It may appear on first consideration that eyes and colour, being both on the upper side, may have been somehow connected in the constitution of the body, whereas the only connexion is external in their common relation to light. This independence is well shown in the modification of the dorsal fin: if this were physiologically affected by the change in the eyes, which is brought about by the twisting of the interorbital region of the skull, the anterior end of the fin would be between the two eyes, since the morphological median line of the body is in that position. In fact, on the contrary, the attachment of the dorsal fin is continued forward where it is required for its mechanical function, regardless entirely of the morphology of the head.

This is even more clearly evident in the structure of the jaws and teeth. These are entirely unaffected by the torsion of the interorbital part of the skull. In cases where the mouth is large and teeth are required on both sides, the prey being active fish of other species, as in Turbot, Brill, and Halibut, the jaws and teeth are equally developed 
on the upper and lower sides, and there is almost complete symmetry in these parts of the skull. In Soles and Plaice, on the other hand, whose food consists of worms, molluscs, etc., living on or in the ground, the jaws of the lower side are well developed and strong, these of the upper side diminished, and teeth are confined to the lower side. Here it is not a question of the jaws being twisted, but simply unequally developed. There is no general and constitutional asymmetry of head or body, but a modification of different organs independently of each other in relation to external conditionslight, food, movement.

On the other hand, let us consider some of the diagnostic characters by which species and genera are distinguished in the Flat-fishes or Pleuronectidae. The genus Pleuronectes is distinguished by the following characters: eyes on the right side, mouth terminal and rather small, teeth most developed on the blind (left) side. Of this genus there are five British species, namely :-

$P$. platessa, the Plaice: scales small, mostly without spinules, reduced and not imbricated, imbedded in the skin; bony knobs on the head behind the eyes, red spots on the upper side.

$P$. flesus, the Flounder: no ordinary scales; rough tubercles along the bases of the marginal fins and along the lateral line; these are modified and enlarged scales; elsewhere scales of any kind are absent.

In these two species the lateral line is nearly straight, having only a slight curve above the pectoral fin.

$P$. limanda, the Dab: scales uniform all over 
the body, with spinules on the projecting edges, making the skin rough; lateral line with a semicircular curve above the pectoral fin.

P. microcephalus, the Lemon-dab: scales small, smooth, and imbedded; skin slimy, head and mouth very small, colour yellowish brown with large round darker marks.

P. cynoglossus, the Witch or Pole-dab: head and mouth smaller than in the Plaice, eyes rather larger ; scales all alike and uniformly distributed, slightly spinulate on upper side, smooth on the lower; blister-like cavities beneath the skin of the head on the lower side.

With regard to the generic characters, it is difficult to give any reason why the mouth should be at the end of the head instead of behind the apex of the snout as in the genus Solea, but, as we have seen already, the small size of the mouth and the greater development of teeth on the lower side are adapted to the food and mode of feeding. It is impossible to say why one genus of Flat-fishes should have the right side uppermost and others, e.g. Sole and Turbot, the left; it would almost seem to have been a matter of chance at the commencement of the evolution : reversed specimens occur as variations in most of the species.

When we consider the specific differences, we find very definite characters in the structure and distribution of the scales, and no evidence has yet been discovered that these differences are related to external conditions. There are, of course, slight differences in habits and habitat, but no constant relation between these and the structural differences of the scales. Plaice and Dab are taken together 
on the same ground, and nothing has been discovered to indicate that the spinulate scales of the Dab are adapted to one peculiarity in habits or conditions, the spineless scales of the Plaice to another. In comparing certain geographical races of Plaice and Flounder the facts seem to suggest that differences of habitat may have something to do with the development of the scales. In the Baltic the Flounders are as large as those on our own coasts, but the thorny tubercles are much more developed, nearly the whole of the upper surface being covered with them. The Plaice, on the other hand, are smaller than those of the North Sea, and the males have the scales spinulate over a considerable portion of the upper side. The chief difference between the Baltic and the North Sea is the reduced salinity of the former, so that it might be supposed that fresher water caused the greater development of the dermal skeleton. On the other hand, a species or geographical variety of the Plaice, whose proper name is $P$. glacialis, is found on the Arctic coasts of Asia and America, on both sides of the extreme North Pacific, and on the east coast of North America. In this form the bony tubercles on the head in the Plaice are replaced by a continuous rough osseous ridge, and the scales are as much spinulated as in the Plaice of the Baltic. On the east coast of North America the males in this form are more spinulated than the females: on the Alaskan coast, and apparently the Arctic coast, the females are spinulated, and the sexual difference in this respect is slight or absent. Lower salinity cannot be the cause of greater spinulation in this case, and thus it might be suggested that the condition was due to lower temperature. But we do 
not find that northern or Arctic species of fish in general have the scales more developed than southern species.

The Dab, which occurs in the same waters as the Plaice, has the spines more spinulated than any of the forms of plaice above mentioned, therefore the absence or slight development of spinules in the typical Plaice is not explained by physical conditions alone. Freshness of water again will not explain the difference of the structure and distribution of scales in Flounder and Plaice, considering the variety of squamation in fishes confined to fresh water. Still less can we attribute any of the peculiarities of scales to utility. We can discover no possible benefit of the condition in one species which would be absent in the case of other species. We can go much further than this, and maintain that there is no reason to believe that scales in general in Teleosteans, or any of their various modifications, are of special utility : they are not adaptive structures at all, although of great importance as diagnostic characters. It may be urged that in some cases, such as the little Agonus cataphractus or the Seahorse among the Syngnathidae, the body is protected by a complete suit of bony armour; but accompanying these in the littoral region are numerous other species such as the Gobies, and even other species of Syngnathidae which have soft unprotected skins.

Similarly with colour characters: the power of changing the colour so as to harmonise with the ground is obviously beneficial and adaptive, but in each species there is a specific pattern or marking which remains constant throughout life and has 
nothing to do with protective resemblance, variable or permanent. 'The red spots of the Plaice are specific and diagnostic, but they confer no advantage over the Dab or the Lemon-dab, in which they are absent, nor can any relation be discovered between these spots and mode of life or habits.

The function of the lateral line organs is still somewhat obscure. The theory that they are sensitive to differences of hydrostatic pressure as the fish moves from one depth to another rests on no foundation, since it has yet to be shown how a change of pressure within the limits of the incompressibility of water can produce a sensation in an organ permeated throughout with water. It is more probable that the organs are affected by vibrations in the water, but we are unable to understand how a difference in the anterior curvature of the lateral line would make a difference in the function in any way related to the difference in conditions of life between Plaice and Dab. There is, however, reason to conclude that the organs, especially on the head, are more important and larger in deeper water, and thus the enlargement of the sensory canals in the head of the Witch, which lives in deeper water than other species, may be an adaptive character.

Another genus of whose characters I once made a special study is that named Zeugopterus. The name was originally given by Gottsche to the largest species Z. punctatus, from the fact that the pelvic fins are united to the ventral, but this character does not occur in other species now included in the genus. There are three species, occurring only in European waters, which form this genus and agree in the following characters. The outline of the 
body is more nearly rectangular than in other Flatfishes from the obtuseness of the snout and caudal end, and the somewhat uniform breadth of the body. The surface is rough from the presence of long slender spines on the scales. There is a large perforation in the septum between the gill cavities, but this occurs also in Arnoglossus megastoma, which is placed in another genus. But the generic character of Zeugopterus, which is most important for the present discussion, is the prolongation of the dorsal and ventral fins on to the lower side of the body at the base of the tail, the attachments of these accessory portions being transverse to the axis of the body. These fishes have the peculiar habit of adhering to the vertical surfaces of the sides of aquaria, even the smooth surfaces of slate or glass. In nature they are taken occasionally on gravelly or sandy ground, but probably live also among rocks and adhere to them in the same way as to vertical surfaces in captivity. Many years ago (Journ. Mar. Biol. Assn., vol. iii. 1893-95) I made a careful investigation of the means by which these fishes were able to adhere to a smooth surface, at least in the case of the largest and commonest species $Z$. punctatus. It was observed that so long as the fish was clinging to a vertical surface the posterior parts of the marginal fins were in rhythmical motion, undulations passing along them in succession from before backwards, the edge of the body to which they were attached moving with them. The effect of these movements was to pump out water backwards from the space between the body and the surface it was clinging to, and to cause water to flow into this space at the anterior edges 
of the head. The subcaudal flaps were perfectly motionless and tightly pressed between the base of the tail and the surface of support, so that any movement of them was impossible. The question arose, however, whether the tail and these flaps acted as a sucker which aided in the adhesion. The flaps were therefore cut off with scissors-an operation which caused practically no pain or injury to the fish-and it adhered afterwards quite as well as when the fin-flaps were intact. The subcaudal prolongations of the fins are therefore not necessary to the adhesion, nor to the pumping action, of the muscles and fins, which went on as before. It seemed probable, therefore, that the pumping action was itself the cause of the adhesion. But the difficulty in accepting this conclusion was that there was a distinct though gentle respiratory movement of the jaws and opercula; and if the pumping of the water from beneath the body caused a negative pressure there, and a positive pressure on the outer side of the body, it seemed equally certain that the respiratory movement must force water into the space beneath the body and so cause a positive pressure there which would tend to force the fish away from the surface with which it was in contact. Examination of the currents of water around the edges of the fish, by means of suspended carmine, showed that water passed in at the mouth and out at the lower respiratory orifice, but also into the space below the body at the upper and lower edges of the head, without passing through the respiratory channel. It was thus proved that the rate at which water was pumped out at the sides of the tail was greater than that at which it passed in by the 
respiratory movements, and consequently there was a resultant negative pressure beneath the body. By means of a model made of a thin flexible sheet of rubber, at each end of which on one side was fastened a short piece of glass tube, I was able to imitate the physical action observed in the fish. A long piece of rubber tube was attached to one of the pieces of glass tube, and brought over the edge of the glass front of an aquarium. The long rubber tube was set in action as a siphon and the sheet of rubber placed against the glass. As long as water was running through the siphon the sheet of rubber remained pressed against the glass and supported. As soon as the current of water was stopped the apparatus fell to the bottom of the tank. In this model water passed out from beneath the rubber through the glass tube attached to the siphon and passed in by the opposite glass tube, and at the sides of it. The latter tube represented the respiratory channel of the fish, and the space between tube and rubber represented the spaces between the head of the fish and the vertical surface to which it clung.

In the fish the marginal fins not only extend to the base of the tail, but are broader at the posterior end than elsewhere, whereas in other Flat-fishes the posterior part of the marginal fins are the narrowest parts. The shape of the fins and the breadth of the body posteriorly, then, are adaptations which have a definite function, that of enabling the fish to adhere to vertical surfaces. But, on the other hand, the extension of the marginal fins in a transverse direction beneath the tail has no use in the process of adhesion, nor has any other use been 
found for it. It is a generic character, so far as we know, without utility. On the other hand, it is very probable that this subcaudal extension of the fins is merely a result of the posterior extension and enlargement of these fins which has taken place in the evolution of the adaptation. If the Lamarckian explanation of adaptation were true, it would be possible to understand that the constant movements of the fins and muscles by which the adhesion was effected caused a longitudinal growth of the fins in excess of the length actually required, and that this extra growth extended on to the body beneath the tail, although the small flaps on the lower side were not necessary to the new function which the fins performed.

When we consider such cases as this we are led to the conclusion that the usual conception of adaptation is not adequate. We require something more than function or utility to express the difference between the two kinds of characters to be distinguished. For example, the absence of pigmentation from the lower sides of Flat-fishes may have no utility whatever, but we see that it differs from the specific markings of the upper side in the fact that it shows a relation to or correspondence with a difference of external conditions-namely, the incidence of light, while in such a case as the red spots of the Plaice we can discover no such correspondence.

We know that the American artist and naturalist Thayer has shown that the lighter colour of the ventral side of birds and other animals aids greatly in reducing their visibility in their natural surroundings, the diminution in coloration compensating for 


\section{CLASSIFICATION AND ADAPTATION}

the diminution in the amount of light falling on the lower side, so that the upper and lower sides reflect approximately the same amount of light, and contrast, which would be otherwise conspicuous, is avoided. But the white lower sides of Flat-fishes are either not visible at all, or, if visible, are very conspicuous, so that the utility of the character is very doubtful.

We may distinguish then between characters which correspond to external conditions, functions, or habits, and those which do not. The word 'adaptation,' which we have hitherto used, does not express satisfactorily the peculiarities of all the characters in the former of these two divisions. If we consider three examples-enlarged hind-legs for jumping as in kangaroo or frog, absence of colour from the lower sides of Flat-fishes, and, thirdly, the finlets on the lower side of Zeugopterus-we see that they represent three different kinds of characters, all related to habits or external conditions. We may say that the third kind are correlated with some other character that has a relation to function or external conditions, as the extension of the fins on the under side of Zeugopterus is correlated with the enlargement of the fins, whose function is to cause the adhesion of the fish to a vertical surface.

With regard to the specific characters of the species of Zeugopterus nothing is known of peculiarities in mode of life which would give an importance in the struggle for existence to the concrescence of the pelvic fins with the ventral in punctatus, to the absence of this character and the elongation of the first dorsal ray in unimaculatus, or to the absence of both characters in norvegicus. No use is known 
for any of the other specific characters, which tend in each case to form a series. Thus in size norvegicus is the smallest, unimaculatus larger, and punctatus largest, the last reaching a length of $8 \frac{1}{2}$ inches. The subcaudal fin-flaps are least developed in norvegicus, most in punctatus; each has four rays in norvegicus and unimaculatus, six in punctatus. The shortening and spinulation of the scales are greatest in punctatus, least in norvegicus. In punctatus there are teeth on the vomer, in unimaculatus none, in norvegicus they are very small.

If we consider fishes in general, we see that there is no evidence of any relation between many of the most important taxonomic characters and function or external conditions. In the sea Elasmobranchs and Teleosteans exist in swarming numbers side by side, but it is impossible to say that one type is more adapted to marine life than the other. There is good reason to believe that bony fishes were evolved from Elasmobranchs in fresh water which was shallow and foul, so that lungs were evolved for breathing air, and that marine bony fishes are descended from fishes with lungs; but no reason has been given for the evolution of bone in place of cartilage or for the various kinds of scales. Professor Houssaye, on the other hand, believes that the number and position of fins is adapted to the shape and velocity of movement of each kind of fish.

If we turn to other groups of animals we find everywhere similar evidence of the distinction between adaptive and non-adaptive characters. Birds are adapted in their whole organisation for flight, the structure of the wing, of the sternum, breast muscles, legs, etc., are all co-ordinated for 


\section{CLASSIFICATION AND ADAPTATION}

this end. But how do we know that feathers in their origin were connected with flight? It seems equally probable that feathers arose as a mutation in place of scales in a reptile, and the feathers were then adapted for flight. Nothing shows the distinction better than convergent adaptation. Owls resemble birds of prey in bill and claw and mode of life, yet they are related to insect-eating swifts and goat-suckers and not to eagles and hawks. Swifts and swallows are similar in adaptive characters, but not in those which show relationship. It may be said that the characters believed to show true affinities were originally adaptive, but we do not know this. Similarly, in reptiles the Chelonia are distinguished by the most extraordinary union of skin-bones and internal skeleton enclosing the body in rigid armour: it may be said that the function of this is protection, that it is adaptation, and can be explained by natural selection, but the adaptation in this case is so indefinite that it is difficult to be convinced of it.

Systematists have always distinguished between adaptive characters and those of taxonomic valuethose which show the true affinities-and they are perfectly right: also they have always distrusted and held aloof from theories of evolution which profess to explain all characters by one universal formula. In my opinion, those who, like Weismann, consider all taxonomic characters adaptive, are equally mistaken with Bateson and his followers, who regard all characters as mutational. No system of evolution can be satisfactory unless it recognises that these two kinds of characters are distinct and quite different in their nature. But it may be 
asked, What objection is there to the theory of natural selection as an explanation of adaptations? The objection is that all the evidence goes to show that the necessary variations only arose under the given conditions, and, further, that the actions of the conditions and the corresponding actions of the organism give rise to stimuli which would produce somatic modifications in the same direction as the permanent modifications which have occurred. My view is, then, that specific characters are usually not adaptations, that other characters of taxonomic value are some adaptive and some unrelated to conditions of life, and that while non-adaptive characters are due to spontaneous blastogenic variations or mutations, adaptive characters are due to the direct influence of stimuli, causing somatic modifications which become hereditary, in other words, to the inheritance of acquired characters. It has become a familiar statement that every individual is the result of its heredity and its environment. The thesis that I desire to establish is that the heredity of each individual and each type is compounded of virriations or changes of two distinct origins, one external and one internal; that is to say, of variations resulting from changes originating in the germ-cells or gametes, and of modifications produced originally in the soma by the action of external stimuli, and subsequently affecting the gametes.

When we study the characters of animals in relation to sex we find that in many cases there are conspicuous organs or characters present in one sex, usually the male, which are absent or rudimentary in the other. The conception of adapta- 


\section{8}

\section{CLASSIFICATION AND ADAPTATION}

tion applies to these also, since we find that these characters consist often of weapons such as horns, antlers, and spurs, used in sexual combat, of copulatory or clasping organs such as the pads on a frog's forefeet, of ornamental plumage like the peacock's tail serving to charm the female, or of special pouches as in species of pipe-fish and frog for holding the eggs or young. Darwin attempted to explain sexual adaptation by sexual selection. The selective process in this case was supposed to be, not the survival of individuals best adapted to secure food or shelter or to escape from enemies, but the success of those males which were victorious in combat, or which were most attractive to the females, and therefore left the greater number of offspring which inherited their variations. But, as Darwin himself admitted, this theory of selection does not in any way explain the differences between the sexes-in other words, the limitation of the characters or organs to one sex-since there is no reason in the process of selection itself why the peculiarity of a successful male should not be inherited by his female offspring as well as by his male offspring. The real problem, then, is the sexlimited heredity, and we shall consider later whether in this kind of heredity also there are characters of internal as well as external origin, blastogenic as well as somatogenic. 


\section{CHAPTER II}

\section{MENDELISM AND THE HEREDITY OF SEX}

We know that new individuals are developed from single cells which have either been formed by the union of two cells or which develop without such union, and that these reproductive cells are separated from pre-existing organisms: the gametes or gonocytes are separated from the parents and develop into the offspring. The zygote has the power of developing particular structures and characters in the complicated organisation of the adult, and we recognise that these characters are determined by the properties and constitution of the zygote; that is to say, of one or both of the gametes which unite to form the zygote. The distinction between peculiarities or 'characters,' determined in the ovum before development, and modifications due to influences acting on the individual during its development or life, is often obvious enough. A child's health, size, mode of speech, and behaviour may be greatly influenced by feeding, training, and education, but the colour of his or her eyes and hair were determined before birth. A human individual has, we know, a number of congenital or innate characters, by which we mean characters which arise from the constitution of the individual at the time of birth, and not from influences acting on him or her after birth. We have to remember, however, 
that modifications may be caused during development in the uterus, as, for example, birth-marks on the skin, and these would not be due to peculiarities in the constitution of the ovum. Professor Karl Pearson and other devotees of the cult of Eugenics have been lately impressing on the public by pamphlets, lectures, and addresses the great importance of nature as compared with nurture, maintaining that the latter is powerless to counteract either the good or bad qualities of the former, and that the effects of nurture are not transmitted to the next generation.

We recognise that the characters of varieties of flowers, fruits, and domesticated animals are not to be produced by any particular mode of treatment. We see the various kinds of orchids or carnations in the same greenhouse, of sweet peas and roses in the same garden. We go to a show and see the extraordinary variety of breeds of pigeons, rabbits, or fowls, and we know that these cannot be produced by treating the progeny of individuals of one kind in special ways, but are the progeny of parents of the same various races. If we want fowls of a particular breed we obtain eggs of that breed and hatch them with the certainty born of experience that we shall obtain chickens of that breed which will develop the colour, comb, size, and qualities proper to it. Similarly, in nature we recognise that the 'characters' of species or varieties are not due to circumstances acting on the individual during its development, but to the properties of the ova or seeds from which the individuals were developed.

Formerly we regarded these congenital or innate characters as derived from the parents or inherited, 
and heredity was the transmission of constitutional characters from parent to offspring. Now that we fix our attention on the fertilised ovum or the gametes by which it is formed we see that the characters are determined by some properties in the constitution of the gametes. What, then, is heredity? Clearly, it is merely the development in the offspring of the same characters which were present in the ova from which the parents developed. When the characters persist unchanged from generation to generation, we call the process by which they are continued heredity. When new characters appear, i.e. new characters determined in the ovum not due to changes in the environment, we call them variations. When a fertilised ovum develops into a new individual, it divides repeatedly to form a very large number of cells united into a single mass. Gradually the parts of this mass are differentiated to form the tissues and organs of the body or soma, but some of the cells remain in their original condition and become the reproductive cells which will give rise to the next gencration. The reproductive cells also undergo division and increase in number, and when they separate from the new individual and unite in fertilisation they still possess all the determinants of the fertilised ovum from which they are descended. Heredity thus continues from gamete to gamete, not from zygote to soma, and then from soma to gamete.

Modern researches have shown that the nucleus, when the cell divides, assumes the form of a spindle of fibres, associated with which are distinct bodies called chromosomes, that the number of these chromosomes where it can be counted is constant 
for all individuals of the same species, and that before the gametes are ready for fertilisation two cell-divisions take place, which result in the reduction of the number of chromosomes to half the original number. When two gametes unite, the specific number is restored. Since the male gamete is very small and seems to contribute to the zygote almost nothing except the chromosomes, which carry with them all the characters of the male parent, it seems a necessary conclusion that the chromosomes alone determine the character of the adult. There are, however, facts which point to an opposite conclusion.

Hegner, ${ }^{1}$ for example, found that in the egg of the beetle Leptinotarsa, which is an elongated oval in shape, there is at the posterior end in the superficial cytoplasm a disc-shaped mass of darkly staining granules, while the fertilised nucleus is in the middle of the egg. When the protoplasm containing these granules was killed with a hot needle, development in some cases took place and an embryo was formed, but the embryo contained no germ cells. Here no injury had been done to the zygote nucleus, but these particular granules and the portion of protoplasm containing them were necessary for the formation of germ cells. In other experiments a large amount of protoplasm at the posterior end of the ovum was killed before the nucleus had begun to segment, and the result was the development of an embryo consisting of the head and part of the thorax, while the rest was wanting. The nucleus segmented and migrated into that part of the

1 R. W. Hegner, 'Experiments with Chrysomelid Beetles,' III., Biological Bulletin, vol. xx. 1910-11. 
superficial cytoplasm which remained alive, and this proceeded to develop that particular part of the embryo to which it would have given rise if the rest of the egg had not been killed. There was no regeneration of the part killed, no formation of a complete embryo. It may be pointed out that segmentation in the insect egg is peculiar. The nuclei multiplied by segmentation migrate into the superficial cytoplasm surrounding the yolk, and then this cytoplasm segments, and each part of the cytoplasm develops into a particular region of the embryo. This, of course, does not prove that the nuclei or their chromosomes do not determine the characlers of the parts of the embryo developed, but they show that the parts of the non-nucleated cytoplasm correspond to particular parts of the embryo. The most important object of investigation at the present time is to find the origin of these properties of the chromosomes. We may say, using the word 'determinant' as a convenient term for that which determines the adult characters, that in order to explain the origin of species or the origin of adaptations we must discover the origin of determinants. Mendelism does not throw any direct light on this question, but it certainly has shown how characters may be inherited as separate and independent units. When one difference between two breeds is considered, e.g. rose comb and single in fowls, and individuals are crossed, we have the determinant for rose and the determinant for single in the same zygote. The result is that rose develops and single is not apparent. In the next generation rose and single appear, as at the beginning, in separate individuals. 
When two or three or more differences are studied we find that they are usually inherited separately without connexion with each other, although in some cases they are connected or coupled. The facts of Mendelism are of great interest and importance, but we have to consider the general theory based on them. This theory is that characters are generally separate units which can exist side by side, but do not mingle, and cannot be divided into parts. When an apparently single character shows itself double or treble, it is concluded that it has not been really divided, but consists of two or three units (Castle). Further, although Mendelism in itself shows no evidence of the origin of the characters, it assumes that they arose as complete units, and one suggestion is that a dominant factor might at some of the divisions in gametegenesis pass entirely into one daughter cell, and therefore be absent from the other, and thus individuals might be developed in which a dominant character was absent. Bateson in his well-known books, Mendel's Principles of Heredity, 1909, and Problems of Genetics, 1913, discusses this question of the origin of the factors which are inherited independently. The difficulty that troubles him is the origin of a dominant character. Naturally, if he persists in regarding the determinant factor as a unit which does not grow nor itself evolve in any way, it is difficult to conceive where it came from. The dominant, according to Bateson, must be due to the presence of something which is absent in the recessive. He gives as an instance the black pigment in the Silky fowl, which is present in the skin and connective tissues. In his own experiments he found this was 
recessive to the white-skin character of the Brown Leghorn, and he assumes that the genetic properties of Gallus bankiva with regard to skin pigment are similar to those of the Brown Leghorn. Therefore in order that this character could have arisen in the Silky, the pigment-producing factor $P$ must be added and the inhibiting factor $D$ must drop out or be lost. He says we have no conception of the process by which these events took place. ${ }^{1}$ Now my experiment in crossing Silky with bankiva shows that no inhibiting factor is present in the latter, so that only one change, not two, was necessary to produce the Silky. Mendelians find it so difficult to conceive of the origin of a new dominant that they even suggest that no such thing ever oceurs: what appears as a new character was present from the beginning, but its development was prevented by an inhibiting factor: when this goes into one cell of a division and leaves the other free, the suppressed character appears. This is the principle proposed to get over the difficulty of the origin of a new dominant. All characters are due to factors, and all factors were present in the original ancestor - say Amoeba. Evolution has been merely 'the rejection of various factors from an original complex, and a reshuffling of those that were left.' Professor Lotsy goes so far as to say that difference in species arose solely from crossing, that all domestic animals are of mixed stocks, and that it is easier to believe that a given race was derived from some ancestor of which all trace has been lost than that all races of fowls, for example, arose by variation from a single species. But the evidence that our varieties of

1 Problems of Genetics, p. 85. 
pigeons have been derived from C. livia, and of fowls from $G$. bankiva, is too strong to be disregarded because it does not agree with theoretical conceptions.

My own experiments in crossing Silky fowls with Gallus bankiva (P.Z.S., 1919) show that the recessive is not always pure, that segregation is not in all cases complete. The colour of the bankiva is what is called black-red, these being probably the actual pigments present, mixed in some parts of the plumage, in separate areas in other parts: the Silky is white. There are seven pairs of characters altogether in which the Silky differs from the bankiva. Both the pigmented skin of the Silky and the colour in the plumage of the bankiva are dominant, so that all the offspring in $F_{1}$ or the first generation are coloured fowls with pigmented skins. But in later generations I found that with regard to skin pigment there were no pure recessives. Since the heterozygote in $F_{1}$ was deeply pigmented, it is certain that a bird with only a small amount of pigment in its skin was a recessive resulting from incomplete segregation of the pigmented character. The pigment occurred chiefly in the skin of the abdomen and round the eyes, and also in the peritoneum and in the connective tissue of the abdominal wall. It varied in different individuals, but in some, at any rate, was greater in later generations than in the earlier. The condition bred true, as pure recessives do; and when such an impure recessive was mated with a heterozygote with black skin, the offspring were half pigmented and half recessive, with some pigment on the abdomen of the latter. 


\section{PLATE I.}
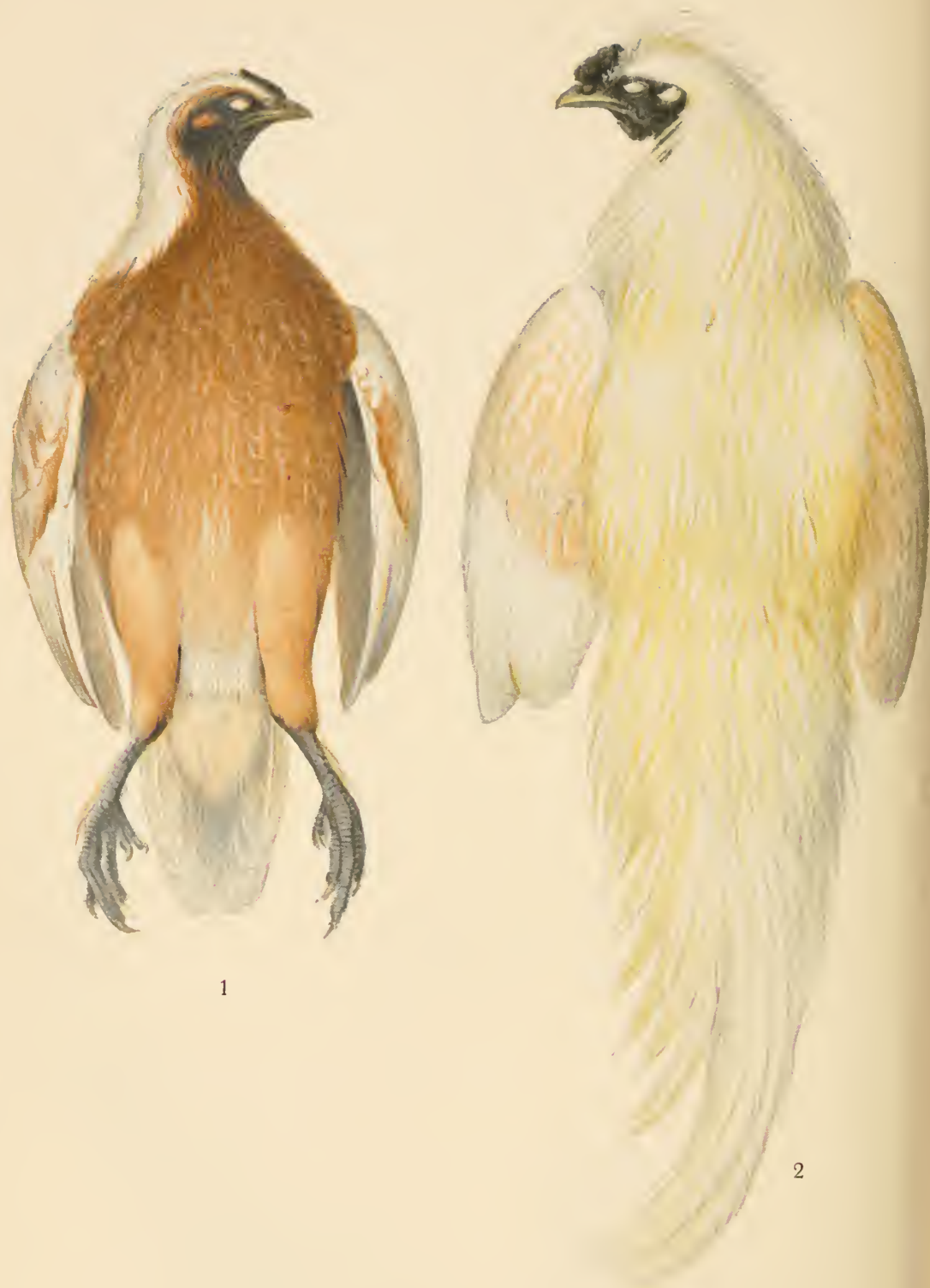

Bale \& Danielsson, Imp. 


\section{EXPLANATION OF PLATE I.}

Fig. 1. Ventral surface of hen produced from cross between silky hen and black-red Bankiva cock, showing "pile" coloration. The dorsal surface is white without any of the reddish brown colour. The hen represented was $F_{5}$ II $3 q$ in the record of the pedigree, i.e., a hen of the second brood of the 5 th generation. It was killed Dec. 12, 1915, when 1 year and 8 mouths old.

Fig. 2. Dorsal surface of cock from the same cross, showing the "pile" coloration in the male. The colour is very slight compared with that of the female, and consists of a slight yellow tinge across the loins and on the upper wing-coverts. The rest of the body is pure white. The specimen was $\mathrm{F}_{6} \mathrm{~V} 1 \delta$ in the pedigree, i.e., a cock of the fifth brood of the 6th generation. It was killed on Dec. 31 1915 , when 7 months old. 


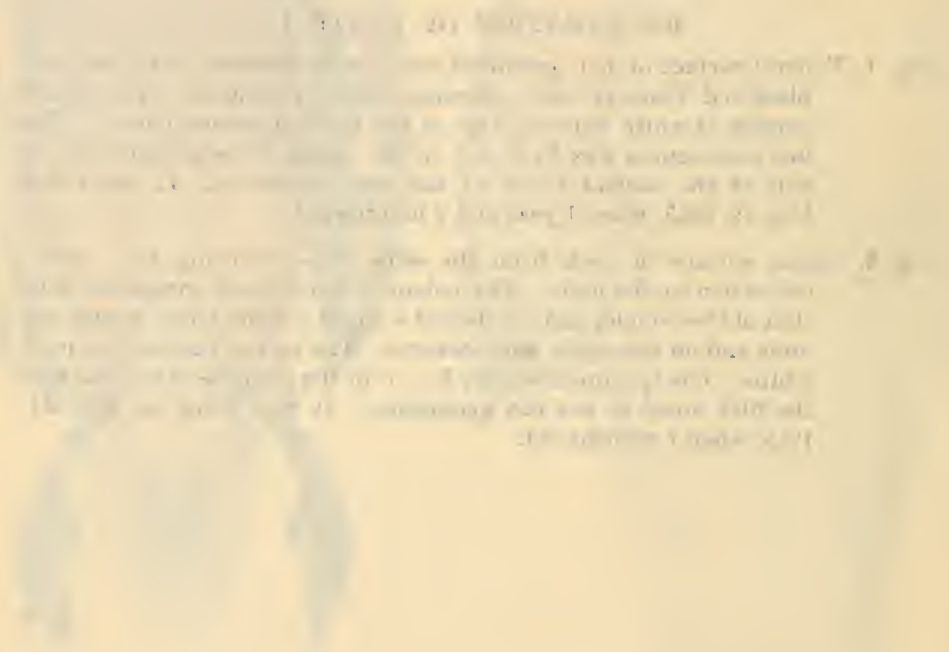


Still more striking was the incomplete segregation in the plumage colour. The white of the Silky was recessive, all the birds of the $F_{1}$ generation being fully coloured. In the $F_{2}$ generation there were two recessive white cocks which when mature showed slight yellow colour across the loins. These two were mated with coloured hens, and in later generations all the recessives instead of being pure white, like the Silky, had reddish-brown pigment distributed as in pile fowls. In the hens (Plate I., fig. 1) it was chiefly confined to the breast and abdomen, and was well developed, not a mere tinge or trace, but a deep coloration, extending on to the dorsal coverts at the lower edge of the folded wings. The back and tail were white. In the cocks the colour was much paler, and extended over the dorsal surface of the wings, where it was darker than on the back and loins (Plate I., fig. 2). These pile-coloured fowls when mated together bred true, with individual differences in the offspring.

The pile fowl as recognised and described by fanciers is dominant in colour, not recessive as in the case above described. In fact, a recessive pile does not appear ever to have been mentioned before the publication of the results of my experiment. From the statements of John Douglas in Wright's Book of Poultry (London, 1885), it appears that fanciers knew long ago that the pile could be produced from a female of the black-red Game mated with a white Game-cock. It would seem, therefore, that the pile is the heterozygote of blackred and 'dominant' white. Bateson, however (Principles of Heredity, 1909, p. 120), writes that the whole problem of the pile is very obscure, and 
treats it as a case of peculiarity in the genetics of yellow pigments. On p. 102 of the same volume he describes the results of crossing White Leghorn with Indian Game or Brown Leghorn, the $\boldsymbol{F}_{\mathbf{1}}$ being substantially white birds with specks of black and brown, though cocks have sometimes enough red in the wings to bring them into the category known as pile. To test the matter I have crossed White Leghorns with a pure-bred black-red Game-cock, and in the offspring out of eight cocks six were fairly good piles, but with not quite so much red on the back as in typical birds: one was a pile with yellow on the back instead of red, and one was white with irregular specks. Of the hens, four were of pile coloration with breast and abdomen of uniform reddish-brown colour, back, neck, and saddle hackles laced with pale brown, tail white. The other four were white with black and brown specks. Whether these pile heterozygotes will breed true I do not yet know.

These results tend to show that factors are not indivisible units, and segregation is rather the difficulty of chromatin or germ plasm from different races uniting together. It must be remembered that the fertilised ovum which forms one individual gives rise also to dozens or hundreds or thousands or millions of gametes. If a given character is represented by a portion of the chromatin in the original ovum, this has to be divided so many times, and each time to grow to the same condition as before. How can we suppose that the divisions shall be exactly equal or the growth always the same? It is inevitable that irregularities will occur, and if the original chromatin produced a certain 
character, who shall say what more or less of that chromatin will produce?

In the case of my recessive pile, my interpretation is that when the chromosomes corresponding to two distinct characters such as colour and absence of colour are formed they do not separate from each other completely. Whether the mixture of the chromosomes occurs in every resting stage of the nucleus in the successive generations of the gametocytes, or whether it occurs only in the synapsis stage preceding reduction division, it is not surprising that the colloid substance of the chromosomes should form a more or less complete intermixture, and that the two original chromosomes should not be again separated in the pure condition in which they came into contact. A part, greater or less, of each may be left mixed with the other. This is the probable explanation of the fact that the recessive white plumage has some of the pigment from the dominant form. Segregation, the repulsion between chromosomes, or chromatin, from gametes of different races may occur in different degrees from complete segregation to complete mixture. When the latter occurs there would be no segregation and the heterozygote would breed true. The most interesting fact is that a given factor in the cases I have described, namely, colour of plumage and pigmentation of skin in the Jungle fowl and the Silky, is not a permanent and indivisible unit, but is capable of subdivision in any proportion. Bateson has already (in his Address to the Australian Meeting of the British Association) expressed the same conclusion. He states that although some Mendelians have spoken of genetic factors as per- 
manent and indestructible, he is satisfied that they may occasionally undergo a quantitative disintegration, the results of which he calls subtraction or reduction stages. For example, the Picotee Sweet Pea with its purple edges can be nothing but a condition produced by the factor which ordinarily makes the fully purple flower, quantitatively diminished. He remarks also that these fractional degradations are, it may be inferred, the consequences of irregularities in segregation.

Bateson, however, proceeds to urge that the history of the Sweet Pea belies those ideas of a continuous evolution with which we had formerly to contend. The big varieties came first, the little ones arose later by fractionation, although now the devotees of continuity could arrange them in a graduated series from white to deep purple. Now this may be historically true of the Sweet Pea, but I would point out that once the dogma of the permanent indivisible unit or factor is abandoned, there is nothing in Mendelism inconsistent with the possibility of the gradual increase or decrease of a character in evolution. I do not suggest that the colour and markings of a species or variety were, in all cases, due to external conditions, but if the effect of external stimuli can be inherited, can affect the chromosomes, then the evidence concerning unit factors no longer contradicts the possibility of a character gradually increasing, under the influence of external stimuli acting on the soma, from zero to any degree whatever. 


\section{Sex and Secondary Sexual Characters}

The mystery of sex is hidden ultimately in the phenomenon of conjugation, that union of two cells which in general seems necessary to the maintenance of life, to be a process of rejuvenation. We know nothing of the nature of this process, or why in general it should produce a reinvigoration of the cell resulting from it. We know little if anything of the relation between the two conjugating cells or gametes, of the real nature of the attraction that causes them to approach each other and ultimately unite together. We have, it is true, some evidence that one cell affects the other by some chemical action, as for instance in the fact that the mobile male gametes of a fern are attracted to a tube containing malic acid, but this may be merely an influence on the direction of movement of the male gamete, while there are cases in which neither cell is actively mobile. What we know in higher animals and plants is that each gamete contains in its nucleus half the number of chromosomes found in the other cells of the parent, and that in the fertilised ovum the chromosomes of both gametes form the new nucleus, in which therefore the original number of chromosomes is restored.

The remarkable fact is that from this fertilised ovum or zygote is developed usually an individual of one sex or the other, male or female, other cases being comparatively exceptional, although each act of fertilisation is the union of the two sexes together. Various attempts have been made to prove that the sex of the organism is determined by conditions affecting it during development sub- 
sequent to fertilisation, but now there is good reason to believe that generally the sex of the individual is determined at fertilisation, though as we shall see there is evidence that it may in certain cases be changed at a later stage.

In Mendelian experiments, a heterozygote individual is one arising from gametes containing opposite members of a pair of characters, in other words, from the union of a gamete carrying a dominant with another carrying a recessive. A pure recessive individual is one arising from the union of two gametes both carrying recessives. If a heterozygote is bred with a pure recessive the offspring are half heterozygote and half recessive. The heterozygote individual in typical eases shows the dominant character. In the formation of its gametes when the reduction division of the chromosomes takes place, half of them receive the dominant character, half the recessive. When the division in the gametes of the recessive individual takes place its gametes all contain the recessive character. Thus, if we indicate the dominant character by $D$ and the recessive by $d$, the constitution of the two individuals is

$$
D d \text { and } d d \text {. }
$$

The gametes they produce are

$$
D+d \text { and } d+d
$$

and the fertilisations are therefore

$$
D d, D d, d d, d d
$$

or heterozygote dominants and pure recessives in equal numbers.

It is evident that the reproduction of the sexes is very similar to this. One of the remarkable facts about sex is that, although the uniting gametes 
are male and female yet they give rise to males and females in equal numbers. If one sex were a dominant this would be in accordance with Mendelian theory. In accordance with the view that the dominant is something present which is absent in the recessive, the Mendelian theory of sex assumes that femaleness is dominant, and that maleness is the absence of femaleness, the absence of something which makes the individual female. If we represent the character of femaleness by $F$ and maleness or the recessive by $f$, we have the ordinary sexual union represented by

$$
F f \times f f
$$

the gametes will then be

$$
F+f \text { and } f+f \text {, }
$$

and the fertilisations

$$
\text { Ff and } f f \text {, }
$$

or males and females in equal numbers, as they are, at least approximately, in fact.

The close agreement of this theory with what actually happens is certainly important and suggests that it contains some truth. But it cannot be said to be a satisfactory explanation. It ignores the question of the nature of sex. According to the theory the female character is entirely wanting in the male. But what is sex but the difference between ovum and spermatozoon, between megagamete and microgamete? The theory then asserts that an individual developed from a cell formed by the union of male and female gametes is entirely incapable of producing female gametes again. Every zygote after conjugation or fertilisation may be said to be bisexual or hermaphrodite. How comes it then that the female quality entirely disappears? Whether the gametocytes are distinguishable at 
an early stage in the segmentation of the ovum, or only at a later stage of development, we know that the gametes ultimately formed have descended by a series of cell-divisions from the fertilised ovum or zygote cell from which development commenced. If segregation takes place at the reduction divisions we might suppose that half the gametes formed are sperms and half are ova, and that in the male the latter do not survive but perish and disappear. But in this case it would be the whole of the chromosomes coming from the original female gamete which would disappear, and the spermatozoon would be incapable of transmitting characters derived from the female parent of the individual in which the spermatozoa were formed. An individual could never inherit character from its paternal grandmother. This, of course, is contrary to the results of ordinary Mendelian experiments, for characters are inherited equally from individuals of either sex, except secondary sexual characters and sex-linked characters which we shall consider later.

Similarly, if we suppose that segregation of ovum and sperm occurs in the female, the sperms must disappear and the ovum would contain no factors derived from the male parent. But the theory supposes that the segregation of male and female does occur in the female, that half the ova are female and half are male. What meaning are we to attach to the words ' male ovum' or even ' male producing ovum, ? It is a fundamental principle of Mendelism that the soma does not influence the gametocytes or gametes; we have therefore only to consider the sex of the gametes themselves, derived from a 
zygote which is formed by the union of two sexes. The quality of maleness consists only in the size, form, and mobility of the sperm in the higher animals and of the microgamete in other cases. In what sense then can an ovum be male? It may perhaps be said that though it is itself female, it has some property or factor which when united with a sperm causes the zygote to be capable of producing only sperms, and conversely the female ovum has a quality which causes the zygote to produce only ova. But since these qualities segregate in the reduction divisions, how is it that the male quality in the $f$ ovum does not make it a sperm? We are asked to conceive a quality, or the absence of a factor, in an ovum which is incapable of causing that ovum to be a sperm, but which, when segregated in the gametes descended from that ovum, causes them all to be sperms. It is impossible to conceive a single quality or factor which at different times produces directly opposite effects. The Mendelian theory is merely a theory in words, which have an apparent relation to the facts, but which when examined do not correspond to any real conceptions.

However, we have to consider a number of remarkable facts concerning the relation of chromosomes to sex. In the ants, bees, and wasps the unfertilised ovum always develops into a male, the fertilised into a female. The chromosomes of the ovum undergo reduction in the usual way, and are only half the number of those present in the nucleus before reduction. We may call this reduced number $N$ and the full number $2 N$. The ova developing by parthenogenesis and giving 
rise to males segment in the usual way, and all the cells both of soma and gametocytes contain only $N$ chromosomes. In the maturation divisions reduction does not occur, $N$ chromosomes passing to one gamete, none to the other, and the latter perishes so that the sperms all contain $N$ chromosomes. When fertilisation occurs the zygote therefore contains $2 N$ chromosomes and becomes female. Here then we have no segregation of $F \times f$ in the ova. The difference of sex merely corresponds to duplex and simplex conditions of nucleus, but it is curious that the simplex condition in the gametes occurs in both ova and sperms.

In Daphnia and Rotifers the facts are different. Parthenogenesis occurs when food supply is plentiful and temperature high. In this case reduction of the chromosomes does not occur at all, the eggs develop with $2 \mathrm{~N}$ chromosomes and all develop into females. Under unfavourable conditions reduction or meiosis occurs, and two kinds of eggs larger and smaller are formed, both with $N$ chromosomes. The larger only develops when fertilised and give rise to females with $2 N$ chromosomes. The smaller eggs develop without fertilisation, by parthenogenesis, and become males. Here then we have three kinds of gametes, large eggs, small eggs, and sperms, each with the same number of chromosomes. It is not the mere number then which makes the difference, but we find a segregation in the ova into what may for convenience be called female ova and male ova.

In Aphidae or plant lice a third condition is found. Here again parthenogenesis continues for generation after generation so long as conditions are favourable, 
i.e. in summer, and the eggs are in the same condition as in Daphnia, etc., that is to say, reduction does not occur, and the number of chromosomes is $2 N$. Under unfavourable conditions males are developed as well as females by parthenogenesis, but the males arise from eggs which undergo partial reduction of chromosomes, only one or two being separated instead of half the whole number. The number then in an egg which develops into a male is $2 N-1$, while other eggs undergo complete reduction and then have $N$ chromosomes. The latter, however, do not develop until they have been fertilised. In the males, when mature, reduction takes place in the gametes, so that two kinds of sperms are formed, those with $N$ chromosomes and those with $N-1$ chromosomes. The latter degenerate and die, the former fertilise the ova, and the fertilised ova develop only into females. The chief difference in this case then is that the reduction in the male to the $N$ or simplex condition takes place in two stages, one in the parthenogenetic ovum, one in the gametes of the mature male. In Hymenoptera and in Daphnia, etc., the whole reduction takes place in the parthenogenetic ovum, and in the mature male, though reduction divisions occur, no separation of chromosomes takes place: at the first division one cell is formed with $N$ chromosomes and one with none, and the latter perishes.

In many insects and other Arthropods which are not parthenogenetic the male has been found to possess fewer chromosomes than the female. The female forms, as in the above cases of parthenogenesis, only gametes of one kind each with $N$ chromosomes, but the male forms gametes of two 
sorts, one with $N$ chromosomes, the other with $N-1$ or $N-2$ chromosomes. On fertilisation two kinds of zygotes are formed, female-producing eggs with $2 N$ chromosomes, and male-producing eggs with $2 N-1$ or $2 N-2$ chromosomes. There is also evidence that in some cases, e.g. the sea-urchin, the female is heterozygous, forming gametes, some with $N$ and some with $N+$ chromosomes, while the male gametes are all $N$. Fertilisation then produces male-producing eggs with $2 N$ chromosomes, femaleproducing with $2 N+$.

Such is the summary given by Castle in 1912.1 It will be seen that he treats the differences as purely quantitative, mere differences in the number of the chromosomes. Professor E. B. Wilson, however, who had contributed largely by his own researches to our knowledge of sex from the cytological point of view, had already published, in $1910,{ }^{2}$ a very instructive résumé of the facts observed up to that time. The important fact which is generally true for insects, according to Wilson, is that there is a special chromosome or chromosomes which can be distinguished from the others, and which is or are related to sex differentiation. This chromosome, to speak of it for convenience in the singular, has been variously named by different investigators. Wilson called it the ' $X$ chromosome,' M'Cluny the 'accessory chromosome,' Montgomery the 'heterochromosome,' while the names ' heterotropic chromosome' and idiochromosome have also been used. For the purpose of the present discussion we may con-

1 Heredity and Eugenics, by Castle and Others. University of Chicago Press, 1912.

2 'The Determination of Sex.' Science Progress, April 1910. 
veniently name it the sex-chromosome. It is often distinguished by its larger size and different shape. Wilson describes the following different cases:-

(1) The sex-chromosome in the male gametocytes is single and fails to divide with the others, but passes undivided to one pole. This may occur in the first reduction division (Orthoptera, Coleoptera, Diptera) or in the second (many Hemiptera). But it is difficult to understand what is meant by 'fails to divide.' In one of the reduction divisions all the chromosomes divide as in ordinary or homotypic nucleus division, but in the other the chromosomes simply separate into two equal groups without division. If there are an odd number of chromosomes, $2 N-1$, in all the gametocytes of the male, as stated in most accounts of the subject, then if one chromosome fails to divide in the homotypic division, we shall have $2 N-2$ in one spermatocyte and $2 N-1$ in the other. Then when the heterotypic division takes place and the number of chromosomes is halved, we shall have two spermatocytes with $N-1$ chromosomes from one of the first spermatocytes and one with $N$ and one with $N-1$ from the other. Thus there will be three spermatozoa with $N-1$ chromosomes and one with $N$ chromosomes, whereas we are supposed to find equal numbers with $N$ and $N-1$ chromosomes. It is evident that what Dr. Wilson means is that the sex-chromosome is unpaired, and that although it divides like the others in the homotypic division, in the heterotypic division it has no mate and so passes with half the number of chromosomes to one pole of the division spindle, while the other group of chromosomes has no sexchromosome. Examples of this are the genera 
Pyrrhocoris and Protenor (Hemiptera) Brachystola and many other Acrididae, Anasa, Euthoetha, Narnia, Anax. In a second class of cases the sexchromosome is double, consisting of two components which pass together to one pole. Examples of this are Syromaster, Phylloxera, Agalena. In a third class the sex-chromosome is accompanied by a fellow which is usually smaller, and the two separate at the differential division. The sizes of the two differ in different degrees, from cases as in many Coleoptera and Diptera in which the smaller chromosome is very minute, to those (Benacus, Mineus) in which it is almost as large as its fellow, and others (Nezara, Oncopeltus) in which the two are equal in size. Again, there are cases in which one sex-chromosome, say $X$, is double, triple, or even quadruple, while the other, say $Y$, is single. In all these cases there are two $X$ chromosomes in the oocytes (and somatic cells) of the female, and after reduction the female gametes or unfertilised ova are all alike, having a single $X$ chromosome or group. On fertilisation half the zygotes have $X X$ and half $X Y$, whether $Y$ is absence of a sex-chromosome, or one of the other $Y$ forms above mentioned. The sex is thus determined by the male gamete, the $X$ chromosome united with that of the female gamete producing female individuals, while the $Y$ united with $X$ produces male individuals.

Professor T. H. Morgan has made numerous observations and experiments on a single culture of the fruit-fly, Drosophila ampelophila, bred in bottles in the laboratory for five or six years. He has not only studied the chromosomes in the gametes of this fly, and made Mendelian crosses with it, 
but has obtained numerous mutations, so that his work is a very important contribution to the mutation doctrine. Drosophila in the hands of Professor Morgan and his students and colleagues has thus become as classical a type as Oenothera in those of the botanical mutationists. Different branches of Morgan's work are discussed elsewhere in this volume, but here we are concerned only with its bearing on the question of the determination of sex. He describes ${ }^{1}$ the chromosomes of Drosophila as consisting in the diploid condition of four pairs, that is to say, pairs which separate in the reduction division so that the gamete contains four single chromosomes, one of each pair. In two of these pairs the chromosomes are elongated and shaped like boomerangs, in the third they are small, round granules, and the fourth pair are the sex-chromosomes: in the female these last are straight rods, in the male one is straight as in the female, the other is bent. The straight ones are called the $X$ chromosomes, the bent one the $Y$ chromosome. The fertilisations are thus $X X$ which develops into a female fly, and $X Y$ which develops into a male. Drosophila therefore is an example of one of the cases described by Wilson.

Dr. Wilson (loc. cit.) discusses the question of how we are to interpret these facts, in particular, the fact that the $X$ chromosome in fertilisation gives rise to females. He remarks that the $X$ chromosome must be a male-determining factor since in many cases it is the only sex-chromosome in the males, yet its introduction into the egg

1 A Critique of the Theory of Evolution. Princeton University Press and Oxford University Press, 1916. 
establishes the female condition. This is the same difficulty which I pointed out above in connection with the Mendelian theory that the female was heterozygous and the male homozygous for sex. Dr. Wilson points out that in the bee, where fertilised eggs develop into females and unfertilised into males, we should have to assume that the $X$ chromosome in the female gamete is a female determiner which meets a recessive male determiner in the $X$ chromosomes of the sperm. When reduction occurs, the $X$ o must be eliminated since the reduced egg develops always into a male. But on fertilisation, since the fertilised egg develops into a female, a dominant $X_{q}$ must come from the sperm, so that our first assumption contradicts itself.

Dr. Wilson, T. H. Morgan, and Richard Hartwig have therefore suggested that the sex-difference as regards gametes is not a qualitative but a quantitative one. In certain cases there is no evident quantitative difference of chromatin as a whole, but there may in all cases be a difference in the quantity of special sex-chromatin contained in the $X$ element. The theory put forward by Wilson then is that a single $X$ element means per se the male condition, while the addition of a second element of the same kind produces the female condition. Such a theory might apply even to cases where no sex-chromosomes can be distinguished by the eye: the ova, in such cases (probably the majority), might also have a double dose of sexchromatin, the males a single dose. This theory, however, is still open to the objection that the female gametes before fertilisation, and half the male gametes, have the half quantity of sex- 
chromatin which by hypothesis determines the male condition, so that here again we have the male condition as something which is distinct from the characteristics of the spermatozoon. But if this is the case, what is the male condition? The parthenogenetic ovum of the bee is male, and yet it is an ovum capable only of producing spermatozoa. If the single $X$ chromosomes is the cause of the development of spermatozoa in the male bee, why does it not produce spermatozoa in the gametes of the female bee, since when reduction takes place all these gametes have a single $X$ chromosome ?

In biology, as in every other science, we must admit facts even when we cannot explain them. The facts of what we call gravitation are obvious, and any attempt to disregard them would result in disaster, yet no satisfactory explanation of gravitation has yet been discovered: many theories have been suggested, but no theory has yet been proved to be true. In the same way it may be necessary to admit that two $X$ chromosomes result in the development of a female, and one $X$, or $X Y$ chromosomes result in the development of a male. But Mendelians have omitted to consider what is meant by male and female. The soma with its male and female somatic characters has nothing to do with the question, since somatic sex-differences may be altogether wanting, and moreover, the essential male character, the formation of spermatozoa, is by the Mendelian hypothesis due to descent of the male gametes from the original fertilised or unfertilised ovum. The Mendelian theory therefore is that when an ovum has two $X$ sex-chromosomes it can only after a number of cell-divisions, at the 
following reduction division, give rise to ova, while an ovum containing one $X$ sex-chromosome, or two different, $X Y$, chromosomes, at the next reduction division gives rise to spermatozoa. The $X$ sex-chromosome is not in itself either female or male, since, as we have seen, either ovum or spermatozoon may contain a single $X$ chromosome. The ovum then with one $X$ chromosome or one $X$ and one $Y$ changes its sex at the next reduction division and becomes male. In parthenogenetic ova this happens without conjugation with a spermatozoon at all: in other cases, since the zygote is compounded of spermatozoon and ovum, we can only say that in the $X X$ zygote, the ovum developing only ova, the female is dominant, in the $X$ or $X Y$ zygote developing only spermatozoa the male is dominant. Hermaphrodite animals, as has been pointed out by Correns and Wilson, cannot be brought under this scheme at all. In the earthworms, for instance, we have, in every individual developed from a zygote, ova and spermatozoa developing in different gonads in different parts of the body. The differentiation here, therefore, must occur in some cell-division preceding the reduction divisions. Every zygote must have the same composition, and yet give rise to two sexes in the same individual.

Further light on the sex problem, as in many other problems in biology, can only be obtained by more knowledge of the physical and chemical processes which take place in the chromosomes and in the relations of these structures to the rest of the cell. The recent advances in cytology, remarkable as they are, consist almost entirely of observations of microscopic structure. They may be said to reveal 
the statics of the cell rather than its dynamics. Cytology is in fact a branch of anatomy, and in the anatomy of the cell we have made some progress, but our knowledge of the physiology of the cell is still infinitesimal. The nucleus, and especially the chromosomes, are supposed in some unknown way to influence or govern the metabolism of the cytoplasm. From this point of view the hypothesis mentioned above that the sex-difference in the gametes is not qualitative but quantitative is probably nearer to the truth. Geddes and Thomson and others have maintained that the sex-difference is one of metabolism, the ovum being more anabolic, the sperm more katabolic. A double quantity of special chromatin may be the cause of the greater anabolism of the ovum. In that case the difficulty indicated in a previous part of this chapter, that the ovum after reduction resembles the sperm in having only one $X$ chromosome, may be explained by the fact that the growth of the ovum and its accumulation of yolk substances has been already accomplished under the influence of the two chromosomes before reduction. Other difficulties previously discussed also appear to be diminished if we adopt this point of view. We need not regard maleness and femaleness as unit characters in heredity of the same kind as Mendelian characters of the soma. Instead of saying that the zygote composed of ovum and spermatozoon is incapable of giving rise in the male to ova, or in the female to sperms, we should hold that the gametocytes ultimately give rise to ova or to sperms according to the metabolic processes set up and maintained in them through their successive cell-divisions under the influence of the double or 
single $X$ chromosome. There still remains the difficulty of explaining why the male gametocytes after reduction develop into similar sperms, with their heads and long flagella, although half of them possess one $X$ chromosome each and the other half none. We can only suppose that the final development of the sperms is the result of the presence of the single $X$ chromosome in the successive generations of male gametocytes before the reduction divisions.

The Mendelian theory of sex-heredity assumed that in the reduction divisions the two sex-characters, maleness and femaleness, were segregated in the same way as a pair of somatic allelomorphs, but the words maleness and femaleness expressed no real conceptions. The view above suggested merely attempts to bring our real knowledge of the difference between ovum and sperm into relation with our real knowledge of the sex-chromosomes and their behaviour in reduction and fertilisation. 


\section{CHAPTER III}

\section{INFLUENCE OF HORMONES ON DEVELOPMENT OF SOMATIC SEX-CHARACTERS}

WE have next to consider what are commonly called secondary sexual characters. These are characters or organs more or less completely limited to one sex. When we distinguish in the higher animals the generative organs or gonads on the one hand from the body or soma on the other, we see that all differences between the sexes, except the gonads, are somatic, and we may call them somatic sexual characters. The question at once arises whether the soma itself is sexual, that is to say, whether on the assumption that the sex of the zygote is already determined before it begins to develop, the somatic cells as well as the gametocytes are individually and collectively either male or female. In previous discussions of the subject I have urged that the only meaning of sex was the difference between the megagamete or ovum, and the microgamete or sperm. But if the zygote, although compounded of ovum and sperm, is predestined to give rise in the gametes descended from it, either to sperms only or to ova only, it may be suggested that all the somatic cells descended from the zygote are likewise either male or female, although they do not give rise to gametes. It is evident, however, that the somatic cells, organs, and characters do not differ necessarily or universally 
in the two sexes. On the one hand, we have extraordinary and very conspicuous peculiarities in the male, entirely absent in the female, such as the antlers of stags, and the vivid plumage of the gold pheasant; on the other we have the sexes externally alike and only distinguished by their sexual organs, as in mouse, rabbit, hare, and many other Rodents, most Equidae, kingfisher, crows and rooks, many parrots, many Reptiles, Amphibia, Fishes, and invertebrate animals. In the majority of fishes, in which fertilisation is external and no care is taken of the eggs or young, there are no somatic sexual differences. Moreover, somatic sexual characters where they do occur have no common characteristics either in structure or position in the body. It may be said that any part of the soma may in different cases present a sex-limited development. In the stag the male peculiarity is an enormous development of bone on the head, in the peacock it is the enlargement of the feathers of the tail. In some birds there are spurs on the legs, in others spurs on the wings. It is no explanation, therefore, to say that these various organs and characters are the expression of sex in the somatic cells.

As I pointed out in my Sexual Dimorphism (1900), the common characteristic of somatic sexual characters is their adaptive relation to some function in the sexual habits of the species in which they occur. There is no universal characteristic of sex except the difference between the gametes and the reproductive organs (gonads) in which they are produced. All other differences, therefore, including genital ducts and copulatory or intromittent organs, are somatic. When we examine these somatic 
differences we find that they can be classified according to their relation to fertilisation and reproduction, including the care or protection of the offspring. The precise classification is of no great importance, but we may distinguish the following kinds to show the chief functions to which the characters or organs are adapted.

1. Genital Ducts and Intromittent Organs.According to the theory of the coelom which we owe to Goodrich, in all the coelomata the coelom is primarily the generative cavity, on the walls of which the gametocytes are situated, and the coelomic ducts are the original genital ducts. In Vertebrates we find two such ducts in both sexes in the embryo, originally formed apparently by the splitting of a single duct. In the male one of these ducts becomes connected with the testis while the other degenerates: the one which degenerates in the male forms the oviduct in the female, while the one which is functional in the male degenerates in the female.

Intromittent organs are formed in all sorts of different ways in different animals. In Elasmobranchs (sharks and skates) they are onlarged portions of the pelvic fins, and therefore paired. In Lizards they are pouches of the skin at the sides of the cloacal opening. In Mammals the single penis is developed from the ventral wall of the cloaca. In Crustacea certain appendages are used for this function. There are a great many animals, from jelly-fishes to fishes and frogs, in which fertilisation is external, and there are no intromittent organs at all.

2. Organs for Capturing or Holding the Female: for example, the thumb-pads of the frog, 
and a modification of the foot in a water-beetle. Certain organs on the head and pelvic fins of the Chimaeroid fishes are believed to be used for this purpose.

3. Weapons.-Organs which are employed in combats between males for the exclusive possession of the females. For example, antlers of stags, horns of other Ruminants, tusks of elephants, spurs of cocks and Phasiamidae generally, horns and outgrowths in males of Reptiles and many Beetles, probably used for this purpose.

4. Allurements.-Organs or characters used to attract or excite the female. These might be called the organs of courtship, such as the peacock's tail, the plumes of the birds-of-paradise, and the brilliant plumage of humming birds and many others. The song of birds is another example, and sound is produced in many Fishes for a similar purpose.

5. Organs for the Benefit of the Offspring: for example, the extraordinary pouches in which the eggs are developed in certain Frogs. In the South American species, Rhinoderma darwinii, the enlarged vocal sacs are used for this purpose. Pouches with the same function are developed in many animals, for instance in Pipe-fishes and Marsupials. Abdominal appendages are enlarged in female Crustacea for the attachment of the eggs, the abdomen also being larger and broader.

The argument in favour of the Lamarckian explanation of the evolution of these adaptive characters is the same as in the case of adaptations common to both sexes, namely that in every case the function of the organs and characters involves special irritations or stimulations by external 
physical agents. Mechanical irritation, especially of the interrupted kind, repeated blows or friction causes hypertrophy of the epidermis and of superficial bone. I have stated this argument and the evidence for it in some detail in my volume on Sexual Dimorphism. It is one of the most striking facts in support of this argument that the hypertrophied plumage which constitutes the somatic sexual character of the male in so many birds is habitually erected by muscular action for the purpose of display in the sexual excitement of courtship. I doubt if there is a single instance in which the male bird takes up a position to present his ornamental plumage to the sight of the female without a special erection and movement of the feathers themselves. Such a stimulation must affect the living epidermic cells of the feather papilla. Even supposing that the feather is not growing at the time, it is probable, if not certain, that the stimulation will affect the papilla at the base of the feather follicle, so as to cause increased growth of the succeeding feather. But we have no reason to believe that erection in display occurs only when the growth of the feathers is completed, still less that it did so always at the beginning of the evolution.

The antlers of stags are the best case in favour of the Lamarckian view of the evolution of somatic sexual characters. The shedding of the skin ('velvet') followed by the death of the bone, and its ultimate separation from the skull, are so closely similar to the pathological processes occurring in the injury of superficial bones, that it is impossible to believe that the resemblance is only apparent and deceptive. In an individual man or mammal, if 
the periosteum of a bone is destroyed or removed the bone dies, and is then either absorbed, or separated from the living bone adjoining, by absorption of the connecting part. In the stag both skin and periosteum are removed from the antler: probably they would die and shrivel of their own accord by hereditary development, but as a matter of fact the stag voluntarily removes them by rubbing the antler against tree trunks, etc. When the bone is dead the living cells at its base dissolve and absorb it, and when the base is dissolved the antler must fall off.

The adaptive relation is not the only common characteristic of these somatic sexual characters. Another most important fact is not only that they are fully developed in one sex, absent or rudimentary in the other, but that their development is connected with the functional maturity and activity of the gonads. There is usually an early immature period of life in which the male and female are similar, and then at the time of puberty the somatic sexual characters of either sex, generally most marked in the male, develop. In some cases, where the activity of the gonads is limited to a particular season of the year, the sexual characters or organs are developed at this season, and then disappear again, so that there is a periodic development corresponding to the periodic activity of the testes or ovaries. Stags have a limited breeding or 'rutting' season in autumn (in north temperate regions), and the antlers also are shed and developed annually. In this case we cannot assert that the development of the antler takes place during the active state of the testes. The antlers are fully developed and the velvet is shed at the commence- 
ment of the rutting season, and development of the antlers takes place between the beginning of the year and the month of August or September. In ducks and other birds there is a brilliant male-breeding plumage in the breeding season which disappears when breeding is over, so that the male becomes very similar to the female. In the North American fresh-water crayfishes of the genus Cambarus there are two forms of males, one of which has testes in functional activity, while in the other these organs are small and quiescent: the one form changes into the other when the testes pass from the one condition to the other.

It has long been known that the development of male sex-characters is profoundly affected by the operation of castration. The removal of the testes is most easily carried out in Mammals, in consequence of the external position of the organs in these animals, and the operation has been practised on domesticated animals as well as on man himself from very ancient times. The effect is the more or less complete suppression of the male insignia, in man, for example, the beard fails to develop, the voice does not undergo the usual change to lower pitch which takes place at puberty, and the eunuch therefore has much resemblance to the boy or woman. Many careful experimental researches have been made on the subject in recent years. The consideration of the subject involves two questions: (1) What are the exact effects of the removal of the gonads in male and female? (2) By what means are these effects brought about, what is the physiological explanation of the influence of the gonads on the soma? 
I have quoted the evidence concerning the effects of castration on stags in my Sexual Dimorphism and in my paper on the 'Heredity of Secondary Sexual Characters.' 1 When castration is performed soon after birth a minute, simple spike antler is developed, only two to four inches in length: it remains covered with skin, is never shed, and develops no branches. When the operation is performed on a mature stag with antlers, the latter are shed soon after the operation, whether they have lost their velvet or not. In the following season new antlers develop, but these never lose their velvet or skin and are never shed.

\section{Castration in Fowls}

The removal of the testes from young cocks has been commonly practised in many countries, e.g. France, capons, as such birds are called, being fatter and more tender for the table than entire birds. The actual effect, however, on the secondary sexual characters has not in former times been very definitely described. The usual descriptions represent the castrated birds as having rather fuller plumage than the entire birds; but the comb and wattles are much smaller than in the latter, more similar to those of a hen. It is also stated that the capon will rear chickens, though he does not incubate, and that they are used in this way in France.

The most precise of the statements on the subject by the earlier naturalists is that of William Yarrell ${ }^{2}$ (1857), who writes as follows:-

' The capon ceases to crow, the comb and gills do

1 Archiv für Entwicklungsmechanik, 1908.

2 Proc. Linn. Soc., 1857. 
not attain the size of those parts in the perfect male, the spurs appear but remain short and blunt, and the hackle feathers of the neck and saddle instead of being long and narrow are short and broadly webbed. The capon will take to a clutch of chickens, attend them in their search for food, and brood them under his wings when they are tired.'

It would naturally be expected, on the analogy of the case of stags, that when a young cock was completely castrated all the male secondary characters would be suppressed, namely, the greater size of the comb and wattles in comparison with the hen, the long neck hackles, and saddle hackles, long tail feathers, especially the sickle-feathers, and the spurs. As a matter of fact, the castrated specimen usually shows only the first of these effects to any conspicuous degree. The comb and wattles of the capon are similar to those of the hen, but he still has the plumage and the spurs of the entire cock. Many investigators have made experiments in relation to this subject, and most of them have found that complete castration is difficult, and that portions of the testes left in the bird during the operation become grafted in some other position either on the parietal peritoneum, or on that covering the intestines, and produce spermatozoa, which of course have no outlet. In such cases the secondary male characters may be more or less completely developed. Thus Shattock and Seligmann (1904) state that ligature of the vas deferens made no difference to the male characters, and that after castration detached fragments were often left in different positions as grafts, when the secondary characters developed. In one particular case only a 
minute nodule of testicular tissue showing normal spermatogenesis was found on post mortem examination attached to the intestine. In this bird there was no male development of comb or wattles, a full development of neck hackles, a certain development of saddle hackles, a few straggling badly curved feathers in the tail and short blunt spurs on the legs. Lode ${ }^{1}$ (1895) found that testes could easily be transplanted into subcutaneous tissue and elsewhere, and that the male characters then developed normally. Hanau ${ }^{2}$ (1896) obtained the same result.

The question, however, to what degree the male characters of the cock are suppressed after complete castration is not so definitely answered in the literature of the subject. Shattock and Seligmann in their 1904 paper make no definite statement on the subject. Rieger (1900), Selheim (1901), and Foges $^{3}$ (1902) state that the true capon is characterised by shrivelling of the comb, wattles, and spurs; poor development of the neck and tail feathers; hoarse voice and excessive deposit of fat. Shattock and Seligmann, on the other hand, have placed in the College of Surgeons Museum the head of a Plymouth Rock which was castrated in 1901. It was hatched in the spring of that year. In December 1901 the comb and wattles were very small, the spurs fairly well developed, and the tail had a somewhat masculine appearance. In September 1902, when the bird was killed, the comb and wattles were still poorly developed, the neck hackles fairly well so; saddle hackles rather well

1 Wiener klin. Wochenschr., 1895.

2 Arch. f. ges. Physiologie, 1896.

3 Pflügers Archiv, 1902. 
developed; the tail contained rather looselygrouped long sickle feathers; the spurs stout. The description states that dissection showed no trace of either testicle, and I am informed by Mr. Shattock that there were no grafts. The description ends with the conclusion that the growth of the spurs, and to a certain extent that of the long, curved sickle feathers, is not prevented by castration. With regard to the spurs this result does not agree with that of the German investigators, but it must be remembered that the latter speak only of the reduction of the spurs, not entire absence. It is important in discussing the effects of castration in cocks to bear in mind the actual course of development of the secondary sexual characters. When the chicks are first hatched they are in the down: rudimentary combs are present, wattles can scarcely be distinguished, and there is no external difference between the sexes. The ordinary plumage begins to develop immediately after hatching, the primaries of the wings being the first to appear. The feathers are completely developed in about five weeks, and still there is no difference between the sexes. The first sexual difference is the greater size of the combs in the males, and this is quite distinct at the age of six weeks. At nine to ten weeks in black-red fowls, in which the cocks have black breasts and red backs with yellow hackles, the black feathers on the breast and red on the back are gradually developing, both sexes previously having been a dull speckled brown, closely similar to the adult hens. The spurs are the last of the male characters to develop, these at the age of four months being still mere nodules, scarcely, if at all, larger than the 
rudiments visible in adult hens. This is the age at which castration is usually performed, as at an earlier age the birds are too small to operate on successfully. It follows, therefore, that the spurs develop after castration, and it would seem that their development does not depend upon the presence of the sexual organs. It is a question, however, whether castration in the cock is ever quite complete. In the original wild species and in the majority of domesticated breeds the spurs are confined to the male sex, and are typical secondary sexcharacters, as much so as the antlers of stags or the beard of man, yet the above discussion shows that there is some doubt whether their development is prevented as much as in other cases by the absence of the sexual organs. Even if it should be proved that in supposed cases of complete castration, such as that of Shattock and Seligmann, some testicular tissue remained at the site of the testes, it would still be true that the development of the comb and wattles is more affected by the removal of the sexual organs than that of the spurs or tail feathers.

My own experiments in castrating cocks were as follows: On August 20, 1910, I operated on a White Leghorn cock about five months old. One testis was removed, with a small part of the end broken off, but the other, after it was detached, was lost among the intestines. On the same day I operated on another about thirteen weeks old, a speckled mongrel. In this case both testes were extracted but one was slightly broken at one end, although I was not sure that any of it was left in the body. An entire White Leghorn of the same age as the first was kept as a control. On August 27 the two 
castrated birds had recovered and were active. Their combs had diminished in size and lost colour considerably, that of the White Leghorn was scarcely more than half as large as that of the control. Such a rapid diminution can scarcely be due to absorption of tissue, but shows that the size of the normal cock's comb is largely due to distension with blood, which ceases when the sexual organs are removed. In the following January, the second cock, supposed to be completely castrated, was seen to make a sexual gesture like a cock, though not a complete action like an entire animal: this showed that the sexual instinct was not completely suppressed. In February this same bird was seen to attempt to tread a hen, while the white one, supposed to be less perfectly emasculated, had never shown such male instinct.

The White Leghorn cock was killed and dissected on May 13, 1911, nine months after castration. I found an oval body of dark, dull brown colour loose among the intestines: this was evidently the left testis which was separated from its natural attachment and lost in the abdomen at the time of the operation. I examined the natural sites of the testes: on the right side there was a small testis of considerable size, about half an inch in diameter. When a portion of this was teased up and examined under the microscope moving spermatozoa were seen, but they were not in swarms as in a normal testis, but scattered among numerous cells. On the left side was a much smaller testis, in the tissue of which I. with difficulty detected a few slowly moving spermatozoa. The vasa deferentia were seen as white convoluted threads on the peritoneum, but contained no spermatozoa. 
On July 29, 1911, a little more than eleven months after the operation, I examined and killed the second of these castrated cocks, the speckled mongrel-bred bird. I measured the comb and wattles while it was alive, in case there might be reduction in the size of these appendages when the bird was killed. The comb was $1 \frac{1}{8}$ inches high by $2 \frac{3}{8}$ inches in length. The spurs were 1 inch long, curved and pointed. Saddle hackles short, hanging only a little below the end of the wing. Neck hackles well developed, similar to those of an entire cock. Longest tail feather $15 \frac{5}{8}$ inches, blue-black in colour.

I had no entire cock of same breed, but measured the entire White Leghorn for comparison. Comb $1 \frac{3}{4}$ inches high by $3 \frac{3}{4}$ inches in length. (It is to be remembered that the comb and wattles are especially large in Leghorns.) Wattle $1 \frac{1}{4}$ inches in vertical length. Spur 1 inch long, stouter and less pointed than in the capon. Longest tail feather 12 inches long.

When killed the capon was found to be very fat : there were masses of fat around the intestines and under the peritoneum, which made it impossible to make out details such as ureter and vas deferens properly. I found a white nodule about half an inch in diameter attached to mesentery. The liquid pressed from this was swarming with spermatozoa in active motion. Two other masses about the same size or a little larger were found on the sites of the original testes. These also were full of mobile spermatozoa, and must have grown from portions of the testes left behind at castration.

In ducks the sexual characters of the male differ from those in the fowl, especially in the fact that they 
almost completely disappear after the breeding season and reappear in the following season. In the interval the drake passes into a condition of plumage in which he resembles the female; and this condition is known as 'eclipse.' The male plumage, therefore, in the drake has a history somewhat similar to that of the antlers in deer. Two investigations of the effects of castration on ducks and drakes have been recorded. H. D. Goodale ${ }^{1}$ removed the generative organs from both drakes and ducks of the Rouen breed, which is strongly dimorphic in plumage. One drake was castrated in the early spring of 1909 when a little less than a year old. This bird did not assume the summer plumage in 1909, that is, did not pass into eclipse. It was in the nuptial plumage when castrated. This breeding or nuptial plumage is well known : it includes a white neck-ring, brilliant green feathers on the head, much claret on the breast, brilliant metallic blue on the wing, and two or more upward curled feathers on the tail. The drake mentioned above was accidentally killed in the spring of 1910. Another drake was castrated on August 8, 1909: only the left testis was removed, the other being ligatured. At this time the bird would be in eclipse plumage. It appears from the description that it assumed the nuptial plumage in the winter of 1909, and did not pass into eclipse again in the summer of 1910. Thus in drakes the effect of castration is that the secondary sexual character remains permanently instead of being lost and renewed annually. Goodale, however, does not describe the moults in detail. In the natural

1 'Castration of Drakes.' Biol. Bulletin, Wood's Hole, Mass., rol. xx., 1910. 
condition the drake must moult twice in the year, once when he sheds the nuptial plumage, and again when he drops the summer dress. Goodale insists, from some idea about secondary sexual characters which is not very obvious, that the eclipse or summer plumage is not the same as that of the female. He states that the male in summer plumage merely mimics the female but does not become entirely like her. In certain parts of the body there are no modifications toward the female type. In others, i.e. head, breast, and keel region, the feathers of the male become quite like, those of the female. 'It can hardly be maintained that this is an example of assumption by the male of the female's plumage, especially as the presence of the testis is necessary for its appearance.' The idea here seems to be that since the eclipse plumage is only assumed when the testis is present, therefore it must be a male character.

Out of five females on which the operation was performed only two lived more than a few days afterwards. One of these $(a)$ was castrated in the spring of 1909 when a little less than a year old, the other $(b)$ on August 13 when twelve weeks old. In October 1909 they showed no marked modifications. In July 1910 it was noticed that they had the male curled feathers in the tail, and $(a)$ had breast feathers similar to those of the male in summer plumage, (b) was rather more strongly modified: she had a very narrow white neck-ring, and breast feathers distinctly of male type. The next moult began in September, and in November was well advanced. On the whole $(a)$ had made little advance towards the male type, but $(b)$ closely resembled the male in nuptial plumage. It had brilliant green feathers 
on the head, a white neck-ring, much claret colour on the breast, and some feathers indistinguishable from those of the male, and also the male sex feathers on the tail. Goodale concludes that the female owes her normal colour to the ovaries or something associated with them which suppresses the male characters and ensures the development of her own type. He considers it is quite as conceivable that selection should operate to pick out inconspicuously coloured females as that selection of brilliantly coloured males should bring about an addition to the female type. But as pointed out above, selection cannot explain the dimorphism in either ease.

It may be mentioned here that owing to the fact that the single (left) ovary in birds is very elosely attached to the peritoneum immediately covering the great post-caval vein, it is generally impossible to remove the whole of the ovary without cutting or tearing the wall of the vein and so causing fatal hemorrhage. The above results observed by Goodale are therefore all the more remarkable, and it may be assumed that he removed at any rate nearly all the ovary.

The research of Seligmann and Shattock ${ }^{1}$ begins with a comparison between the stages of the development of the nuptial plumage and the stages of spermatogenesis. In the young pheasant the male plumage is fully developed in the autumn of its first year, but no pairing occurs and no sexual instinct is exhibited till the following spring. The wild duck pairs in autumn or early winter, after the assumption

1 'Relation between Seasonal Assumption of the Eclipse Plumage in the Mallard (Anas boscas) and the Functions of the Testicle.' Proc. Zool. Soc., 1914. 
of the nuptial plumage, but copulation does not occur till spring is advanced. The investigation here considered was made upon specimens of semidomesticated Anas boscas, such as are kept in London parks and supplied from game farms. The testes attain their maximum size during the breeding season-end of March or beginning of April. At this time each organ is almost as large as a pigeon's egg, is very soft, and the liquid exuding from it when cut is swarming with spermatozoa. The bird is of course in full nuptial plumage. By the end of May, although the plumage is unchanged, the testes have diminished to the size of a haricot bean, and spermatogenesis has ceased. They diminish still further during June, July, and August, and acquire a yellow or brownish colour, while microscopically there is no sign of activity in the spermatic cells. The change from nuptial plumage to eclipse takes place between the beginning of June and the middle of July. The reappearance of the nuptial plumage takes place in the month of September, and while this process takes place there is no sign of change or renewed activity in the testes. During October and November, when the brilliant plumage is fully developed, the testes increase slowly in size but remain yellow and firm and exude no liquid on incision. Spermatogenesis does not commence until the end of November or beginning of December. The testes increase greatly in size in January and February, and again reach their maximum size by the end of March. It is shown, therefore, that the loss of the nuptial plumage takes place in June when spermatogenesis has ceased and the testes are diminishing in size, but the redevelopment of this plumage takes place 
in September without any renewed activity of the testis and long before the beginning of spermatogenesis. The case of the antlers in the stag is probably very similar.

The important statement is made with regard to castration (under anaesthetics, of course) that it was found impossible to extirpate the testes completely. When the bird was killed some months after the operation, a greater or lesser amount of regenerated testicular tissue was found either on the original site of the organs or engrafted upon neighbouring organs. This experience, it will be noted, agrees with my own in the case of fowls. There were, however, reasons for believing that the results observed within the first six or eight months after the operation are not much different from those which would follow complete castration.

Castration carried out when the drake was in nuptial plumage produced the same effect which was observed by Goodale, namely, delay, and imperfection in the assumption of the eclipse condition, but the observations of Seligmann and Shattock are more precise and detailed. One example described was castrated in full winter plumage in December 1906. On July 11, when normally it would have been in eclipse, the nuptial plumage was unmodified except for a diffuse light-brown coloration on the abdomen, which is stated to be due not to any growth of new feathers but to pigmentary modification in the old. By September 1 this bird was almost in eclipse but not quite; curl feathers in the tail had disappeared, the breast was almost in full eclipse, the white ring was slightly indieated at the sides of the neck, the top of the head and the nape had still a 
good deal of gloss. After this the nuptial plumage developed again, and on November 12 the bird was in full nuptial plumage, with good curl feathers in the tail. The only trace of the eclipse was the presence of a few brown feathers on the flanks. This bird was killed July 30, 1908, when the bird was in eclipse, but not perfectly so, as there were vermiculated feathers mixed with eclipse feathers on the breast, abdomen, and flanks. Dissection showed on the right side a series of loosely attached nodular grafts of testicular tissue, in total volume about the size of a haricot bean: on the left side two small nodules, together about the size of a pea, and two other grafts at the root of the liver and on the mesentery. Several other cases are described, and the general result was that the eclipse was delayed and never quite complete, while although the nuptial plumage was almost fully developed in the following winter, it retained some eclipse feathers, and was also delayed and developed slowly.

Several drakes were eastrated in July when in the eclipse condition, and although the authors state, in their general conclusions, that this does not produce any constant appreciable effect upon the next passage of the bird into winter plumage, they describe one bird so treated which on November 18 retained many eclipse feathers: the general appearance of the chestnut area of the breast was eclipse.

It must be remembered that not only was the castration in these cases incomplete, but also that it was performed on mature birds. Birds differ from Mammals, firstly, in the difficulty of carrying out complete castration, and secondly, in the fact that the occurrence of puberty is not so definite, and 
that immature birds are so small and delicate that it is almost impossible to operate upon them successfully.

\section{Assumption of Male Characters by the Female}

That male somatic sexual characters are latent in the female is shown by the frequent appearance of such characters in old age, or in individual cases. The development of hair on the face of women in old age, or after the child-bearing period, is a wellknown fact. Rörig, ${ }^{1}$ who carefully studied the antlers of stags, states that old sterile females, and those with diseased ovaries, develop antlers to some degree. Cases of crowing hens, and female birds assuming male plumage have long been known, but the exact relation of the somatic changes to the condition of the ovaries in these cases is worthy of consideration in view of the results obtained by Goodale after removal of the ovaries from ducks. Shattock and Seligmann ${ }^{2}$ record the case of a gold pheasant hen which assumed the full male plumage after the first moult: it had never laid eggs or shown any sexual instincts. The only male character which was wanting was that of the spurs. The ovary was represented by a smooth, slightly elevated deep black eminence $1 \mathrm{~cm}$. in length and $1.5 \mathrm{~mm}$. in breadth at its upper end. These authors also mention three ducks in male plumage in which the ovary was similarly atrophied but not pigmented.

1 'Ueber Geweihbildung und Geweihentwicklung.' Arch. Ent.-Mech., $\mathrm{x}$. and $\mathrm{xi}$.

2 'True Hermaphroditism in Domestic Fowl, etc.' Trans. Path. Soc., Lond., 57. 1, 1906. 
They regard the condition of the ovary as insufficient to explain the development of the male characters, and suggest that such birds are really hermaphrodite, a male element being possibly concealed in a neighbouring organ such as the adrenal or kidney. This hypothesis is not supported by observation of testicular tissue in any such case, but by the condition found in a hermaphrodite specimen of the common fowl described in the paper. This bird presented the fully developed comb and wattles and the spurs of the cock, but the tail was quite devoid of curved or sickle feathers, and resembled that of the hen. Internally there were two oviducts, that of the left side normally developed, that of the right diminutive and less than half the full length. The gonad of the left side had the tubular structure of a testis, but showed no signs of active spermatogenesis, but in its lower part contained two ova. The organ of the right side was somewhat smaller, it had the same tubular structure, and in one small part the tubules were larger, showed division of nuclei (mitotic figures), and one of them showed active spermatogenesis.

In discussing Heredity and Sex in 1909, ${ }^{1}$ Bateson referred to the effects of castration as evidence that in different types sex may be differently constituted. Castration, he urged, in the male vertebrate on the whole leads merely to the non-appearance of male features, not to the assumption of female characters, while injury or disease of the ovaries may lead to the assumption of male characters by the female. This was supposed to support the view that the male is homozygous in sex, the

1 Mendel's Principles of Heredity. Camb. Univ. Press, 1909. 
female heterozygous in Vertebrates: that is to say, the female sex-character and the female secondary sex-characters are entirely wanting in the male. This argument assumes that the secondary characters are essentially of sexual nature without inquiring how they came to be connected with sex, and it ignores the fact that the influence of castration on such characters is a phenomenon entirely beyond the scope of Mendelian principles altogether. The fact that castration does affect, in many cases very profoundly, somatic characters confined to one sex, proves that Mendelian conceptions, however true up to a certain point, are by no means the whole truth about heredity and development. For it is the essence of Mendelism as of Weismannism that not only sex but all other congenital characters are determined in the fertilised ovum or zygote. The meaning of a recessive character in Mendelian terminology is one that is hidden by a dominant character, and both of them are due to factors in the gametes, particularly in the chromosomes of the gametes which come together in fertilisation. For example, in fowls rose comb is dominant over single. A dominant is something present which is absent in the recessive: the rose comb is due to a factor which is absent from the single. The two segregate in the gametes of the hybrid or heterozygote, and if a recessive gamete is fertilised by another recessive gamete the single comb reappears. But castration shows that the antlers of stags and other such characters are not determined in the zygote when the sex is determined, but owe their development, partly at least, to the influence of another part of the body, namely, the testes during the subsequent 
life of the individual. According to Mendelism the structure and development of each part of the soma is due to the constitution of the chromosomes of the nuclei in that part. The effects of castration show that the development of certain characters is greatly influenced in some way by the presence of the testes in a distant part of the body. The Mendelians used to say it was impossible to believe in the heredity of somatic modifications due to external conditions, because it was impossible to conceive of any means by which such modifications could affect the constitution of the chromosomes in the gametes within the modified body. It would have been just as logical to deny the proved effects of castration, because it was impossible to conceive of any means by which the testes could affect the development of a distant part of the body.

But this is not all. The supposed fact that female secondary characters in Vertebrates are absent in the male is completely disproved for Mammals by the presence of rudimentary mammary glands in the male. It is true that secondary sex-characters are usually positive in the male, while those of the female are apparently negative, but in the case of the mammary glands the opposite is the case. There is no room for doubt that the mammary glands are an essentially female somatic sex-character, not only in their function but in the relation between the periodicity of that function and those of the ovaries and uterus, and it is equally certain from their presence in rudimentary condition in the male that they are not absent from the male constitution. 


\section{Influence of Gonads due to Hormones}

The existence and the influence of hormones or internal secretions may be said to have been first proved in the case of the testes, for Professor A. A. Berthold ${ }^{1}$ of Göttingen in 1849 was the first to make the experiment of removing the testicles from cocks and grafting them in another part of the body, and finding that the animals remained male in regard to voice, reproductive instinct, fighting spirit, and growth of comb and wattles. He also drew the conclusion that the results were due to the effect of the testicle upon the blood, and through the blood upon the organism. Little attention was paid to Berthold's experiment at the time. The credit of having been the first to formulate the doctrine of internal secretion is generally given to Claude Bernard. He discovered the glycogenic function of the liver, and proved that in addition to secreting bile, that organ stores up glycogen from the sugar absorbed in the stomach and intestines, and gives it out again as sugar to the blood. In 1855 he maintained that every organ of the body by a process of internal secretion gives up products to the blood. He did not, however, discover the action of such products on other parts or functions of the body. Brown-Séquard, in his address before the Medical Faculty of Paris in 1869, was the first to suggest that glands, with or without ducts, supplied special substances to the blood which were useful or necessary to the normal health, and in $\mathbf{1 8 8 9}$ at a meeting of the Société de Biologie he described the experiment he lad made upon himself by the injection of testicular

1 'Transplantation der Hoden,' Archiv f. Anat. u. Phys., 1849. 
extract. This was the commencement of organotherapy. Since that time investigation of the more important organs of internal secretion-namely, the gonads, thyroid, thymus, suprarenals, pituitary, and pineal bodies-has been carried on both by clinical observation and experiment by a great number of physiologists with very striking results, and new hormones have been discovered in the walls of the intestine and other organs.

Here, however, we are more especially concerned with the gonads and other reproductive organs. A great deal of evidence has now been obtained that the influence of the testes and ovaries on secondary sexual characters is due to a hormone formed in the gonads and passing in the blood in the course of the circulation to the organs and tissues which constitute those characters. The fact that transplanted portions of testes in birds (cocks and drakes) are sufficient to maintain the secondary characters in the same condition as in normal individuals shows that the nexus between the primary and somatic organs is of a liquid chemical nature and not anatomical, through the nervous system for example. Many physiologists in recent years have maintained that the testicular hormone is not derived from the male germ-cells or spermatocytes, but from certain cells between the spermatic tubuli which are known as interstitial cells, or collectively as the interstitial gland.

The views of Ancel and Bouin, ${ }^{1}$ published in 1903, may be described in large part as theory. They state that the interstitial cells appear in the male embryo before the gametocytes present distinctive

$$
{ }^{1} \text { C. R. Soc. de Biol., Iv. }
$$


sex-characters. They conclude that the interstitial cells supply a nutritive material (hormone?), which has an effect on the sexual orientation of the primitive generative cells. In addition to this function, the interstitial cells by their hormone also give the sexual character to the soma. When castration is carried out at birth the male somatic characters do not entirely disappear, because the hormone of the interstitial cells has acted during intrauterine life. The functional independence between the interstitial cells and the seminal tubules is shown by the fact that if the vasa deferentia are closed the seminal gland (i.e. tubules) degenerates while the interstitial cells do not. In the embryo the interstitial gland is large, in the adult proportionately small.

There is complete disagreement between the results of Ancel and Bouin on the one hand, and those of Shattock and Seligmann on the other, with regard to the effects of ligature of the vasa deferentia. The latter authors, as mentioned above, found that after ligature not only the somatic characters but the testis itself developed normally. The experiments were performed on Herdwick sheep and domestic fowls. They state that on examination the testes were found to be normally developed, and spermatogenesis was in progress. The experiments of Ancel and Bouin were carried out on rabbits seven to eight weeks old, and consisted in removing one testis, and ligaturing the vas deferens of the other. About six months after the operation the testis left in situ was smaller, the seminal tubules contained few spermatogonia, though Sertoli's cells (cells on the walls of the tubules to which the true spermatic cells are attached) were unchanged; 
while the interstitial cells were enormously developed, by compensatory hypertrophy in consequence of the removal of the other testis. At the same time the male instincts and the other generative organs were unchanged. In a few cases, however, Ancel and Bouin observed atrophy of the interstitial cells as well as the spermatic cells. They believe this is due to the nerves supplying the testis being included in the ligature. This is rather a surprising conclusion in view of the fact that testicular grafts show active spermatogenesis. It is difficult to understand why nerve connection should be necessary for the interstitial cells and not for the spermatic, and, moreover, if the interstitial cells are really the source of the hormone on which the somatic characters depend, they must be acting in the grafts in which the nerve connections have been all severed.

The facts concerning cryptorchidism, that is to say, failure of the descent of the testes in Mammals, seem to show that the hormone of the testis is not derived from semen or spermatogenesis, for in the testes which have remained in the abdomen there is no spermatogenesis, while the interstitial cells are present, and the animals in some cases exhibit normal or even excessive sexual instinct, and all the male characteristics are well marked. It may be remarked, however, in criticism of this conclusion that the descent of the testes being itself a somatic sexual character of the male, its failure when the interstitial cells are normal and the spermatic cells defective, would rather tend to prove that the defect of the latter is itself the cause of cryptorchidism.

Many investigators have found that the Röntgen 
rays destroy the spermatic cells of the testis in Mammals, leaving the cells of Sertoli, the interstitial tissue, nerves, and vessels uninjured. Tandler and Gross ${ }^{1}$ found that the antlers of roebuck were not affected after the testes had been submitted to the action of the rays, showing that the interstitial cells were sufficient to maintain the normal condition of the antlers. Simmonds, ${ }^{2}$ however, found that isolated seminal tubules remained, and regeneration took place, and concludes that both spermatic cells and interstitial cells take part in producing the testis hormone. The conclusions of two other investigators have an important bearing on this questionnamely, that of Miss Boring ${ }^{3}$ that there is no interstitial tissue in the bird's testis, and that of Miss Lane-Claypon, ${ }^{4}$ that the interstitial cells of the ovary arise from the germinal epithelium, and are perfectly equipotential with those which form the ova and Graafian follicles. It seems possible, although no such suggestion has been made, that the interstitial cells might either normally or exceptionally give rise to ova and spermatocytes. The observations of Seligmann and Shattock on the relation of spermatogenesis to the development of nuptial plumage in drakes probably receive their explanation from the above facts. Spermatogenesis is not the only source of the testicular hormone: changes in the secretory activity of the interstitial cells or spermatocytes are sufficient to account for periodic development of somatic sex-characters, and the same reasoning applies to the antlers of stags.

1 Wiener klinische Wochenschrift, 1907.

2 Fortschr. a. d. G. d. Röntgenstr., xiv., 1909-10.

3 Biol. Bull., xxiii. $1912 . \quad$ 'Proc. Roy. Soc., 1905. 


\section{The Mammary or Milk Glands}

The milk glands in Mammals constitute one of the most remarkable of secondary sexual characters. Except in their functional relations to the primary organs, the ovaries, and to the uterus, there is nothing sexual about them. They are parts of the skin, being nothing more or less than enormous enlargements of dermal glands, either sebaceous or sudoriparous. Uterine and mammary functions are generally regarded as essentially female characteristics, and are included in the popular idea of the sex of woman. Scientifically, of course, they are not at all necessary or universal features of the female sex, but are peculiar to the mammalian class of Vertebrates in which they have been evolved. Milk glands, then, are somatic sex-characters common to a whole class, instead of being restricted to a family like the antlers in Cervidae. There is not the slightest trace or rudiment of them in other classes of Vertebrates, such as Birds or Reptiles. They are not actually sexual in their nature, since their function is to supply food for the young, not to play a part in the relations of the sexes. What is sexual about them is-firstly, that they are normally fully developed only in the female, rudimentary in the male; secondly, that their periodical development and functional activity depends on the changes which take place in the ovary and uterus. Many investigators have endeavoured to discover the nature of the nexus between the latter organs and the milk glands.

That this nexus is of the nature of a hormone is generally agreed, and may be regarded as having 
been proved in 1874 when Goltz and Ewald ${ }^{1}$ removed the whole of the lumbo-sacral portion of the spinal cord of a bitch and found that the mammae in the animal developed and enlarged in the usual way during pregnancy and secreted milk normally after parturition. Ribbert ${ }^{2}$ in 1898 transplanted a milk gland of a guinea-pig to the neighbourhood of the ear, and found that its development and function during pregnancy and at parturition were unaffected. The effective stimulus, therefore, is not conveyed through the nervous system, but must be a chemical stimulus passing through the vascular system.

Physiologists, however, are not equally in agreement concerning the source of the hormone which regulates lactation. Starling and Miss Lane-Claypon concluded from their experiments on rabbits that the hormone originated in the fœtuses themselves within the pregnant uterus. In virgin rabbits it is difficult to find the milk glands at all. When found the nipple is minute and sections through it show the gland to consist of only a few ducts a few millimetres in length. Five days after impregnation the gland is about $2 \mathrm{~cm}$. in diameter. Nine days after impregnation the glands have grown so much that the whole inner surface of the skin of the abdomen is covered with a thin layer of gland tissue. In six cases by injecting subcutaneously extracts of foetus tissue Starling and Lane-Claypon obtained a certain amount of growth of the milk glands. The hormone in the case of the pregnant rabbit is of course acting continuously for the whole period of pregnancy, while the artificial injection took place only once

1 Pflïgers Archiv, ix., 1874.

2 Fortschrille der Medicin, Bd. 7. 
in twenty-four hours, and the amount of hormone it contained may have been absorbed in a very short time. The amount of growth obtained experimentally in five weeks was less than that occurring in pregnancy in nine days. Extracts of uterus, placenta, or ovary produced no growth, although the ovaries used were taken from rabbits in the middle of pregnancy. In one experiment ovaries from a pregnant rabbit were implanted into the peritoneum of a non-pregnant rabbit, but on post-mortem examination of the latter eleven days later the implanted ovaries were found to be necrosed and no proliferation of milk gland had taken place.

The conclusions of Starling and Lane-Claypon were confirmed by Foa, ${ }^{1}$ and by Biedl and Königstein. ${ }^{2}$ Foa states that extracts of fœtuses of cows also produced swelling of the mammae in a virgin rabbit.

O'Donoghue, however, concludes from a study of the Marsupial Dasyurus that the stimulus which acts upon the milk glands proceeds from the corpora lutea in the ovary. In this animal changes in the pouch occur in pregnancy, which are doubtless also due to hormone stimulation, but which we will not consider here. The most important evidence in O'Donoghue's paper ${ }^{3}$ is that development of the milk glands takes place after ovulation not succeeded by pregnancy; that is to say, when corpora lutea are formed but no fertilised ova or fotus are present in the uterus. In one case, eighteen days after heat, the milk gland was in a condition resembling that found in the stages twenty-four and thirty-six hours after

\footnotetext{
1 Archivio d. Fisiologia, v., 1909.

2 Zeitschrift f. exp. Path. und Therap., 1910.

${ }^{3}$ Quart. Journ. Mic. Sci., lvii,, 1911-12.
} 
parmition. In another specimen, twenty-one days after heat, the milk glands were still more advanced, with distended alveoli and enlarged ducts. The alveoli contained a secretion which was almost certainly milk. O'Donoghue states that the entire series of growth changes in these animals up to twenty-one days after heat is identical with that which occurs in normally pregnant animals.

O'Donoghue's conclusion is in agreement with that of Basch, ${ }^{1}$ who states that implantation of the ovaries from a pregnant bitch under the skin of the back of a one-year-old bitch that was not pregnant was followed by proliferation of the mammary glands of the latter. After six weeks the glands were considerably enlarged, and after eight weeks they were caused to secrete milk by the injection of extract of the placenta. It has to be remembered, however, that the milk glands undergo considerable growth, especially in the human species, at puberty and at every menstruation, or at œstrus in animals, which corresponds to menstruation. In these cases there is no question of any influence of the fœetus, and experiment has shown that if the ovaries are removed before puberty, neither the milk glands nor the uterus undergo the normal development, and menstruation does not occur. According to Marshall and Jolly ${ }^{2}$ the symptoms of ostrus in castrated bitches were found to result from the implantation of ovaries from other individuals in the condition of œstrus.

Before considering further the question of the corpora lutea as organs of internal secretion, we may briefly refer to the origin and structure of these

1 Monatsschr.f. Kinderh. V., No. ix., Dec. 1909.

2 Quart. Journ. Exp. Phys., i. and ii., 1908. 
bodies and of other parts of the mammalian ovary. The mature follicle containing the ovum differs from that of other Vertebrates in the fact that it is not completely filled by the ovum and the follicular cells surrounding it, but there is a cell-free space of large size into which the ovum covered by follicular cells projects. In the wall of the follicle two layers are distinguished, the theca externa, which is more fibrous, and the theca interna, which is more cellular. In the connective tissue stroma of the ovary between the follicles are scattered, or in some cases aggregated, epithelioid cells known as the interstitial cells, and it is stated that the cells of the theca interna are exactly similar to the interstitial cells. According to Limon $^{1}$ and Wallart ${ }^{2}$ the interstitial cells are actually derived from those of the theca interna of the follicles. Numbers of ova die without reaching maturity, the follicular cells degenerate, and the follicle becomes filled with the cells of the theca interna, which have a resemblance to those of the true corpus luteum. These degenerate follicles have been termed spurious corpora lutea, or atretic vesicles. The interstitial cells are the remains of these atretic vesicles. The true corpora lutea arise from follicles in which the ova have become mature and from which they have escaped through the surface of the ovary. As a result of the escape of the ovum and the contents of the cell-free space, the follicle contracts and the follicular (so-called granulosa) cells secrete a yellow substance, lutein, and enlarge. Buds from the theca interna invade the follicle and form the connective tissue of the corpus luteum.

1 Arch. d'Anat. micr., v., 1902.

2 Arch. f. Gynoek, vi. 271. 
Somewhat similar processes take place in the ovaries of Teleostean fishes, as I know from my own observations, but no corpora lutea are formed in these, although the degenerating follicles in course of absorption correspond to corpora lutea. The spawning of Fishes, usually annual, corresponds to ovulation in Mammals, and in the ovary after spawning the numerous collapsed follicles containing the follicular cells may be seen in all stages of absorption. ${ }^{1}$ At other times of the year sections of the ovary show here and there ova which after developing to a certain stage die and undergo absorption with their follicles.

In the higher Mammals (Eutheria) the corpora lutea show a special relation in their development to the occurrence of pregnancy, that is to say, they have a different history when ovulation is followed by pregnancy to that which they have when the ova, from the escape of which they arise, are not fertilised. When fertilisation occurs the corpus luteum increases in size during the first part of the period of gestation (four months, or nearly a half of the whole period in the human species). It then remains without much change till parturition, after which it shrinks and is absorbed. When pregnancy does not occur the corpus luteum is formed, but begins to diminish within ten or twelve days in the human species and is then gradually absorbed. According to O'Donoghue, in the Marsupial Dasyurus there seems to be no difference either in the development of the milk glands or of the corpora lutea between the pregnant and the non-pregnant animal. Sandes ${ }^{2}$

1 Cunningham, 'Ovaries of Teleosteans.' Quarl. Journ. Mic. Sci., vol. xl. pt. I., 1897.

2 Proc. Lin. Soc., New South Wales, 1903. 
showed that in the same species the corpora lutea persisted not only during the whole of pregnancy, which Professor J. P. Hill ${ }^{1}$ estimates at a little over eight days, but during the greater part of the period of lactation, which according to the same authority is about four months. In the specimens of Dasyurus described by O'Donoghue, in which the millk glands developed after ovulation without ensuing pregnancy, normally developed corpora lutea were present in the ovary. Of the five females which he mentions, the first three, one with unfertilised ova in the uteri, two five and six days after heat, could not have been pregnant, but the other two killed eighteen and twenty-one days after heat might, since pregnancy lasts only eight days, have been pregnant, the young having died at parturition or before. To make certain on this point it would have been necessary to examine the ovaries and millk glands of females which had been kept separate from a male the whole time. There is no doubt, however, about the development of the milk glands in the first three specimens, which were certainly not pregnant.

It is difficult to reconcile entirely the evidence described by O'Donoghue from Dasyurus, with that obtained from higher Mammals, although on the whole there is reason to conclude that the corpora lutea have an important influence on the development of the milk glands. According to LaneClaypon and Starling, if the ovaries and uteri are removed from a pregnant rabbit before the fourteenth day the development of the mammary gland ceases, retrogression takes place, and no milk appears in the gland. If, on the other hand, the operation be

1 Anat. Anz., xviii., 1900. 
performed after the fourteenth day, milk appears within two days after the operation. It is to be concluded from this that the cause of secretion of milk is the withdrawal of a stimulus proceeding from ovary or uterus. But O'Donoghue believes that milk is secreted in Dasyurus when no pregnancy has occurred. Ancel and Bouin ${ }^{1}$ have shown that the growth of the mammary glands was produced in rabbits by the artificial rupture of egg follicles and consequent production of corpora lutea: the growth of the glands continued up to the fourteenth day, after which regression set in. This shows that the development of the milk glands in rabbits is due to the corpora lutea. On the other hand, LaneClaypon and Starling state that in rabbits the corpora lutea diminish after the first half of pregnancy, while the growth of the milk glands is many times greater during the second half than during the first half of the period, and during the second half the ovaries may be removed entirely without interfering with the course of pregnancy or the normal development of the milk glands. It is evident, therefore, that in rabbits, whatever influence the corpora lutea may have in the first half of pregnancy, they have none in the second half, and that at this period the essential hormone proceeds from the developing fœtus or fœtal placenta. Again, if it is the withdrawal of a hormone stimulus which changes the milk gland from growth to secretion, it cannot be the corpora lutea which are exclusively concerned even in Dasyurus, for they persist during lactation, while secretion begins shortly after parturition.

1 C. R. Soc. de Biol., t. Ixvii., 1909. 
Gustav Born suggested, and Fränkel tested the suggestion experimentally, that the corpus luteum of pregnancy is a gland of internal secretion whose function is to cause the attachment of the ovum in the uterus and the normal development of uterus and placenta. Fränkel found that removal of both ovaries in rabbits between the first and sixth days after fertilisation prevented pregnancy, and that the same result followed if the corpora lutea were merely destroyed in situ by galvano-cautery. Either process carried out between the eighth and twentieth days of pregnancy causes abortion.

Lane-Claypon and Starling also found that removal of both ovaries in the rabbit before the fifteenth day was apt to cause abortion, but at a later stage the same operation could be performed without interfering with the course of pregnancy. According to these authors numberless instances prove that in women double ovariotomy does not necessarily interfere with the course of pregnancy or the development of the milk glands. Parturition may take place and be followed by normal lactation. This shows that a hormone from the corpora lutea is not necessary either to the uterus or the milk glands, at any rate in the last third of pregnancy, though of course this does not prove that such a hormone is not necessary for the earlier stages both of pregnancy and growth of the milk glands.

The results of Steinach, if confirmed, would prove conclusively that the ovaries and testes produce hormones which determine the development of all the sexual characters, not merely physical but psychical. He adopts the view that the interstitial cells or gland are the source of the active hormone. 
He claims by transplantation of the gonads in young rats and guinea-pigs to have feminised males and masculised females. The females are smaller, and have finer, softer hair than the males. The testes were removed and ovaries implanted in young males. The animals so treated grew less than the merely castrated specimens, and therefore when full-grown resembled females in size. In the young state both sexes have fine, soft hair, the feminised males had the same character, like the normal females. They also developed teats and millk glands like the females, and were sought and treated as females by the normal males. When the implanted ovaries are able to resist the influence of their new surroundings, the female interstitial gland, which Steinach calls the puberty gland, develops so much that an intensification of the female character takes place : the animals are smaller than normal females, the milk glands develop and secrete milk, which can be easily pressed out, and if young are given to them they suckle them and show all the maternal instincts.

Why the ovary in normal circumstances only when in the gravid condition calls forth this perfection of femaleness is to be shown in a later publication. By acting with Röntgen rays on the region where the ovaries lie, Steinach and his colleague Holzknecht brought about all the symptoms of pregnancy, development of teats and milk glands, secretion of milk, and great growth of the uterus in all its layers.

Masculising of females was much more difficult than feminising of males because the testicular tissue was less resistent, and could not be grafted so casily. When it succeeded, however, degeneration of the 
seminal tubules took place, with increase of the interstitial or Leydig's cells. The vaginal opening in rats disappeared, partly or completely. The sexual instincts became male, the animals recognised a female in heat from one that was not, and attempted to copulate.

Steinach considers that he has proved from these results that sex is not fixed or predetermined but dependent on the puberty gland. By sex here he obviously means the instincts and somatic characters, for sex in the first instance, as we have already pointed out, means the difference between ovary and testis, between ova and spermatozoa. It is difficult to accept all Steinach's results without confirmation, especially those which show that the feminised male is more female than the normal female. Such a conclusion inevitably suggests that the investigator is proving too much.

The subject of the influence of hormones from the gonads is mentioned, but not fully discussed, in a volume by Dr. Jacques Loeb, entitled The Organism as a Whole. ${ }^{1}$ Loeb entirely omits the problem of the origin of somatic sex-characters, and fails to perceive that the fact that such characters are dependent to a marked degree on hormones derived from the gonads, together with their relation to definite habits and functions connected with the behaviour of the sexes to each other, is proof that these characters are not gametogenic, but were originally due to external stimulation of particular parts of the soma.

1 Putnam's Sons, 1916. 


\section{CHAPTER IV}

ORIGIN OF SOMATIC SEX-CHARACTERS IN EVOLUTION

In his Mendel's Principles of Heredity, 1909, Bateson does not discuss the nature of somatic sex-characters in general, but appears to regard them as essential sex-features, as male or female respectively. As mentioned above, he argues from the fact that injury or disease of the ovaries may lead to the development of male characters in the female, that the female is heterozygous for sex, and from the supposed fact that castration of the male leads merely to the non-appearance of male somatic characters, that the female sex-factor is wanting in the male. He does not distinguish somatic sex-characters from primary sex-factors, and discusses certain cases of heredity limited by sex as though they were examples of the same kind of phenomenon as somatic sex-characters in general. One of these cases is the crossing by Professor T. B. Wood of a breed of sheep horned in both sexes with another hornless in both sexes. In the $F_{1}$ generation the males were horned, the females hornless. Here, with regard to the horned character, both sexes were of the same genetic composition, i.e. heterozygous, or if we represent the possession of horns by $H$, and their absence by $h$, both sexes were $H h$. Thus $H h{ }^{\star}$ was horned and $H h$ q was hornless, or, as Bateson expresses it, the horned character was dominant in males, recessive in females. Bateson 
offers no explanation of this, but it obviously suggests that some trace of the original dimorphism of the sheep in this character was retained in both horned and hornless breeds. We may suppose that the factor for horns had disappeared entirely from the hornless sheep by a mutation, but in the horned breed another mutation had been a weakening of the influence of the sexual hormones on the development of the character, which, as in all such cases, is really inherited in both sexes. In the $F_{1}$, when the horned character in the female is only inherited from one side, the hereditary tendency is not enough to overcome the influence of the absence of the testis hormone and presence of the ovarian hormone, and so the horns do not develop. The Mendelian merely sees a relation of the character to sex, but overlooks entirely the question of the dimorphism in the original species from which the domesticated breeds are descended. Similarly, with regard to cattle where it has been found that hornlessness is dominant or nearly so in both sexes, no reference is made to the opposite fact that wild cattle have horns in both sexes and are not dimorphic in this character.

Bateson proceeds to consider colour-blindness as though its heredity were of similar kind. He refers to it as a male character latent in the female, and remarks that we should expect that disease or removal of the ovaries might lead to the occasional appearance of colour-blindness in females. He also discusses the case of Abraxas grossulariata and its variety lacticolor, and other cases of sex-linked heredity, apparently with the idea that all such cases are similar to those of sexual dimorphism. $A$. lacticolor occurs in nature only in the female sex, and 
when bred with grossulariata ot produces t's and o's all grossulariata, these of course being heterozygous. When the $F_{1}$ grossulariata of was bred with the wild lacticolor $\&$ it produced both forms in both sexes, and thus lacticolor of was obtained for the first time. When this lacticolor ${ }^{t}$ was bred with $F_{1}$ grossulariata $q$ it produced all the of's grossulariata and all the o's lacticolor. Bateson's explanation is that the female, according to the Mendelian theory of sex, is heterozygous in sex, the male homozygous and recessive, and that lacticolor is linked with the female sex-character, grossulariata being repelled by that character. Thus we have, the lacticolor character being recessive,

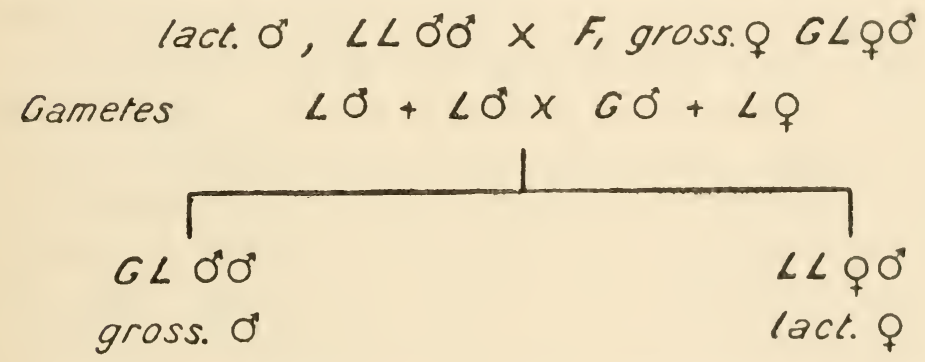

It will be seen that although in the progeny of this mating all the grossulariata were males and all the lacticolor females, yet this case is by no means similar to that of sexual dimorphism in which the characters are normally always confined to the same sex. For the lacticolor character in the parent was in the male, while in the offspring it was in the female. We cannot say here that in the theoretical factors which are supposed to represent what happens, the lacticolor character is coupled with the female sexfactor, for we find it with the male sex-character in the lacticolor $\delta$. It is so coupled only in the heterozygous grossulariata , and at the same time the grossulariata character is repelled. 
According to Doncaster ${ }^{1}$ sex-limited, or as it is now proposed to call it sex-linked, transmission in this case means that the female grossulariata transmits the character to all her male offspring and to none of the female, while a heterozygous male grossulariata mated with lacticolor female transmits the character equally to both sexes: that is to say, the heredity is completely sex-limited in the female but not at all in the male. This is evidence that the female produces two kinds of eggs, one male producing and the other female producing.

With regard to the ordinary form of colourblindness, Bateson's first explanation was that it was like the horns in the cross-bred sheep, dominant in males, recessive in females. About 4 per cent. of males in European countries are colour-blind, but less than $\frac{1}{2}$ per cent. of females. Affected males may transmit the defect to their sons but not to their daughters : but daughters of affected persons transmit the defect frequently to their sons. Bateson gives $^{2}$ a scheme of the transmission, but corrects this in a note stating that colour-blindness does not descend from father to son, unless the defect was introduced by the normal sighted mother also, i.e. was carried by her as a recessive. The fact that unaffected males do not transmit the defect shows, according to Bateson, that it is due to the addition of a factor to the normal, not to omission of a factor.

According to later researches as quoted by Doncaster, colour-blindness is due to the loss of some factor which is present in the normal individual. The normal male is heterozygous for this normal factor. If we denote the presence of the normal

1 Determination of Sex, Camb. Univ. Press, 1914.

2 Mendel's Principles of Heredity, 1909. 
factor by $N$ and its absence or recessive by $n$, then the male is $N n$, while the female is homozygous or $N N$. But in addition to this it is the male in this case which is heterozygous for sex, and $n$ goes to the male-producing sperms, $N$ to the female-producing. Thus in the mating of normal man with normal woman the transmission is as follows:-

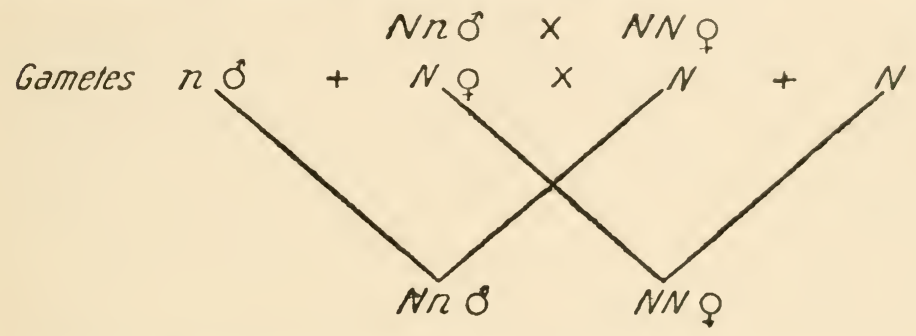

That is all offspring normal, but the males again heterozygous.

An affected male has the constitution $n n$, and if he marries a normal woman the descent is as follows :-

$n \pi \sigma^{\circ} \times N N Q$

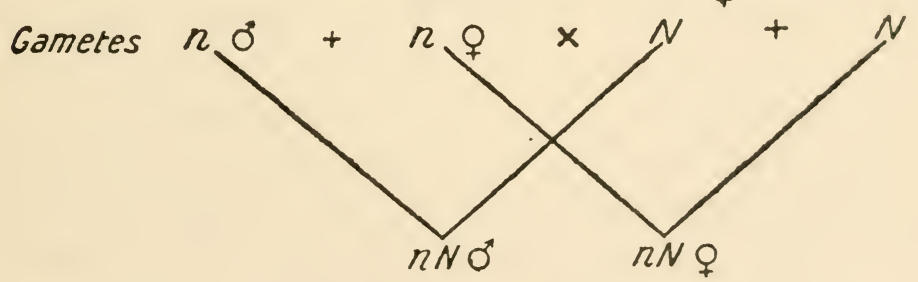

When a normal male is mated with a heterozygous $n N$ female we get

$$
n N O \times n N O
$$

Gametes $\quad n \sigma^{n}+N O \times n+N$

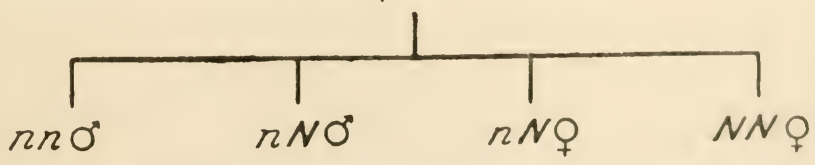

that is, half the sons are normal and half colour-blind, 
while half the females are homozygous and normal, and the other half heterozygous and normal.

T. H. Morgan ${ }^{1}$ has observed a number of cases of sex-linked inheritance in the mutations which occurred in his cultures of Drosophila. The eye of the wild original fly is red, one of the mutants has a white eye, i.e. the red colour and its factor are absent. When a white-eyed male is mated to a red-eyed female all the offspring have red eyes. If these are bred inter se, there are, as in ordinary Mendelian cases, three red-eyed to one white-eyed in the $F_{2}$ generation, but white eyes occur only in the males, in other words half the males are white-eyed. On the other hand, when a white-eyed female is mated to a red-eyed male all the daughters have red eyes, and all the sons white eyes. This has been termed crisscross inheritance. If these are bred together the result in $F_{2}$ is equal numbers of red-eyed and white-eyed females, and equal numbers of red-eyed and whiteeyed males. The ration of dominant to recessive is 2 to 2 instead of the usual Mendelian ration of 3 to 1 .

According to Morgan the interpretation is as follows: In the nucleus of the female gametocytes there are two $X$ chromosomes related to sex, in those of the male there is one $X$ chromosome and one $Y$ chromosome of slightly different shape. The factor for red eye occurs in the sex-chromosomes, that is to say, according to this theory, the sex-chromosome does not merely determine sex but carries other factors as well, and this fact is the explanation of sex-linked inheritance. The factor for red eye then is present in both $X$ chromosomes of the wild female, absent from both $X$ and $Y$ chromosomes

$$
1 \text { A Critique of the Theory of Evolution. }
$$




\section{SEX-CHARACTERS IN EVOLUTION 113}

of the white-eyed male. The gametes of the female each carry one $X$ red chromosome, of those of the male half carry an $X$ white chromosome, and half the $Y$ white chromosome. The fertilised female ova therefore carry an $X$ red chromosome + an $X$ white chromosome, the male producing ova one $X$ red chromosome and one $Y$ white chromosome. They are all therefore red-eyed, but heterozygous-that is, the red eye is due to one red-eye factor, not two. When the $F_{\mathbf{1}}$ are bred together, half the female gametes carry one $X$ red chromosome, the other half one $X$ white chromosome; half the male gametes carry one $X$ red chromosome, the other half one $Y$ white chromosome. The fertilisations are therefore one $X$ red $X$ red, one $X$ red $X$ white, one $X$ red $Y$ white, and one $X$ white $Y$ white. These last are the white-eyed males. The two different crosses are represented diagrammatically on p. 114, the dark rod representing the $X$ red chromosome, the clear rod the $X$ white chromosome, and the bent clear rod the $Y$ white chromosome.

According to Morgan, the heredity of colourblindness in man is to be explained exactly in the same way as that of white eye in Drosophila. A colour-blind man married to a normal (homozygous) woman transmits the peculiarity to half his grandsons and to none of his grand-daughters. Colourblind women are rare, but in the few cases known where such women have married normal husbands the defect has appeared only in the sons, as in the second of the diagrams on p. 114. It must be explained that according to this theory the normal male is always heterozygous, because the $Y$ chromosome never carries any other factor except that for sex ; 
F.I

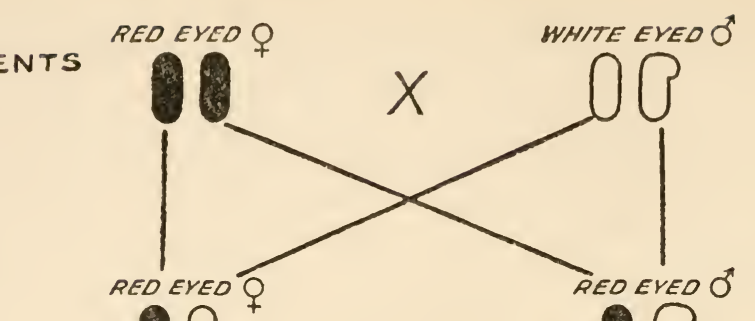

F. 2

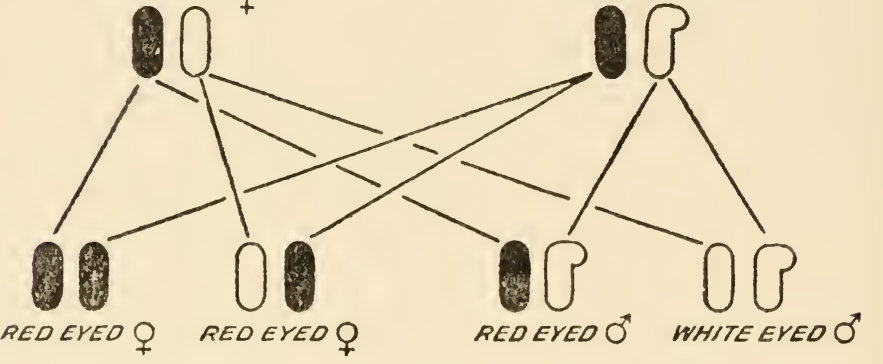

Homozygous. Heterozygous. Heterozygous. Homozygous.

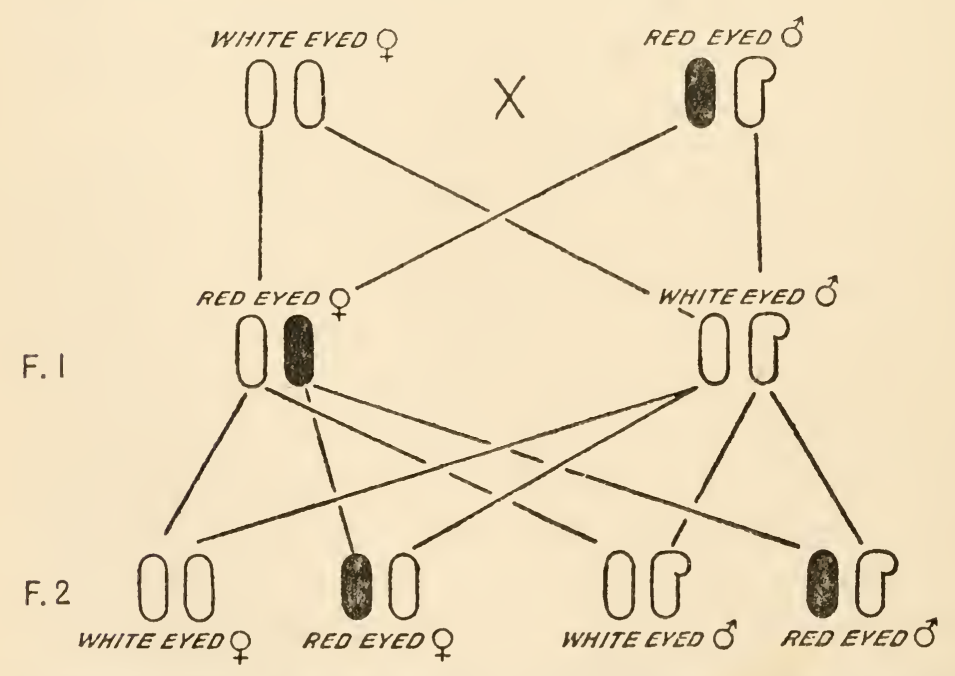

Homozygous. Heterozygous. Homozygous. Heterozygous. 
it is thus of no more importance than the absence of an $X$ chromosome which occurs in those cases where the male has one sex-chromosome and the female two. According to the researches of von Winiwarter ${ }^{1}$ on spermatogenesis in man, the latter is actually the case in the human species. This investigator found that there were 48 chromosomes in the female cell, 47 in the male; after the reduction divisions the unfertilised ova had 24 chromosomes, half the spermatids 24 and half 23 , so that sex is determined in man by the spermatozoon.

Morgan believes that the heredity of haemophilia (the constitutional defect which prevents the spontaneous cessation of bleeding) follows the same scheme, and also at least some forms of stationary night-blindness - that is, the inability to see in twilight.

We may mention a few other cases in animals, referring the reader for a fuller account to the works cited. One example is the barred character of the feathers in the breed of fowls called Plymouth Rock. In this case the female is heterozygous for sex as in Abraxas grossulariata, and the barred character is sex-linked. When a barred hen is crossed with an unbarred cock all the male offspring are barred, all the females plain. On the other hand, if a barred cock is crossed with an unbarred hen, the barred character appears in all the offspring, both males and females. The female thus transmits the character only to her sons. If we represent the barred character by $B$, and its absence by $b$, we can represent the heredity as follows:-

1 'Spermatogenc̀se humaine,' Arch. de Biol., xxvii., 1912. 
Barred Female with Unbarred Male

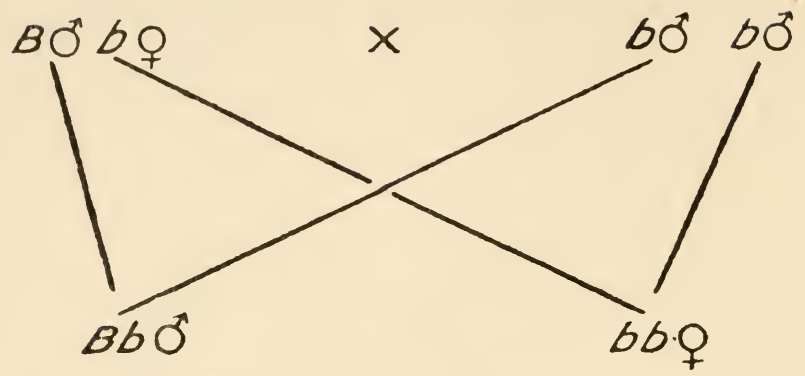

Barred male.

Unbarred female.

Heterozygous.

Homozygous.

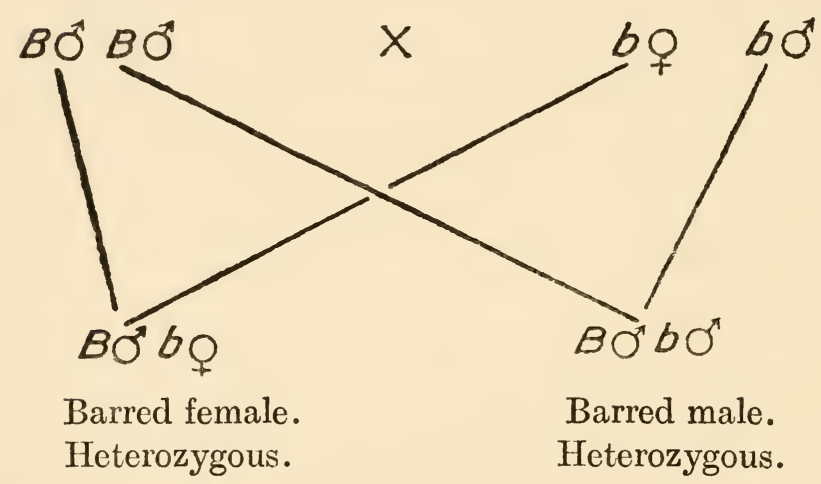

This case is thus exactly similar to that of Abraxas grossulariata and $A$. lacticolor. The barred character, like grossulariata, is dominant, the unbarred recessive, and to explain the results it is necessary to assume that the female is not only heterozygous for the barred character, but also for sex, with the female sex-factor dominant. The recessive character in this case is linked to the female sex-chromosome, or, as Bateson described it, the dominant character is repelled by the female sex-factor. We may make a diagram of the kind given by Morgan if we use a rod of different shape for the female-producing sex- 
chromosome, and use the black rod for the dominant character :-

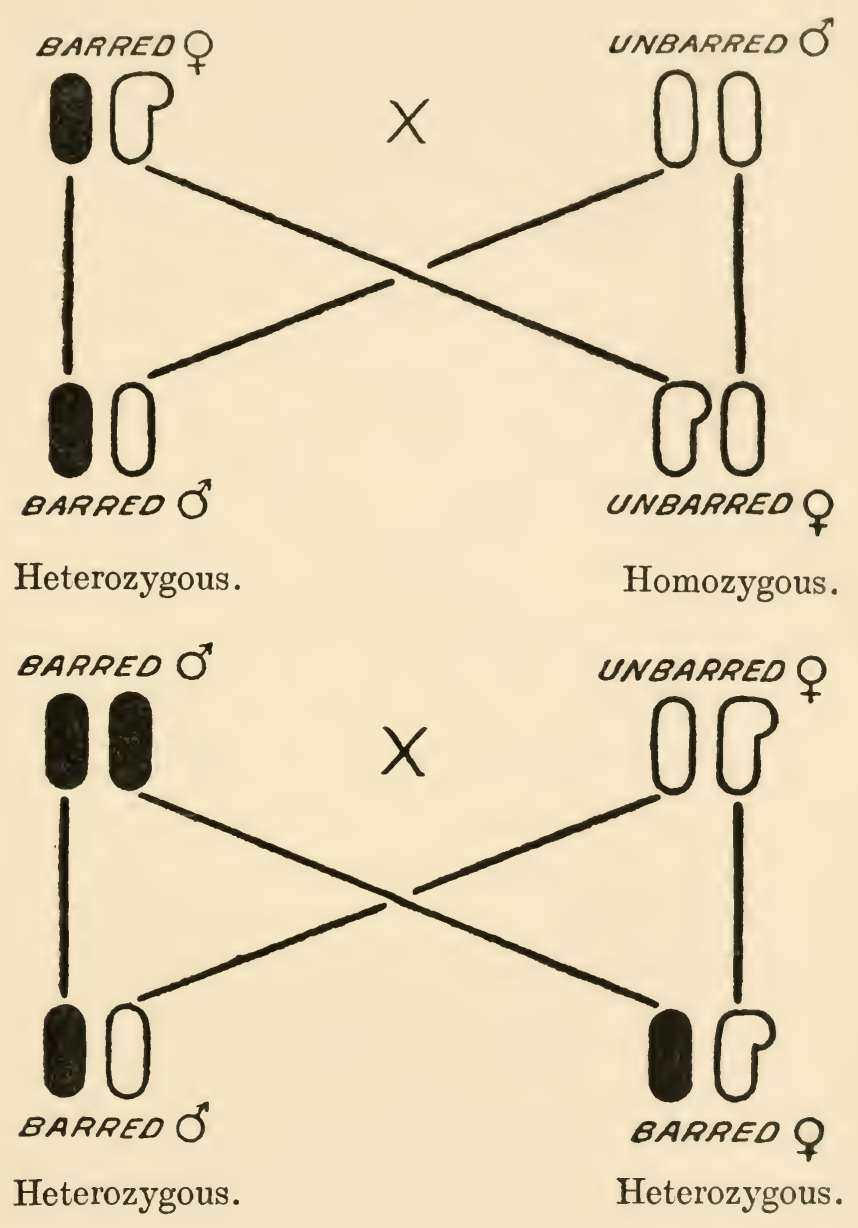

Another case is that of tortoise-shell, i.e. black and yellow cats. The tortoise-shell with very rare exceptions is female, the corresponding male being yellow, without any black colour. Doncaster found that a yellow male mated to a black female produced black male offspring and tortoise-shell females. 
When a black male is mated to a yellow female, the female kittens are tortoise-shell as before, but the males yellow. The Mendelian hypothesis which explains these results is that the male is always heterozygous, or has only one colour factor whether yellow or black, and transmits these colours only to his daughters, while the female has two colour factors, either $B B, Y Y$, or $B Y$. Thus the crosses are:-
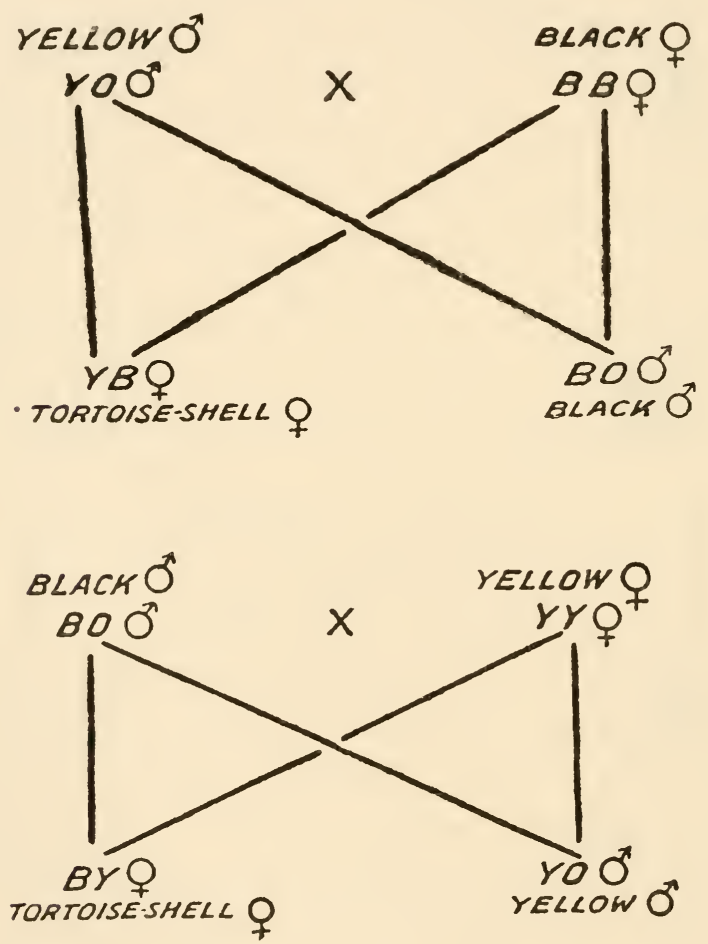

The sex must be determined therefore by the spermatozoa, as in the case of colour-blindness, etc., in man, and the colour factor must always be in the female-producing sperm. 


\section{Sexual Dimorphism}

It is obvious from the above facts that however interesting and important sex-linked heredity may be, it is not the same thing as the heredity of secondary sexual characters, and does not in the least explain sexual dimorphism. In the first place, the term sex-linked does not mean occurring always exclusively in one sex, but the direct contrary-transmitted by one sex to the opposite sex-and in the second place there is no suggestion that the development of the character is dependent in any way on the presence or function of the gonad. The problem I am proposing to consider is what light the facts throw on the origin of the secondary sexual characters in evolution. In endeavouring to answer this question there are only two alternatives: either the characters are blastogenic-that is, they arise from some change in the gametocytes occurring somewhere in the succession of cell-divisions of these cells-or they arise in the soma and are impressed on the gametocytes by the influence of the soma within which these gametocytes are containedthat is to say, they are somatogenic. That characters do originate by the first of these processes may be considered to be proved by recent researches, and such characters are called mutations. There can be little doubt that the so-called sex-linked characters, of which examples have been given above, have originated in this way, and that their relation to sex is part of the mutation. According to T. H. Morgan, it is simply due to the fact that the determinants for such characters are situated in the sex-chromosome. Morgan, however, also states that a case of true 
sexual dimorphism arose as a mutation in his cultures of Drosophila. The character was eosin colour in the eye instead of the red colour of the eye in the original fly. In the female this was dark eosin colour, in the male yellowish eosin. But this case differs from the characters particularly under consideration here in two points: (1) there is no suggestion that it was adaptive, (2) or that it was influenced by hormones from the gonads.

No character whose development is dependent in greater or less degree on the stimulation of some substance derived from the gonads can have originated as a mutation, because the term mutation means a new character which develops in the soma as a result of the loss or gain of some factor or determinant in the chromosomes. To say that certain mutations consist of new factors which only cause the development of characters in the soma when the part of the soma concerned is stimulated by a hormone, is a mere assertion unsupported at present by any evidence. As an example of the way in which Mendelians misunderstand the problem to be considered, I may refer to Doncaster's book, The Determination of $S e x,{ }^{1}$ in which he remarks: 'It follows that the secondary sexual characters cannot arise simply from the action of hormones; they must be due to differences in the tissues of the body, and the activity of the ovary or testis must be regarded rather as a stimulus to their development than as their source of origin.' This seems to imply a serious misunderstanding of the idea of the action of the hormones from the gonads and of hormones in general. No one would suggest that the hormones

1 Canı. Univ. Press, 1914, p. 99. 
from the testis should be regarded as in any sense the origin of the antlers of a stag. If so, why should not antlers equally develop in the stallion or in the buck rabbit, or indeed in man? How far Doncaster is right in holding that the soma is different in the two sexes is a question already mentioned, but it is obvious that in each individual the somatic sexual characters proper to its species are present potentially in its constitution by heredity-in other words, as factors or determinants in the chromosomes of the zygote from which it was developed; but the normal development of such characters in the individual soma is either entirely dependent on the stimulus of the hormone of the gonad or is profoundly influenced by the presence or absence of that stimulus. The evidence, as we have seen, proves that, at any rate in the large number of cases where this relation between somatic sex-characters and hormones produced by the reproductive organs exists, the characters are inherited by both sexes. In one sex they are fully developed, in the other rudimentary or wanting. But the sex, usually the female, in which they are rudimentary or wanting is capable of transmitting them to offspring, and also is capable of developing them more or less completely when the ovaries are removed, atrophied or diseased. If we state these facts in the terms of our present conceptions of chromosomes and determinants or factors, we must say that the factors for these characters are present in the chromosomes of both male and female gametes. The question then is, how did these factors arise? If they were mutations not caused by any influence from the exterior, what is the reason why these particular characters 
which alone have an adaptive relation to the sexual or reproductive habits of the animal are also the only characters which are influenced by the hormones of the reproductive organs? The idea of mutations implies neither an external relation nor an internal relation in the organ or character; but these characters have both, the external relation in the function they perform in the sexual life of the individual, the internal relation in the fact that their development is affected by the sexual hormones. There is no more striking example of the inadequacy of the current conceptions of Mendelism and mutation to cover the facts of bionomics and evolution.

The truth is that facts and experiments within a somewhat narrow field have assumed too much importance in recent biological research. No increase in the number of facts or experimental results of a particular class will compensate for the want of sound reasoning and a comprehensive grasp of the phenomena to be explained. The coexistence of the external and the internal relation in the characters we are considering suggests that one is the cause of the other, and as it is obvious that the relation for instance of a stag's antlers to a testicular hormone could not very well be the cause of the use of the antlers in fighting, the reasonable suggestion is that the latter is the cause of the former. We have already seen that the development and shedding of the antler are processes of essentially the same kind physiologically, or pathologically, as these which can be and are occasionally produced in the individual soma by mechanical stimulus and injury to the periosteum. The fact that a hormone from 
the testis affects the development of the antler, as well as our knowledge of hormones in general, suggests a special theory of the heredity of somatic modifications due to external stimuli. Physiologists are apt to look for a particular gland to produce every internal secretion. But the fact that the wall of the intestine produces secretion, which carried by the blood causes the pancreas to secrete, shows that a particular gland is not necessary. There is nothing improbable in supposing that a tissue stimulated to excessive growth by external irritation would give off special substances to the blood. We know that living tissues give off waste products, and that these are not merely pure $\mathrm{CO}_{2}$ and $\mathrm{H}_{2} \mathrm{O}$, but complicated compounds. The theory proposed by me in 1908 was that we have within the gonads numerous gametocytes whose chromosomes contain factors corresponding to the different parts of the soma, and that these factors or determinants might be stimulated by waste products circulating in the blood and derived from the parts of the soma corresponding to them. There is no reason to suppose that an exostosis formed on the frontal bone as a result of repeated mechanical stimulation due to the butting of stags would give off a special hormone which was never formed in the body before, but it would probably in its increased growth give off an increased quantity of intermediate waste products of the same kind as the tissues from which it arose gave off before. These products would act as a hormone on the gametocytes, stimulating the factors which in the next generation would control the development of the frontal bone and adjacent tissues. 
The difficulty of this theory is one which has occurred to biologists who have previously made suggestions of a connexion between hormones and heredity-namely, how hormones or waste products from one part of the body could differ from these from the same tissue in another part of the body. If there were no special relation, hypertrophy of bone on one part of the body such as the head would merely stimulate the factor for the whole skeleton in the gametocytes, and the result would merely be an increased development of the whole skeleton. On the other hand, we have the evident fact that a number of chromosomes formed apparently of the same substance, by a series of equal chromosome divisions determine all the various special parts of the complicated body. This is not more difficult to understand than that every part of the body should give off special substances which would have a special effect on the corresponding parts of the chromosomes. We know that skin glands in different parts of the body produce special odours, although all formed of the same tissue and all derived from the epidermis. It seems not impossible that bones of different parts of the body give off different hormones. If the factors in the gametes were thus stimulated they would, when they developed in a new individual, produce a slightly increased development of the part which was hypertrophied in the parent soma. No matter how slight the degree of hereditary effect, if the stimulation was repeated in every generation, as in the case of such characters as we are considering it undoubtedly was, the hereditary effect would constantly increase until it was far greater than the 
direct effect of the stimulation. We may express the process mathematically in this way. Suppose the amount of hypertrophy in such a case as the antlers to be $x$, and that some fraction of this is inherited. Then in the second generation the same amount of stimulation together with the inherited effect would produce a result equal to $x+\frac{x}{n}$. The latter fraction being already hereditary, a new fraction $\frac{x}{n}$ would be added to the heredity in each generation, so that after $m$ generations the amount of hereditary development would be $x+\frac{m x}{n}$. If $n$ were 1000 , then after 1000 generations the inherited effect would be equal to $x$. This, it is true, would not be a very rapid increase. But it is possible that the fraction $\frac{x}{n}$ would itself increase, for the heredity might very well consist not only in a growth independent of stimulation, but in an increasing response to stimulation, so that $x$ itself might be increasing, and the fraction $\frac{x}{x}$ would become larger in each generation. The death and loss of the skin over the antler, originally due to the laceration of the skin in fighting, has also become hereditary, and it is certainly difficult to conceive the action of hormones in this part of the process. All we can suggest is that the hormone from the rapidly growing antler, including the covering skin, is acting on the corresponding factor in the gametocytes for a certain part of every year, and then, when the skin is stripped off, the hormone disappears. The factor then may be said to be stimulated for a time and then 
the stimulus suddenly ceases. The bone also begins to die when the skin and periosteum is stripped off, and the hormone from this also ceases to be produced.

The annual shedding and recrescence of the antler, however, is only to be understood in connexion with the effect of the testicular hormone. According to my theory there are two hormone actions, the centripetal from the hypertrophied tissue to the corresponding factor in the gametocytes, and the centrifugal from the testis to the tissue of the antler or other organ concerned. The reason why the somatic sexual character does not develop until the time of puberty, and develops again each breeding season in such cases as antlers, is that the original hypertrophy due to external stimulation occurred only when the testicular hormone was circulating in the blood. The factor in the gametocytes then was in each generation acted upon by both hormones, and we must suppose that in some way the result was produced that the hereditary development of the antler in the soma only took place when the testicular hormone was present. It is to be remembered that we are unable at present to form a clear conception of the process of development, to understand how the simple fertilised ovum is able by cell-division and differentiation to develop into a complicated organism with organs and characters predetermined in the single cell which constitutes the ovum. If we accept the idea that characters are represented by particular parts of the chromosomes, according to Morgan's scheme, our theory of development is the modern form of the theory of preformation. When in the course of development the cells of the head 
from which the antlers arise are formed, each of these cells must be supposed to contain the same chromosomes as the original ovum from which the cells have descended by repeated cell-division. The factors in these chromosomes corresponding to the forehead have been stimulated while in the parent animal by hormones from the outgrowth of tissue produced by external mechanical stimulation, while at the same time they were permeated by the testicular hormone produced either by the gametocytes themselves or by interstitial cells of the testis. When the head begins to form in the process of individual development, the factors, according to my theory, have a tendency to form the special growth of tissue of which the incipient antler consists, but part of the stimulus is wanting, and is not completed until the testicular hormone is produced and diffused into the circulation-that is to say, when the testes are becoming mature and functional.

I do not claim that this theory is complete-it is impossible to understand the process completely in the present state of knowledge-but I maintain that it is the only theory which affords any explanation of the remarkable facts concerning the influence of the hormones from the reproductive organs on the development of secondary sexual characters, while at the same time explaining the adaptive relation of these characters or organs to the sexual habits of the various species. On the mutation hypothesis, adaptation is purely accidental. T. H. Morgan consider's that the appearance of two slightly different shades of eye colour in male and female in a culture of a fruitfly in a bottle is sufficient to settle the whole problem of sexual dimorphism, and to supersede Darwin's 
complicated theory of sexual selection. The possibility of a Lamarckian explanation he does not even mention. He would doubtless assume that the antlers of stags arose as a mutation, without explaining how they came to be affected by the testicular hormone, and that when they arose the stags found them convenient as fighting weapons. But the complicated adaptive relations are not to be disposed of by the simple word mutation. The males have sexual instincts, themselves dependent on the testicular hormone, which develop sexual jealousy and rivalry, and the Ruminants fight by butting with their heads because they have no incisor teeth in the upper jaw, or tusks, which are used in fighting in other species. Doubtless, mutations have occurred in antlers as in other characters; in fact all hereditary characters are subject to mutation. This is the most probable explanation, not only of the occasional occurrence of hornless individual stags, but of the differences between the antlers of different species, for there is no reason to believe that the special character of the antler in each species is adapted to a special mode of fighting in each species.

The different structure of the horns of the Bovine and Ovine Ruminants is, in my view, the result of a different mode of fighting. If we suppose that the fighting was slower and less fierce in the Bovidae, so that the skin over the exostosis was subject to friction but not lacerated, the result would be a thickening of the horny layer of the epidermis as we find it, and the fact that the skin and periosteum are not destroyed explains why the horns are not shed but permanent. 
There is a tendency among Mendelians and mutationists to overestimate the importance of experiments in comparison with reasoning, either inductive or deductive. Bateson, however, has admitted that Mendelian experiments and observations on mutation have not solved the problem of adaptation. It seems to be demanded, nevertheless, that characters must be produced experimentally and then inherited before the hereditary influence of external stimuli can be accepted. Kammerer's experiments in this direction have been sceptically criticised, and it must be granted that the evidence he has published is not sufficient to produce complete conviction. But experiments of this kind are from the nature of the case difficult if not impossible. There is, however, another method-namely, to take a character which is certainly to some extent hereditary, and then to ascertain by experiment if it is 'acquired.' If it be proved that a hereditary character was originally somatogenic, it follows that somatogenic characters in time become hereditary. This is the reasoning I have used in reference to my experiments on the production of pigment on the lower sides of Flat-fishes, and I obtained similar evidence with regard to the excessive growth of the tail feathers in the Japanese Tosa-fowls, ${ }^{1}$ which is a modification of a secondary sexual character. In these fowls the feathers of the tail in the hens are only slightly lengthened.

I learned from Mr. John Sparks, who himself brought specimens of the breed from Japan, that the Japanese not only keep the birds separately on high

1 'Observations and Experiments on Japanese Long-tailed Fowls,' Proc. Zer' Soc., 1903. 
perches in special cages, but pull the tail feathers gently every morning in order to cause them to grow longer. One question which I had to investigate on my specimens, hatched from eggs obtained from Mr. Sparks, was the relation of the growth of the feathers to the moult which occurs in ordinary birds. My experiment consisted in keeping two cocks, A and $B$, the first of which was left to itself, while in the second the feathers were gently pulled by stroking between the finger and thumb from the base outwards. The feathers in the tail were seven pairs of rectrices, two rows of tail coverts, anterior and posterior, four or five pairs in each row, a number of transition feathers: all these were steel-blue, almost black; in front of them on the saddle were a number of reddish yellow, very slender saddle hackles.

In September 1901, when the birds were just over three months old, the adult feathers of the tail were all growing. The growing condition can be distinguished by the presence of a horny tubular sheath extending up the base of the feather for about one inch. When growth ceases this sheath is shed. In cock A growth continued till the end of the following March, when the longest feathers, the central rectrices, were 2 feet $4 \frac{1}{2}$ inches long. One of the feathersnamely, one of the anterior tail coverts-was accidentally pulled out on 11th February 1902, when it was $15 \frac{1}{4}$ inches long and had nearly ceased to grow and formed its quill, and it immediately began to grow again and continued to grow till the following September, when it was accidentally broken off at the base : it was then 18 inches $(44.5 \mathrm{~cm}$.) long.

The effect of stroking in cock B was to pull out from time to time one of the growing feathers. Of 
the original feathers, one, the left central posterior covert, continued to grow till 13th July 1902, when it was 2 feet $9 \frac{1}{2}$ inches long without the part contained in the follicle. All the feathers pulled out immediately commenced to grow again, except the last two pulled out 27th May and 13th July, which did not grow again till the following moulting season, in September.

The first right central rectrix in cock B was accidentally pulled out on 13th April 1902, when it was 2 feet $9 \frac{7}{8}$ inches long. Its successor began to grow immediately, and in course of time pieces of it were broken off accidentally without injury to the base in the socket, which continued to grow until 16th June 1905, when it was torn out of its socket. The total length of the feather with the pieces previously broken off, which were measured and preserved, was 11 feet $5 \frac{1}{2}$ inches. It therefore continued to grow without interruption for three years and two months at an average rate of $3 \cdot 6$ inches per month.

In cock A only four of the short outer rectrices were moulted in the beginning of September 1902 : the longer feathers-namely, central rectrices and tail coverts-which ceased to grow naturally in the spring of 1902, were not moulted till the beginning of October. This shows the great importance of pulling out the feathers as soon as they show signs of ceasing to grow, in order to obtain the abnormally long feathers. The central rectrices continued to grow till the beginning of September 1903, when that of the left side was 3 feet 6 inches long, that of the right about an inch shorter. The coverts had ceased to grow of their own accord some time before this, and thecentral ones of the posterior row were about 3 feet long. 
As it seemed possible that there was some natural congenital difference in growth of feathers between cocks A and B, I commenced early in March 1903 to pull and stroke the feathers of the left side only in cock A, leaving those of the right side untouched. On 30th July on the left side the central rectrix and the first and second posterior coverts were still growing, on the right side the central rectrix was also growing, but the first and second posterior coverts had ceased growth and formed their quills. The first posterior covert on the left or pulled side was 3 inches longer than that of the right. The second posterior covert on the left side was still longer. The first and second posterior coverts of left side did not cease growth till 26th August. On 2nd September the left central rectrix was almost at the end of its growth, the right had ceased to grow a little before. The left was about an inch longer than the right. Thus both in length and in duration of growth the feathers of the pulled side were longer than those of the right, and this was the result of treatment continued only six months, and commenced some months after the feathers had begun to grow. I have no doubt, however, that the pulling out of the feather as soon as it shows signs of forming quill, so that its successor at once grows again, is even more important in producing the great length of feather than the stroking of the feather itself.

In this case, then, there is no doubt $(a)$ that the long-tailed birds are artificially treated with the utmost care and ingenuity by the Japanese, who produced them; $(b)$ that the mechanical stimulus in my experiments did cause the feathers to grow for a longer period and attain greater length; 
(c) that the tendency to longer growth is, even when no treatment is applied, distinetly inherited. It is a legitimate and logical conclusion that the inherited tendency is the result of the artificial treatment. No other breed of fowls shows such excessive growth of tail feathers. It may be admitted that individuals differ considerably in their congenital tendency to greater growth, i.e. greater length of the tail feathers, but according to my views this is not contradictory to the main conclusion, for every hereditary character shows individual variation.

It may be pointed out here that on the Lamarckian theory the conception of adaptations is not teleological : they do not exist for a certain purpose, but are the result of external stimulations arising from the actions and habits of the organism. The latter conception is the more general, for cases of somatic sexual characters exist which cannot be said to have a use or function. For example, the comb and wattles of Gallus are sexually dimorphic, being in the original species larger in the cock than in the hen. There is no convincing evidence that these appendages are either for use or ornament. They are, in fact, a disadvantage to the bird, being used by his adversary to take hold of when he strikes. The first thing that happens when cocks fight is the bleeding and laceration of the comb, as they peck at each other's heads. This laceration of the skin is, in my view, the primary cause of the evolution of these structures, leading to hypertrophy. But in this, as in other cases, the hereditary result is regular, constant, and symmetrical, while the immediate effect on the individual is doubtless irregular. 


\section{CHAPTER V}

MAMMALIAN SEXUAL CHARACTERS. EVIDENCE OPPOSED TO THE HORMONE THEORY

Perhaps the most remarkable of all somatic sexual characters are those which are almost universal in the whole class of Mammalia, the mammary glands in the female, the scrotum in the male. We have considered the evidence concerning the relation of the development and functional action of the milk glands to hormones arising in the ovary or uterus, now we have to consider the origin of the glands and of their peculiar physiology in evolution. The obvious explanation from the Lamarckian point of view, and in my opinion the true one, is that they owed their origin at the beginning to the same stimulation which is applied to them now in every female mammal that bears young. There is, as we haveseen, a difficulty in explaining how the occurrence of parturition causes the secretion of milk to begin, but it is certain that the secretion soon stops if the milk is not drawn from the glands by the sucking action of the offspring, or the artificial imitation of that action. A cow that is not milked or milked incompletely ceases to give milk. When the stimulus ceases, lactation ceases. The pressure of the secretion in the alveoli causes the cells to cease to secrete, much in the same way that pressure in the ureters injures the secretory action of the renal 
epithelium. In the earliest Mammals we may suppose that the young were born in a well-developed condition, for at first the supply of milk would not have been enough to sustain them for a long time as their only food. We must also suppose that the mother began to cherish the young, keeping them in contact with her abdomen. Then being hungry they began to suck at her hair or fur. The actual development of the milk glands in Marsupials has been described by Bresslau ${ }^{1}$ and by $\mathrm{O}^{\prime}$ Donoghue. ${ }^{2}$ The rudiment of the teat is a depression or invagination of the epidermis from the bottom of which six stout hairs arise. The follicles of these hairs extend down into the derma, and from the upper end of the follicle, i.e. near the aperture of the invagination, a long cellular outgrowth extends down into the derma, branches at its end, and becomes hollow. These branches are the tubules of the future milk gland. Another outgrowth from the follicle forms a sebaceous gland. Later on the hairs and the sebaceous glands entirely disappear, and the milk gland alone is left with its tubules and ducts opening into the cavity of the teat. This is clear evidence that the milk gland was evolved in connexion with hairs, and was an enlargement of glands opening into the hair follicle, but it is difficult to understand why a sebaceous gland is developed and afterwards disappears. This would seem to indicate that the milk gland was not a hypertrophied sebaceous gland, but a distinct outgrowth, which however had nothing to do with sweat glands.

That the intra-uterine gestation, or its cessation, were not originally necessary to determine the
1 Stuttgart, 1901.
2 Q.J.M.S., Ivii., 1911-12. 
functional periodicity of the milk glands is proved by their presence in the Monotremes, which are oviparous. It is evident from the conditions in these mammals that both hair and milk glands were evolved before the placenta.

It may also be pointed out here that, according to the evidence of Steinach, in the milk glands at least among somatic sexual characters there is no difference between the male and female in the heredity of the organs. The zygote therefore, whether the sex of it is determined as male or female, has the same factor for the development of milk glands. On the chromosome theory as formulated by Morgan this factor must be in the somatic chromosomes and not in the sex-chromosomes, and must be present in every zygote. All the cells of the body, assuming that somatic segregation does not occur, must possess the same chromosomes as the zygote from which it developed, and whether the sex chromosomes are $X X$ or $X Y$ or $X$, there must be at any rate one chromosome bearing the factor for milk glands. The functional development of these depends normally, according to the evidence hitherto discovered, on the presence or absence of hormones from the ovary or from the uterus.

If we attribute, as in my opinion we must, the primary origin of the milk glands in evolution to the mechanical stimulus of sucking, we may attempt to reconstruct the stages of the evolution of the present relation of the glands to the other organs and processes of reproduction. In the earliest stage represented by the Monotremata or Prototheria, there was no intra-uterine development. We must suppose that in the beginning the sucking stimulus 
caused both growth and secretion, for at first there was nothing but sebaceous or sweat glands, and although a mutation might be supposed to have produced larger glands, no mutation could explain the influence of hormones on the growth and function of such glands. Then heredity of the effect of stimulus took place to some slight degree, and this would occur, according to my theory, only in the presence of the hormone from the ovary in the same condition as that in which the modification was first caused. This would be of course after ovulation, and after hatching of the eggs. In the next stage, if we adopt the modern view that Marsupials are descended from Placental Mammals, the eggs would be retained for increasing periods in the uteri, and would be born in a welldeveloped condition, since lactation would demand active sucking effort on the part of the young. The early Placentalia would inherit from the Monotremelike ancestors the development of the milk glands after ovulation, although no sucking was taking place while the young were inside the uterus. It seems probable that the relation between parturition and actual milk secretion originated with the sucking stimulus of the young after birth.

There is good evidence that the secretion of milk may continue almost indefinitely under the stimulus of sucking or milking. Neither menstruation nor gestation put an end to it. Cows may continue to give milk until the next parturition, and if castrated during lactation will continue to yield milk for years. Women also may continue to produce milk as long as the child is allowed to suck, and this has bcen in some cases two or three years or even more. Moreover, lactation may be induced by the repeated act 


\section{MAMMALIAN SEXUAL CHARACTERS}

of sucking without any gestation. This has happened in mares, virgin bitches, mules, virgin women, and in one woman lactation was continued uninterruptedly for forty-seven years, to her eighty-first year, long after the ovary had ceased to be functional. Lactation has also been induced in male animals, e.g. in a bull, a male goat, male sheep, and in men. ${ }^{1}$ We may conclude, therefore, that the secretion of milk normally begins by heredity after parturition, and this, in accordance with what we have learned about hormones in connexion with the reproductive system, is probably the consequence of the withdrawal of the hormone absorbed from the fœtus. I do not think it is necessary to suppose, as do LaneClaypon and Starling, that the hormone physiologically inhibits the dissimilative process and augments the assimilative, and that the withdrawal of the hormone at parturition therefore causes the dissimilative process, i.e. secretion of milk. My conclusion is that the process of secretion set up by the mechanical stimulus of sucking is inherited as it was acquired, so that it only begins to take place in the individual in the absence of the hormone from the fœtus, which was absent when the process was acquired. The growth of the gland during gestation would then be due to the postponement of the process of secretion in consequence of the presence of the fœtal hormone, and in this way this hormone has become in the course of evolution at once the stimulus to growth and the cause of the inhibition of secretion.

This interpretation does not, however, agree with the case of Dasyurus. If the fœtal hormone is

1 Knott, 'Abnormal Lactation,' American Medicine, vol. ii. (new series), 1907. 
absorbed from the pouch, as I have suggested in order to explain the persistence of the corpora lutea during lactation, then the secretion of milk after parturition ought not to take place. But in this case the sucking stimulus has been applied to the glands after a very short gestation, while the hormone from the fœtus is being absorbed in the pouch, and therefore the hereditary correlation between secretion and absence of fotal hormone may be assumed to have been lost in the course of evolution.

We have next to consider the question of the evolution of the corpora lutea. If these bodies are formed only in Mammals which have uterine gestation, and not in Prototheria, they cannot be the only essential source of the hormone which stimulates the development of the milk glands, since the latter develop in Prototheria. Again it is difficult, it might be said impossible, to believe that an accidental mutation gave rise to corpora lutea the secretion of which caused uterine gestation and ultimately the formation of the placenta. It seems more probable that the retention of the originally yolked ova within the oviduct, however this retention arose, was the essential cause of the formation of the placenta and all the changes which the uterus undergoes in gestation. The absorption of nutriment from the walls of the uterus, and the chemical and mechanical stimulation of those walls, might well be the cause of the diversion of nutrition from the ovary, leading gradually to the decline of the process of secretion of yolk in the ova.

The conceptions and the mode of reasoning of the physiologist are very different from those of the evolutionist. The former concludes from certain 
experiments that a given organ of internal secretion has a certain function. The corpora lutea, for example, according to one theory are ductless glands, the function of whose secretion is to establish the ova in the uterus and promote their development. Another function suggested for the secretion of the corpora lutea is to prevent further ovulation during pregnancy. The evolutionist, on the other hand, asks what was the origin of the corpora lutea, why should the ruptured ovarian follicles after the escape of the ova in Mammals undergo a progressive development and persist during the greater part or the whole of pregnancy? It seems obvious that the corpora lutea in evolution were a consequence of intra-uterine gestation, for they occur only in association with this condition, and it is impossible to suppose that a mutation could arise accidentally by which the ruptured follicles should produce a secretion which would cause the fertilised ova to develop within the oviducts. The developing ovum within the uterus may, however, reasonably be supposed to give off something which is absorbed into the maternal blood, and this something would be of the same nature as that which was given off by the ovum while still within the ovarian follicle. The presence of this hormone might cause the follicular cells to behave as though the ovum was still present in the follicle, so that they would persist and not die and be absorbed. But this leaves the question, what is lutein and why is it secreted? Lutein is a colouring matter sometimes found in blood-clots, and probably derived from haemoglobin. In the corpus luteum the lutein is contained in the cells, not in a blood-clot. 
Chemical investigation shows that the lutein of the corpus luteum is almost if not quite identical with the colouring matter of the yolk in birds and reptiles. Escher ${ }^{1}$ found that the lutein of the corpus luteum had the formula $\mathrm{C}_{40} \mathrm{H}_{56}$ and was apparently identical with the carotin of the carrot, while the lutein of egg-yolk was $\mathrm{C}_{40} \mathrm{H}_{56} \mathrm{O}_{2}$ and more soluble in alcohol, less soluble in petroleum ether, than that of the corpus luteum. The difference, if it exists, is very slight, and it is evident that one compound could easily be converted into the other. Moreover, the hypertrophied follicular cells which constitute the corpus luteum secrete fat which is seen in them in globules. The similarity of their contents therefore to yolk is very remarkable, and it may be suggested that the hormones absorbed from the ovum or embryo in the uterus acts upon the follicular cells in such a way as to cause them to secrete substances which in the ancestor were passed on to the ovum and formed the yolk. It may be urged that this idea is contradictory to the previous suggestion that the absorption of nourishment by the intra-uterine embryo was the cause of the gradual decline of the process of yolk-secretion by the ova in the ovary, but it is not really so. Originally in the reptilian ancestor, or in the Monotreme, the ovum in the follicle secreted yellow-coloured yolk. The materials for this, at any rate, passed through the follicle cells, and it is probable that these cells were not entirely passive, but actively secretory in the process. Substances diffusing from the ovum would be present in the follicle cells during this process, and probably act as a stimulus. The same substances

1 Ztschr. f. Physiol. Chem., 83 (1912). 
diffusing from the ovum during its development in the uterus would continue to stimulate the follicle cells, and thus explain not merely their persistence, but their secretory activity. The ovum being no longer present in the ovary, the secretions would remain in the follicular cells, and the corpus luteum would be explained.

If this theory is sound, it would follow that corpora lutea are not formed in cases where the ova are not retained in the oviduct during their development. The essential process in the development of these structures is the hypertrophy and, in some cases at least, multiplication of the follicular cells in the ruptured follicle. I have already mentioned that this process does not occur in Teleosteans whose ovaries were studied by me. These were species of Teleosteans in which fertilisation is external. Marshall, in his Physiology of Reproduction, ${ }^{1}$ quotes a number of authors who have published observations on the changes occurring in the ruptured follicle in the lower Vertebrata, and also in the Monotremes. According to Sandes, ${ }^{2}$ in the latter there is a pronounced hypertrophy of the follicular epithelium after ovulation, but no ingrowth of connective tissue or blood-vessels from the follicular wall. Marshall himself examined sections of the corpus luteum of Ornithorhynckus and saw much hypertrophied and apparently fully developed luteal cells, but no trace of any ingrowth from the wall of the follicle. This fact would appear to be quite inconsistent with the theory above proposed, but

1 London, 1910, p. 151.

2 'The Corpus Luteum of Dasyurus,' Proc. Lin. Soc., New South Wales, 1903. 
it must be remembered that the ovum of Monotremes is known to remain for a short period in the oviduct, or in other words to pass through it very slowly, and to absorb fluid from its walls, as shown by the considerable increase in size which the ovarian ovum undergoes before it is laid. It would be interesting to know how long the rudimentary corpus luteum persists in Ornithorhynchus: the period, according to my views, should be very short. It is remarkable that in the results quoted by Marshall a well-developed corpus luteum was found and exclusively found in the lower Vertebrates which are viviparous. For example, among fishes in the Elasmobranchs Myliobatis and Spinax; in Teleosteans, in Zoarces; in Reptiles, in Anguis and Seps. Bühler, on the other hand, confirmed my own negative result with regard to oviparous Teleosteans, and also found no hypertrophy of the follicle in Cyclostomes which are also oviparous. In the viviparous forms mentioned there is yolk in the ovum which is retained in oviduct or ovary, but additional nutriment is also absorbed from the uterine or ovarian walls. In these cases there is no placenta and generally no adhesion of ovum or embryo to walls of oviduct or ovary. These facts alone would be sufficient to disprove the theory that the corpora lutea are organs producing a secretion whose function is to cause the attachment of the embryo to the uterine mucosa. It is also, in my opinion, unreasonable to suppose that the rudimentary corpora lutea of lower viviparous Vertebrates arose as a mutation the result of which was to cause internal development of the ovum. Habits might easily bring about retention of the fertilised ova for gradually increasing 
periods, $^{1}$ and the correlation between the retained developing ova and the hypertrophy of the ruptured follicles is comprehensible on my theory of the influence of substances absorbed by the walls of oviduct or ovary from the developing ovum.

The case of Dasyurus, however, seems inconsistent with this argument, for, as previously mentioned, Sandes found that in this Marsupial the corpora lutea persisted during the greater part of the period of lactation, which continues for four months after parturition. During the whole of this time there are no embryos in the uteri, and therefore it might be urged absorption of hormones from the embryos cannot be the cause of the persistence of corpora lutea in pregnancy. But it seems to me that a complete answer to this objection is supplied by the peculiar relations of the embryos to the pouch in Dasyurus and other Marsupials. The skin of the pouch while the embryos are in it is very soft, congested, and glandular; at the same time the embryos when transferred to the pouch at parturition are very small, immature, and have a soft delicate skin. The relation of embryos to pouch in Dasyurus, therefore, is closely similar to that of embryos to uterus after the first few days of pregnancy in the Eutheria. It is true there is no placenta, but the mouths of the embryos are in very close contact with the teats, and both the skin of the embryos and that of the pouch are soft and moist. If any special substances are given off by the embryos in the uterus in ordinary gestation, the same substances would continue to be

1 According to Geddes and Thomson (Evolution of Sex, 1889), the common grass-snake has been induced under artificial conditions to bring forth its young alive. 
given off by the embryos in the marsupial pouch, and these must be absorbed by the skin of the pouch. In this way it seems to me we have a logical explanation of the fact that the corpora lutea in the Marsupial are not absorbed at parturition as in Eutheria. As Sandes says the 'greater part of the period of lactation,' it would appear that absorption of the corpora lutea takes place when the young Dasyurus have grown to some size, become covered with hair, and are able to leave the teats or even the pouch at will. Under these conditions it is obvious that diffusion of chemical substances from the young through the walls of the pouch would come to an end. It would be interesting in this connexion to know more of the relation of egg and embryo to the pouch and to the corpora lutea in Echidna. In Ornithorhynchus the eggs are hatched in a nest and there is no pouch.

On this view that the corpora lutea are the result, not the cause, of intra-uterine gestation, it would no longer be possible to maintain the theory that the corpus luteum in the human species is the cause by its internal secretion of the phenomenon of menstruation. This was the theory of Born and Fränkel. ${ }^{1}$ Biedl's conclusion is that the periodic development and disintegration of the uterine mucous membrane in the menstrual cycle is due to the hormone of the interstitial cells of the ovary. Leopold and Ravana found that ovulation as a rule coincides with menstruation, but may take place at any time. Here, again, the problem must be considered from the point of view of evolution. It can scarcely be doubted that the thickening and growth of the

1 See Biedl, Internal Secretory Organs (Eng. trans.), 191:, p. 404. 
mucous membrane in the menstrual cycle is of the same nature as that which takes place in pregnancy. When the ovum or ova are not fertilised the development comes to an end after a certain time, differing in different species of Mammals, and the membrane sloughs, returns to its original state, and then begins the same process of development again.

Menstruation, then, must be interpreted as an abortive parturition, both in woman and lower Mammals, though in the latter it is not usually accompanied by hemorrhage, and is called pro-œstrus. The question then to be considered is, what determines parturition and menstruation? The presence of the fertilised ovum must have been the original cause of the hypertrophy of the uterine mucous membrane, and in its congenital or hereditary development the chemical substances diffusing from the ova in the uterus or even in the Fallopian tube may well be the stimulus starting the hypertrophy. But what determines the end of the pregnancy? Is it merely the increasing distension of the uterus by the developing fœtus? This could scarcely be the case in the Marsupials in which the fœtus when born is quite minute. Nor can we attribute parturition to renewed ovulation, for this occurs in Dasyurus only once a year. All we can suggest at present is that a certain periodic development takes place by heredity in presence of the hormones exuded by the fertilised ovum and the embryo developed from it. When the ovum or ova, not being fertilised, die, the period of development is (usually) shortened and pro-œstrus or menstruation occurs. In the dog, however, the period of the cstrous cycle is about the same as that of gestation-namely, six months. 
The so-called descent of the testicles occurs exclusively in Mammals, in which with a few important exceptions it is universal. This is a very remarkable case of the change of position of an organ in the course of development. The original position of the testis on either side is quite similar to that of the same organ in birds or reptiles. The genital ridge runs along the inner edge of the mesonephros, with which the testicular tubules become connected. The testis, with the mesonephros, forming the epididymis, closely attached to it, projects into the cœlom, and without losing its connexion with the peritoneum changes its position gradually during development, passing backwards and downwards until it comes to lie over the wall of the abdomen just in front of the pubic symphysis of the pelvic girdle. There the abdominal wall on either side of the middle line becomes thin and distended to form a pouch, the scrotal sac, into which the testis passes, still remaining attached to the peritoneum which lines the pouch, while the distal end of the vas deferens retains its original connexion with the urethra. The movement of the testis can thus be accurately described as a transposition or dislocation.

Various causes have been suggested for the formation of the scrotum, but no one has ever been able to suggest a use for it. It has always been quite impossible to bring it within the scope of the theory of natural selection. The evolution of it can only be explained either on the theory of mutation or some Lamarckian hypothesis. The process of dislocation of the testis does not conform to the conception of mutation, nor agree with other cases of that phenomenon. A mutation is a change of structure affecting 
more or less the whole soma, but showing itself especially in some particular organ or structure. But I know of no mutation occurring under observation which consisted, not in a change of structure or function, but merely in a change of position of an organ from one part of the body to another, and moreover a change which takes place by a continuous process in the course of development. If the testes were developed from the beginning in a different part of the abdomen, there might be some reason in calling the change a mutation. Moreover, if it is a mutation, why has it never occurred in any other class of Vertebrates except Mammals ?

In 1903 Dr. W. Woodland published ${ }^{1}$ a Lamarckian theory of this mammalian feature, the probability of which it seems to me has been increased rather than decreased by the progress of research concerning heredity and evolution since that date. Dr. Woodland correlated the dislocation of the testes with the special mechanical features of the mode of locomotion in Mammalia. His words are: 'The theory here advocated is to the effect that the descent of the testes in the Mammalia has been produced by the action of mechanical strains causing rupture of the mesorchial attachments, such strains being due to the inertia of the organs reacting to the impulsiveness involved in the activity of the animals composing the group.' The 'impulsiveness' is the galloping or leaping movement which is characteristic of most Mammals when moving at their utmost speed, as seen, for example, in horses, deer, antelopes, dogs, wolves, and other Ungulata and Carnivora. It is obvious that when the body is descending to

1 Proc. Zool. Soc., 1903, Part I. 
the ground after being hurled upwards and forwards, the abdominal organs have acquired a rapid movement downwards and forwards; when the body reaches the ground its movement is stopped suddenly, while the abdominal organs continue to move. The testes therefore are violently jerked downwards away from their attachments and at the same time forward. The check to the forward movement, however, is momentary, while the body is immediately thrown again upwards and forwards, which by the law of inertia means that the testes are thrown still more downwards and backwards. There is no reason to suppose, as Dr. Woodland suggests, that any rupture of the mesorchium was the usual result of these strains, but a constant pull or tension was caused in the direction in which the testes actually move during development. On this theory we have to consider (1) how such strains could cause a shifting of the peritoneal attachment, (2) why the testes should be supposed to be particularly affected more than other abdominal organs. The answer to the first question is that the strains would cause a growth of the connecting membrane (mesorchium) at the posterior end, accompanied by an absorption of it at the anterior end. The answer to the second question is that the testes are at once the most compact and heaviest organs in the abdomen, and at the same time the most loosely attached. The latter statement does not apply to the mesonephros or epididymis which has moved with the testis, but the latter cannot function without the former, and it may be supposed that the close attachment of the epididymis to the testis had come about in the early Mammalia before the change of position was evolved. 
It is evident that the violent shocks of the galloping or leaping movement do not occur in Birds, Reptiles, or Amphibia. Ostriches run very fast and do not fly, but their progression is a stride with each foot alternately, not a gallop. The Anura among the Amphibia are saltatory, but their leaps are usually single, or repeated only a few times, not sustained gallops. The exceptions among the Mammalia still more tend to prove the close correspondence between the 'impulsive' mode of progression and the dislocation of the male gonads. In the Monotremata there is no scrotum, the testes are in a position similar to that which obtains in Reptiles, and they are the only Mammals in which these organs are anterior to the kidneys. In locomotion they are sluggish, there is no running or galloping among them. Ornithorhynchus is aquatic in its habits, and Echidna is nocturnal and moves very slowly. In Marsupials the scrotum is in front of the penis, but really in the same position as in other Mammals - that is, in front of the ventral part of the pelvic girdle. It is the penis which is different, as the skin around the organ has not united in a ventral suture below it, while the organ itself has not grown forward adnate to the abdominal skin as in most other Mammals. The scrotum is always anterior to the origin of the penis, although in the Eutheria apparently behind that organ. The larger Marsupials like the kangaroos are eminently saltatory, and the others are active in locomotion. The aquatic Mammals Sirenia and Cetacea have no scrotum, the testes being abdominal. It is unnecessary to inquire whether this is the original position, or whether they are descended from 
ancestors which had a scrotum: in either case the position of the testes corresponds to the absence of what Dr. Woodland calls impulsiveness in progression. The Fissipedia offer an instructive example, for while the Otariidae have the hind feet turned forward and can move on land somewhat like ordinary Mammals, the Phocidae cannot move their hind legs independently or turn them forward, and can only drag themselves about on land for short distances. In the former the testes are situated in a well-defined scrotum, in the latter these organs are abdominal. The Phocidae are probably descended from Mammals of the terrestrial type with a scrotum, which has disappeared in the course of evolution. Perhaps the most curious exception is that of the elephants, in which the testes are abdominal. Here, in consequence of their structure and massive shape, locomotion is usually a walk, and though they run occasionally the gait is a trot, not a sustained gallop, and leaping is out of the question. Sloths which hang from branches upside down have abdominal testes, but even here they are in a posterior position, between the rectum and the bladder, so there has apparently been a degree of dislocation, probably inherited from ancestors with more terrestrial habits.

The fact that the ovaries do not occupy normally a position similar to that of the testes is in accordance with the theory, for they are very much smaller than the testes; and yet they have undergone some change of position, for they are posterior to the kidneys.

The facts agree also with the hormone theory, for it is to be noted that although the development of 
the scrotum is confined to the males, the 'descent' or dislocation takes place in the fœtus, and not at the period of puberty. This is in accordance with the fact that the mechanical conditions to which the change is attributed are not related to sexual habits, but to the general habits of life which begin soon after birth. The development, therefore, may be considered to be related to the presence of a hormone derived from the normal testis, but not to a special quantity or quality of hormone associated with maturity or the functional activity of the organ. In Rodents, however, there is a difference in the organs, not only at maturity, but in every rutting season, at any rate in Muridae such as rats and others. In the rutting season the testes become much larger and descend into the scrotal sacs, at other times of the year being apparently more or less abdominal. In rabbits and hares, which have a much more impulsive progression, the organs seem to be always in the scrotal sacs.

It might be thought that in this case, although the hormone theory of heredity might be applied, there was no reason to suppose that a hormone derived from the testis in the individual development was necessary in order that the hereditary change should take place. If the individual was male and therefore had a testis, this organ would by heredity go through the process of dislocation. But there is the curious fact that when the descent is not normal and complete, in what is called cryptorchidism, the organs are always sterile. The retention of the testes within the abdomen may be regarded as a case of arrested development, like many other abnormalities, but this does not explain why the 
retained testes should always be sterile, without spermatogenesis. If the inherited or congenital process of dislocation requires the presence of hormones produced by a normal testis, then we can understand why a defective testis does not descend completely, because it does not produce the hormone which is necessary to stimulate the hereditary mechanism to complete dislocation. It is often stated that in cryptorchidic individuals the sexual instincts and somatic sexual characters are well developed, which would appear contradictory to the above explanation, but according to Ancel and Bouin such individuals in the case of the pig show considerable differences in the secondary signs of sex and in the external genital organs, presenting variations which lie between the normal and the castrated animal.

We have here, then, in the position of the testes in Mammalia a condition which is not in the slightest degree 'adaptive' in the ordinary sense-that is, fulfilling any special function or utility. The condition must be regarded as distinctly disadvantageous, since the organs are more exposed to injury, and the abdominal wall is werkened, as we know from the risk of scrotal hernia in man. But from the Lamarckian point of view the facts support the conclusion that the condition is the effect of certain mechanical strains, and is of somatic origin, while the correlations here reviewed are entirely unexplained by any theory of mutation or blastogenic origin. 


\section{Opposing Evidence}

We have now to review certain cases which seem to support conclusions contrary to those which we have maintained in the preceding pages, and to consider the evidence which has been published in support of other theories. It must be admitted that the occurrence of male secondary characters on one side of the body, and female on the other, is inconsistent with the view that the development of such characters is due to the stimulus of a hormone, since the idea of a hormone means something which diffuses by way of the blood-vessels, lymph-vessels, and interstices of the tissues, throughout the body, and the hormone theory of secondary sexual characters assumes that these characters are potentially present by heredity in both sexes. The occurrence of male somatic characters on one side or in one part of the body and female on the other, usually associated with the corresponding gonads, has been termed gynandromorphism, and has long been known in insects. Cases of this condition have been observed, though much more rarely, in Vertebrates. I am not aware of any authentic instance in Mammals, and the supposition that in stags reduction or abnormality of one antler may be the result of removal or injury to the testis of one side, or the opposite, have been completely disproved by experiments in which unilateral castration has been carried out without any effect on the antlers at all. In birds, however, a few cases have been recorded by competent observers with a definiteness of detail which leaves no possibility of doubt. One of the more recent of these is that of a pheasant of the 
white-ringed Formosan variety, $P$. torqualus, of the Chinese pheasant. ${ }^{1}$ On the left side this bird shows the plumage, colour, and the spur of the male; on the right leg there is no spur except the small rudiment normally occurring in the hen. The difference in plumage between the two sides, however, is not complete. The white collar is strictly limited to the left side, but the iridescent blue green of head and neck is present on both sides, though more marked on the left. Only a few male feathers appear in the wing coverts of the left side. The breast feathers are rufous, especially on the left side. The tail coverts show marked male characters, more especially on the left side. In the tail, however, the barred character of the male is not present on one side, absent on the other, but in most of the feathers is confined to one, the outer side of each feather. With regard to the gonads, in this bird a single organ was found on the left side, i.e. in the position of the ovary in normal females, and there was no trace of a gonad on the right side. The organ present was small, $\frac{3}{4}$ inch long by $\frac{1}{2}$ inch broad, and microscopic sections showed in one part actively growing areas of tubular gland structure in some of which bodies like spermatozoa could be detected, while in another were fibrous tissue with degenerating cysts. The latter appear to have been degenerating egg follicles. The author concludes that the organ was originally a functional ovary, and that the ovarian portion had atrophied while a male portion had become functionally active.

1 C. J. Bond, 'Unilateral Development of Secondary Male Characters in a Pheasant,' Journ. of Genetics, vol. iii., 1914. 
Another case in birds was described by Poll ${ }^{1}$ and is mentioned by Doncaster. ${ }^{2}$ It is that of a Bullfinch which had the male and female plumage sharply separated on the two sides of the body. The right side of the ventral surface was red like a normal male, the left side grey like a normal female. In this case there was a testis on the right side, on the left an ovary as in normal females.

A third case in birds, somewhat different from the two first mentioned, is that of a domestic fowl described by Shattock and Seligmann. ${ }^{3}$ It was a bird of the Leghorn breed, two years old, and had the fully developed comb and wattles of the cock. Each leg bore a thick blunt spur, nearly an inch in length, but in the Leghorn breed spurs are by no means uncommon in hens of mature age, before they have ceased to lay eggs. In plumage the characters were mainly female. The colour being white could not show sexual differences, the neck hackles were but moderately developed, saddle hackles practically absent, the tail resembled that of the hen. There was a fully developed oviduct on the left side, on the right another less than half the full length. There was also a vas deferens on each side. There was a gonad on each side, that of the right about one fourth the size of that on the left. In microscopic structure the right gonad resembled a testis consisting entirely of tubuli lined by an epithelium consisting of a single layer of cells. In one part of this organ the tubules were larger than elsewhere, and one of them exhibited spermatogenesis in progress.

1 S.B. Ges. Naturf. Freunde, Berlin, 1909.

2 Determination of Sex, Cambridge, 1914.

3 Trans. Pathol. Soc. (London), vol. 57, Part I., 1906. 
The left and larger gonad had a quite similar structure, but at its lower end were found two ova enclosed within a follicular epithelium.

With regard to the last case it is to be remarked that though the gonad on the right side was entirely male, there was no unilateral development of male characters. With regard to the other two cases it must be pointed out (1) that the difference between the two somatic sex-characters on the two sides is chiefly a difference of colour, except the difference in the spurs in Bond's pheasant; (2) that the evidence already cited shows that in fowls castration does not prevent the development of the colour and form of the male plumage, nor of the spurs: that in drakes, although castration does not seem to have been carried out on young specimens before the male plumage was developed, when performed on the mature bird it prevents the eclipse, and does not cause the male to resemble the hen. Castration, then, tends to prove that in Birds the development of the male characters is not so closely dependent on the stimulation of testicular hormone as in Mammals. The characters must therefore be developed by heredity in the soma, which implies that the soma must itself be differentiated in the two sexes. The development must therefore be more in the nature of gametic coupling. It does not follow that the primary sex-character or the somatic characters are exclusive in either sex. We may suppose that the zygote contains both sexes, one or other of which is dominant, and that dominance of one primary sex involves dominance of the corresponding sexual characters. This does not, however, agree with the result of removal of the ovaries in ducks, for this 
causes the characters of the male to appear, so that the dominance of the female is not a permanent condition of the soma but is dependent on the ovarian hormone.

In the hermaphrodite individuals mentioned above the difference of dominance is on two sides of the body instead of two different individuals. It may also be remarked here that while it is very difficult to believe that spurs were not due in evolution to the mechanical stimulation of striking with the legs in combat, and while specially enlarged feathers are erected in display, we cannot at present attribute the varied and brilliant colour of male birds to the direct influence of external stimuli.

In Lepidoptera among insects the evidence concerning castration tends to prove that hormones from the gonads play no part at all in the development of somatic sexual characters. Kellog, an American zoologist, in $1905^{1}$ described experiments in which he destroyed by means of a hot needle the gonads in silkworm caterpillars (Bombyx mori), and found no difference in the sexual characters of the moths reared from such caterpillars. Oudemans had previously obtained the same result in the Gipsy Moth, Limantria dispar. Meisenheimer ${ }^{2}$ made more extensive experiments on castration of caterpillars in the last-mentioned species, in which the male is dark in colour and has much-feathered antennae, while the female is very pale and has antennae only slightly feathered. In the moths developed from the castrated larvae there was no alteration in the

1 Journ. Exper. Zool. (Baltimore), vol. i., 1905.

2 Experimentelle Studien zur Soma- und Geschlechtsdifferenzierung. Jena, 1909. 
male characters, and in the females the only difference was that some of them were slightly darker than the normal. Meisenheimer and Kopec after him claim to have grafted ovaries into males and testes into females, with the result that the transplanted organs remained alive and grew, and in some cases at least became connected with the genital ducts. Even in these cases the moth when developed showed the original characters of the sex to which belonged the caterpillar from which it came, although it was carrying a gonad of the opposite sex. It will be seen that these results are the direct opposite of those obtained by Steinach on Mammals. We have no evidence that the darker colour of the normal male in this case is adaptive, or due to external stimuli, but the feathering of the antennae is generally believed to constitute a greater development of the olfactory sense organs, and is therefore adaptive, enabling the male to find the female. This is therefore the kind of organ which would be expected to be affected by hormones from the generative organs. It is stated that the sexual instincts were also unaltered, a male containing ovaries instead of testes readily copulating with a normal female.

These results, almost incredible as they appear, are in harmony with the relatively frequent occurrence of gynandromorphism in insects. ${ }^{1}$ One of the most remarkable cases of this is that of an ant (Myrmica scabrinodis) the left half of which is male, the right half not merely female, but worker-that is, sterile female, without wing. Cases in Lepidoptera, e.g. Amphidasys betularia, have frequently been recorded.

1 See Doncaster, Determination of Sex (Camb. Univ. Press, 1914). chap. ix. 
Presumably not only the antennae and markings, but also the genital appendages and the gonads themselves, are male and female on the two sides. On the view that both sexes and the somatic sex-characters of both sexes are present in each zygote, and that the actual sex is due to dominance, we must conclude that the male primary and secondary characters are dominant on one side, and the female on the other, and it is evident that hormones diffusing throughout the body cannot determine the development of somatic sexual characters here. Various attempts have been made to explain gynandromorphism in insects in accordance with the chromosome theory of sex-determination. These are discussed by Doncaster in the volume already cited, but from the point of view of the present work the important question is that concerning the somatic sex-characters. According to Doncaster it has been found that in some Lepidoptera the different sexchromosomes occur in the female, not in the male as in other insects. Half the eggs, therefore, contain an $X$ chromosome, and half a $Y$, while all the sperms contain an $X$ chromosome. Doncaster has seen in Abraxas grossulariata ova with two nuclei both undergoing maturation. If one of these in reduction expelled a $Y$ chromosome, the other an $X$, then one would retain an $X$ and the other a $Y$. Each was fertilised by a sperm, one becoming therefore $X X$ or male and the other $X Y$ or female. It may be supposed that as there was only the cytoplasm of one ovum, each nucleus would determine the characters of half the individual developed. The question remains, therefore, where are the factors of the somatic sex-characters? One suggestion which 
might be made is that the female characters are present in the $Y$, in this case female producing chromosome, or, if the female characters are merely negative, that the male eharacters are in the $X$ chromosome, but only show themselves in the homozygous condition, thus :-

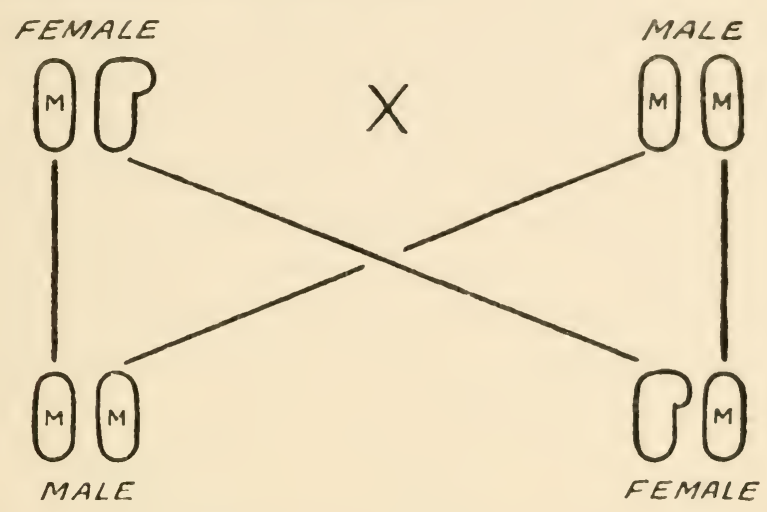

The male characters in the male, $X X$, would appear because present in two chromosomes, but would be recessive in the female because present only in one chromosome. The validity of this scheme, however, is disproved by the fact that males can transmit the female characters of their race, as in the case mentioned by Doncaster where a male Nyssia zonaria when crossed transmits the wingless character of its own female.

Another, perhaps better, suggestion is that the somatic characters of both sexes are present in each. Then as each somatic cell is descender without segregation from the fertilised ovum, we may suppose that the presence of the sex-chromosomes in the somatic cells themselves in some way determines whether male or female characters shall develop, without the aid of any hormones from the gonads. 
This theory would be quite compatible with the belief that adaptive somatic sex-characters may be due to external stimulation, for supposing that the hypertrophy or modification is conveyed to the determinants in the gametocytes, and was confined to one sex, e.g. the male, then these determinants would be modified in association with the sexchromosomes of that sex, and thus though after reduction and fertilisation they would be present in the female zygote also, they would not develop in that sex. Thus supposing $M$ to represent a modification acquired in the male and $m$ the absence of the modification, such as the feathered antenna of a moth, and the sex-chromosomes to be $X$ and $Y$, then we should have in the gametocytes-

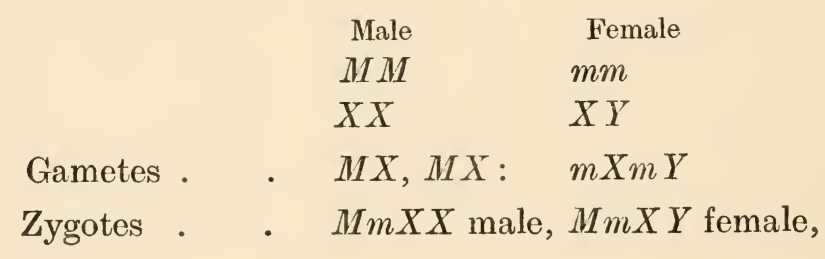

and the character $M$ would only appear in the male because it only develops in association with $X X$ in the somatic cells descended from the male zygote. This would be the result in the first generation in which a somatic modification affected the factors in the chromosomes. In the next generation $m$ in the male would be affected, and the male for the sake of simplicity might be supposed to become $M M X X$. When the female gametes segregated, some would always be $m Y$, and some zygotes therefore $M X m Y$. Others might be $M M X Y$. On this theory, therefore, there would always be some females heterozygous for the male character. 
Geoffrey Smith, one of the many promising young scientific investigators whose careers were cut short in the War, maintained views concerning somatic sex-characters different from that which explains their development as due to a hormone from the testis or ovary. Nussbaum in $1905^{1}$ had recorded experiments on Rana fusca (which is identical with the British species commonly called $R$. temporaria) which appeared to prove that in the male frog after castration the annual development of the thumb-pad and the muscles of the fore-leg does not take place, and if these organs have begun to enlarge before castration they atrophy again. When pieces of testis were introduced into the dorsal lymph-sac of a castrated frog the thumb-pads and muscles developed as in a normal frog. Geoffrey Smith and Edgar Schuster ${ }^{2}$ investigated the subject again with results contrary to those of Nussbaum.

Smith and Schuster begin by describing the normal cycle of changes in the testes on the one hand and the thumb-pad on the other. After the discharge of the spermatozoa in March or April the testes are at their smallest size. From this time onwards till August they steadily increase in size, attaining their maximum at the beginning of September. From then till the breeding season no increase in size or alteration of cellular structure occurs, the testes apparently remaining in a state of complete inactivity during this period. With regard to internal development, after the discharge of spermatozoa in the breeding season the spermatogonia divide and

1 'Ergebnisse der Anat. und Entwicklungsgesch.,' Bd. xv.: l'flugers Archiv, Bd. cxxvi., 1909.

${ }^{2}$ Quart. Journ. Mic. Sci., Ivii., 1911-12. 
proliferate, forming groups of cells known as spermatocysts. In June and July spermatogenesis is active, and from August to October the formation of ripe spermatozoa is completed.

The corresponding changes in the thumb-pads are as follows. Immediately after the breeding season the horny epidermis of the pad with its deeply pigmented papillae is cast off, and the thumb remains comparatively smooth from April or May until August or September. When the large papillae are shed, smaller papillae remain beneath, and are gradually obliterated by the epidermis growing up between them. The epidermis is therefore growing while the spermatogenesis is taking place. In August and September the epidermic papillae begin to be obvious, and from this time till February a continuous increase in the papillae and their pigmentation occur. Geoffrey Smith argues that the development of this somatic character occurs while the testes are inactive and unchanged. Considering that the testes throughout the winter months are crammed with spermatozoa, which must require some nourishment, and which may be giving off a hormone all the time, the argument has very little weight. Smith and Schuster found that ovariotomy, with or without subsequent implantation of testes or injection of testis extract, had no effect in causing the thumb of the female to assume any male characters.

Castration during the breeding season causes the external pigmented layer with its papillae to be cast off very soon-that is to say, it has the same effect as the normal discharge of the spermatozoa. Smith and Schuster found that castration at other 
seasons caused the pad to remain in the condition in which it was at the time, that there was no reduction or absorption as Nussbaum and Meisenheimer found, and that allo-transplantation of testes-that is, the introduction of testes from other frogs either into the dorsal lymph-sacs or into the abdominal cavity-or the injection of testis extract, had no effect in causing growth or development of the thumb-pad.

There seems to be one defect in the papers of both Nussbaum and Smith and Schuster-namely, that neither of them mentions or apparently appreciates the fact that the thumb-pads, apart from the dermal glands, consist of horny epidermis developed from the living epidermis beneath. The horny layer is not shown clearly in the figures of Smith and Schuster. It seems impossible that the horny layer or its papillae could atrophy in consequence of castration, or be absorbed. The horny part of the frog's thumb-pad is comparable with the horny sheath of the horns in the mammalian Prong-buck (Antilocapra) which are shed after the breeding season and annually redeveloped. Meisenheimer claims that he produced development of papillae on the thumb-pad, not only by implantation of pieces of testis, but also by implantation of pieces of ovary. This seems so very improbable that it suggests a doubt whether the same investigator was not mistaken with regard to the results of his experiments in transplanting gonads in Moths.

Smith and Schuster conclude that the normal development of the thumb-pad depends on the presence of normal testes, but that there is no sufficient evidence that the effect is due to a hormone derived from the testis. It is equally probable, 
according to Smith, that the testicular cells take up some substance or substances from the blood, thus altering the composition of the latter and perhaps stimulating the production of these substances in some other organ of the body. These substances may be provisionally called sexual formative substances. Smith's theory therefore is that the action of the testes in metabolism is rather to take something from the blood than to add something to it, and that it is this subtractive effect which influences the development of somatic sexual organs.

Geoffrey Smith in fact, in the paper above considered, attempts to apply to the frog the views he put forward ${ }^{1}$ in relation to the effect of the parasite Sacculina on the sexual organs of crabs. The species in which he made the most complete investigation of the influence of the parasite was Inachus scorpio (or dorsettensis). Figures showing the changes in the abdomen produced by the presence of Sacculina are given in Doncaster's Determination of Sex, Pl. xv. Sacculina is one of the Cirripedia, and therefore allied to the Barnacles. It penetrates into the crab in its larval stage, and passes entirely into the crab's body, where it develops a system of branching root-like processes. When mature the body of the Sacculina containing its generative organs forms a projection at the base of the abdomen of the crab on its ventral surface, and after this is formed the crab does not moult. Crabs so affected do not show the usual somatic sexual characters, and at one time it was supposed that only females were attacked. It is now known that both sexes of the

- Fauna und Flora des Golfes von Neapel, 29 Monographie Rhizocephala. 
host may be infected by the parasite, but the presence of the latter causes suppression of the somatic sex-differences. The entry of the parasite is effected when the crab is young and small, before the somatic sex-characters are fully developed. The gonads are not actually penetrated, at least in some cases, by the fibrous processes of the parasite, but nevertheless they are atrophied and almost disappear. In Inachus the abdomen of the normal male is very narrow and has no appendages except two pairs of copulatory styles. The abdomen of the female is very broad, and has four pairs of biramous appendages covered with hairs, the normal function of which is to carry the eggs. The effect of the parasite in the male is that the abdomen is broader, the copulatory styles reduced, and biramous hairy appendages are developed similar to those of the female, but smaller. In the female the abdomen remains broad, but the appendages are much smaller than in the normal female, about equal in size to those of the 'saceulinised' male. Smith interpreted the alteration in the male as a development of female secondary characters, but it is obvious from the condition in Macrura or tailed Decapods, like the lobster or erayfish, that the abdomen or tail of the male originally carried appendages similar to those of the female, and that the male character is a loss of these appendages. The absence of the male character therefore necessarily involves a development of these appendages, and there is not much more reason for saying that the male under the influence of the parasite develops female characters, than for saying that the male character is absent. There is no evidence in the facts con- 
cerning parasitic castration for Geoffrey Smith's conclusion that the female characters are latent in the male, but the male characters not latent in the female: both return to a condition in which they resemble each other, and the primitive form from which they were differentiated.

By his studies of parasitic castration Geoffrey Smith was led to formulate a theory for the explanation of somatic sex-characters different from that of hormones. He found that in the normal female crab the blood contained fatty substances which were absorbed by the ovaries for the production of the yolk of the ova. When Sacculina is present these substances are absorbed by the parasite; the ovary is deprived of them, and therefore atrophies. In the male the parasite requires similar substances, and its demand on the blood of the host stimulates the secretion of such substances, so that the whole metabolism is altered and assimilated to that of the female. It is this physiological change which causes the development of female secondary characters. He describes this change as the production of a hermaphrodite sexual formative substance, on the ground that in at least one case eggs were found in the testis of a male Inachus which had been the host of a Sacculina, but had recovered. It must however be noted that the Sacculina itself is hermaphrodite, with ovaries much larger than the testes. It is possible that while the parasite prevents the development of testis or ovary in the host, it gives up to the body of the host a hormone from its own ovaries which tends to develop the female secondary characters: for the parasite is itself a Crustacean, and therefore the hormone from its 
ovaries would not be of too different a nature to act upon the tissues of the host.

The observation of Geoffrey Smith that eggs may occur in the testis of a crab after recovery from the parasite appears of more importance than his peculiar theoretical suggestions, for it tends to show that sex is not always unalterably fixed at fertilisation. In this case the influence of a parasite predominantly female would seem to be the real cause of the development of eggs in the testis of the host. Geoffrey Smith does not discuss the origin of the somatic sexual characters in evolution, or attempt to show how his theories of sexual formative substance, and of the influence of the gonads by subtraction rather than addition, would bear upon the problem. 


\section{CHAPTER VI}

ORIGIN OF NON-SEXUAL CHARACTERS : THE PHENOMENA OF MUTATION

According to the theory here advocated, modifications produced by external stimuli in the soma will also be inherited in some slight degree in each generation when they have no relation to sex or reproduction. In this case the habits and the stimuli which they involve will be common to both sexes, and the hormones given off by the hypertrophied tissues will act upon the corresponding determinants in the gametocytes. The modifications thus produced will therefore be related to habits, and the theory will include all adaptations of structure to function, but other characters may also be included which are the result of stimuli and yet have no function or utility.

The majority of evolutionists in recent years have taught that influences exerted through the soma have no effect on the determinants in the chromosomes of the gametes, that all hereditary variations are gametogenic and none somatogenic. Mendelians believe that evolution has been due to the appearance of characters or factors of the same kind as those which distinguish varieties in cultivated organisms, and which are the subject of their experiments, but they have found a difficulty, as already mentioned in Chapter II, in forming any idea of the origin of a 
new dominant character. A recessive character is the absence of some positive character, and if in the cell-divisions of gametogenesis the factor for the positive character passes wholly into one cell, the other will be without it, will not ' carry' that factor. If such a gamete is fertilised by a normal gamete the organism developed from the zygote will be heterozygous, and segregation will take place in its gametes between the chromosome carrying the factor and the other without it, so that there will now be many gametes destitute of the factor in question. When two such gametes unite in fertilisation the resulting organism will be a homozygous recessive, and the corresponding character will be absent. In this way we can conceive the origin of albino individuals from a coloured race, supposing the colour was due to a single factor.

In Bateson's opinion the origin of a new dominant is a much more difficult problem. In 1913 he discussed the question in his Silliman Lectures. ${ }^{1} \mathrm{He}$ considers the diffieulty is equally hopeless whether we imagine the dominants to be due to some change internal to the organism or to the assumption of something from without. Accounts of the origin of new dominants under observation in plants usually prove to be open to the suspicion that the plant was introduced by some accident, or that it arose from a previous cross, or that it was due to the meeting of complementary factors. In medical literature, however, there are numerous records of the spontaneous origin of various abnormalities which behave as dominants, such as brachydactyly, and Bateson considers the authenticity of some of

1 Problems of Genetics, Oxford Univ. Press, 1913. 


\section{ORIGIN OF NON-SEXUAL CHARACTERS}

these to be beyond doubt. He concludes that it is impossible in the present state of knowledge to offer any explanation of the origin of dominant characters. In a note, however, he suggests the possibility that there are no such things as new dominants. Factors have been discovered which simply inhibit or prevent the development of other characters. For example, the white of the plumage in the White Leghorn fowl is due to an inhibiting factor which prevents the development of the colour factor which is also present. Withdraw the dominant inhibiting factor, and the colour shows itself. This is shown by crossing the dominant white with a recessive white, when some birds of the $F_{2}$ generation are coloured. ${ }^{1}$ Similarly, brachydactyly in man may be due to the loss of an inhibiting factor which prevents it appearing in normal persons. It is evident, however, that it is difficult to apply this suggestion to all cases. For example, the White Leghorn fowl must have descended from a coloured form, probably from the wild species Gallus bankiva. If Bateson's suggestion were valid we should have to suppose that the loss of the factor for colour caused the dominant white to appear, and then when this is withdrawn colour appears again, so that the colour factors and the inhibiting factors must lie over one another in a kind of stratified alternation. And then how should we account for the recessive white?

In his Presidential Address to the meeting of the British Association in Australia, 1914, Bateson explains his suggestion somewhat more fully with a command of language which is scarcely less remarkable than the subject matter. The more true-

1 Bateson, Principles of Heredity, p. 104. 
breeding forms are studied the more difficult it is to understand how they can vary, how a variation can arise. When two forms of Antirrhinum are crossed there is in the second generation such a profusion of different combinations of the factors in the two grandparents, that Lotsy has suggested that all variations may be due to crossing. Bateson does not agree with this. He believes that genetic factors are not permanent and indestructible, but may undergo quantitative disintegration or fractionation, producing subtraction or reduction stages, as in the Picotee Sweet Pea, or the Dutch Rabbit. Also variation may take place by loss of factors as in the origin of the white Sweet Pea from the coloured. But regarding a factor as something which, although it may be divided, neither grows nor dwindles, neither develops nor decays, the Mendelian cannot conceive its beginning any more than we can conceive the creation of something out of nothing. Bateson asks us to consider therefore whether all the divers types of life may not have been produced by the gradual unpacking of an original complexity in the primordial, probably unicellular forms, from which existing species and varieties have descended. Such a suggestion in the present writer's opinion is in one sense a truism and in another an absurdity. That the potentiality of all the characters of all the forms that have existed, pterodactyls, dinosaurs, butterflies, birds, etc. etc., including the characters of all the varieties of the human race and of human individuals, must have been present in the primordial ancestral protoplasm, is a truism, for if the possibility of such evolution did not exist, evolution would not have taken place. But that every distinct heredi- 


\section{ORIGIN OF NON-SEXUAL CHARACTERS}

tary character of man was actually present as a Mendelian factor in the ancestral $A$ mocba, and that man is merely a group of the whole complex of characters allowed to produce real effects by the removal of a host of inhibiting factors, is incredible. The truth is that biological processes are not within our powers of conception as those of physics and chemistry are, and Bateson's hypothesis is nothing but the old theory of preformation in ontogeny. Just as the old embryologists conceived the adult individual to be contained with all its organs to the most minute details within the protoplasm of the fertilised ovum or one of the gametes, so the modern Mendelian, because he is unable to conceive or to obtain the evidence of the gradual development of a hereditary factor, conceives all the hereditary factors of the whole animal kingdom packed in infinite complexity within the protoplasm of the primordial living cells. That man is complex and Amoba simple is merely a delusion; the truth according to Mendelism is that man is merely a fragment of the complexity of the original Amoba.

Mendelism studies especially the heredity of characters, and only incidentally deals with recorded instances of the appearance of new forms, such as the origin of a salmon-coloured variety of Primula from a crimson variety. The occurrence of new characters, or mutations as they are called, has been specially studied by other investigators, and I propose briefly to consider the two most important examples of such research, namely, that by Professor T. H. Morgan, which deals with the American fruit - fly Drosophila, and the other which concerns the mutations of the genus of plants 
Enothera, exemplified by our well-known Evening Primrose.

Professor T. H. Morgan informs us ${ }^{1}$ that within five or six years in laboratory cultures of the fruitfly, Drosophila ampelophila, arose over a hundred and twenty-five new types whose origin was completely known. The first of these which he mentions is that of eye colour, differing in the two sexes, in the female dark eosin, in the male yellowish eosin. Another mutation was a change of the third segment of the thorax into a segment similar to the second. Normally the third segment bears minute appendages which are the vestiges of the second pair of wings; in the mutant the wings of the third segment are true wings though imperfectly developed. A factor has also occurred which causes duplication of the legs. Another mutation is loss of the eyes, but in different individuals pieces of the eye may be present, and the variation is so wide that it ranges from eyes which until carefully examined appear normal, to the total absence of eyes. Wingless flies also arose by a single mutation. These were found on mating with normal specimens to be all recessive characters, thus agreeing with Bateson's views. The next one deseribed is dominant. A single male appeared with a narrow vertical red bar instead of the broad red normal eye. When this male was bred with normal females all the eyes of the offspring were narrower than the normal eye, though not so narrow as in the abnormal male parent. It may be pointed out that this is scarcely a sufficient proof of dominance. If the mutation

1 A Critique of the Theory of Evolution (Oxford Univ. Press, 1916), p. 60 . 
were due to the loss of one factor affecting the eye, the heterozygote carrying the normal factor from the mother only might very well develop a somewhat imperfect eye.

Morgan arranges the numerous mutations observed in Drosophila in four groups, corresponding in his opinion to the four pairs of chromosomes occurring in the cells of the insect. After the meiotic or reduction divisions each gamete of course contains in its nucleus four single chromosomes. One of the four pairs consists of the sex-chromosomes. All the factors of one group are contained in one chromosome, and it is found in experiments that the members of each group tend to be inherited together-that is to say, if two or more enter a cross together, in other words, if a specimen possessing two or more mutations is crossed with another in which they are absent, they tend to segregate as though they were a single factor. This fact agrees with the hypothesis that the factors in such a case are contained in a single chromosome which segregates from the fellow of its pair in the reduction divisions. Exceptions may occur, however, and these are explained by what is called 'crossing over.' When one chromosome of a pair, instead of being parallel to the other in the gametocyte, crosses it at a point of contact, then when the chromosomes separate, part of one chromosome remains connected with the part of the other on the same side and the two parts separate as a new chromosome, so that two factors originally in the same chromosome may thus come to lie in different chromosomes. In consequence of this, two or more factors which are usually 'coupled' or inherited together may come to appear in different individuals. 
Morgan emphasises the statement that a factor does not affect only one particular organ or part of the body. It may have a chief effect in one kind of organ, e.g. the wings or eyes, but usually affects several parts of the body. Thus the factor that causes rudimentary wings also produces sterility in females, general loss of vigour, and short hind legs.

The facts to which I shall refer concerning Enothera are for the most part quoted on the authority of Dr. Ruggles Gates, and taken from his book The Mutation Factor in Evolution (London, 1915). The occurrence of mutations in Enotherc was first noticed by De Vries, the Dutch botanist, in the neighbourhood of Amsterdam in 1886. He found a large number of specimens of Enothera Lamarchiana growing in an abandoned potato-field at Hilversum, and these plants showed an unusual amount of variation. He transplanted nine young plants to the Botanic Garden of Amsterdam, and cultivated them and their descendants for seven generations in one experiment. Similar experiments have been made by himself and others. The large majority of the plants produced from the E. Lamarckiana by self-fertilisation were of the same form with the same characters, but a certain percentage presented 'mutations' - that is, characters different from the parent form, and in some cases identical with those of plants occurring occasionally among those growing wild in the field where the observations began. Nine of these mutants have been recognised and defined, and distinguished by different names. The characters are precisely described and in many cases figured by Gates in the volume cited above. The first mutant to be recognised-in 1887- 
was one called lata. It must be explained that the young plant of Enothera has practically no stem, but a number of leaves radiating in all directions from the growing point which is near the surface of the soil. The plant is normally biennial, and in the first season the internodes are not developed. This first stage is called the 'rosette.' From the reduced stem are afterwards developed one or more long stems with elongated internodes, bearing leaves and flowers. In the mutation lata the rosette leaves are shorter and more crinkled than those of Lamarckiana, and the tips of the leaves are very broad and rounded. The stems of the mature plant are short and usually more or less decumbent with irregular branches. The flowerbuds are peculiarly stout and barrel-shaped, with a protrusion on one side. The seed-capsules are short and thick, containing relatively few seeds, and the pollen is wholly or almost wholly sterile.

It is to be noted here, a fact emphasised by De Vries in his earliest publications on the subject, that in nearly all, if not all cases, a mutation does not consist in a peculiarity of a single organ, but in an alteration of the whole plant in every part. In this respect mutations as observed in Enothera seem to be in striking contrast to the majority of Mendelian characters. Mutation in fact seems to be a case of what the earlier Darwinians called correlation, while Mendelian characters may apparently be separated and rejoined in any combination. For example, in breeds of fowls any colour or any type of plumage may be obtained with single comb or with rose comb. In my own experiments on fowls the loose kind of plumage first known in the Silky fowl, which is white, 
could be combined with the coloured plumage of the type known as black-red. At the same time it must be borne in mind that since the factor, whether a portion of a chromosome or not, is transmitted in heredity as a part of a single cell, the gamete, and since every cell of the developed individual is derived by division from the single zygote cell formed by the union of the two gametes, the factor or determinant must be contained in every cell of the soma, except in cases where differential division, or what is called somatic segregation, takes place. Thus the factor which eauses the comb to be a rose comb in a fowl must be present in the cells that produce the plumage or the toes or any other part of the body. Morgan, as mentioned above, finds in Drosophile that factors do affect several parts of the body. It is, however, curious to consider that the factor which produces intense pigmentation of the skin and all the connective tissue in the Silky fowl has no effect on the colour of the plumage in that breed, which is a recessive white. The plumage is an epidermic structure, and therefore distinct from the connective tissue, but it is difficult to understand why a pigment factor though present in every cell has no effect on epidermic cells.

The Mendelians, when the mutations of Enothera were first described, endeavoured to show that they were merely examples of the segregation of factors from a heterozygous combination. They suggested in fact that Enothera Lamarckiana was the result of a cross, or repeated crosses, between plants differing in many factors, that the numerous mutations were similar to the variety of different types which are produced by breeding together the grey 
mice arising from a cross between an albino and a Japanese waltzing mouse in Darbishire's experiment. Since that time, however, the natural distribution and the cultural history of Enothera has been very thoroughly worked out. Enothera Lamarckiana is the common Evening Primrose of English gardens. The species of the sub-genus Onagra to which Lamarckiana belongs were originally confined to America (Canada, United States, and Mexico), but Lamarckiana itself has never been found there in a wild state. Attempts, however, to produce it by crossing of other forms have not succeeded, and a specimen has been discovered at the Muséum d'Histoire Naturelle at Paris, collected by Michaux in North America about 1796, which agrees exactly with the Enothera Lamarckiana naturalised or cultivated in Europe. The plant was first described by Lamarck from plants grown in the gardens of the Muséum d'Histoire Naturelle, under the name $\mathscr{E}$. grandiflora, which had been introduced by Solander from Alabama, but Seringe subsequently decided that Lamarck's species was distinct from grandiflora, and named it Lamarckiana. Gates states that Michaux was in the habit of collecting seeds with his specimens, and that it is therefore highly probable that Lamarck's specimens were grown directly from seeds collected in America by Michaux. Gates considers that the suggestion of the hybrid origin of Lamarckiana in culture is thus finally disposed of. By the year 1805, Lamarckiana was apparently naturalised and flourishing on the coast of Lancashire, and in 1860 it was brought into commerce, probably from these Lancashire plants, by Messrs. Carter. The cultures of De Vries are 
descended from these commercial seeds, but the Swedish race of Lamarckiana, as well as those of English gardens, differ in several features and must have come from another source or been modified by crossing with grandiflora. This last remark is quoted from Gates, but it seems improbable that the Dutch plants should be derived from those of Lancashire, and those of English gardens from a different source. The fact seems to be, according to other parts of Gates's volume, that there are various races of Lamarckiana in English gardens and in the Isle of Wight, as well as in Sweden, etc., and that these races differ from one another less than the mutants of De Vries and his followers.

An important point about these mutations is that their production is a constant feature of Lamarckiana. Whenever large numbers of the seeds of this plant are grown, a certain proportion of the plants developed present these same mutations; not always all of them-some may be absent in one culture, present in another, but four of them are fairly common and of constant occurrence. The total proportion of mutant plants compared with the normal was 1.55 per cent. in one family, 5.8 per cent. in another. It would appear therefore, supposing that mutations arose subsequently in the same determinate way from previous mutations, that evolution, though in a number of divergent directions from one ancestral form, would proceed along definite lines, and that there would be nothing accidental about it. We should thus arrive at a demonstration of what Eimer called orthogenesis, or evolution in definite directions.

The mutation lata cannot be said to breed true, as 


\section{ORIGIN OF NON-SEXUAL CHARACTERS}

the pollen is almost entirely sterile. It has therefore been propagated by crossing with Lamarckiana pollen, with the result that both forms are obtained with lata varying in proportion from 4 per cent. to 45 per cent.

Rubrinervis is a mutation from Lamarckiana, chiefly distinguished by red midribs in the leaves and red stripes on the sepals. When propagated from self-fertilised seed it produced about 95 per cent. of offspring with the same characters, and the remaining 5 per cent. mutants, one of which was laevifolia which had been found by De Vries among plants growing wild at Hilversum. Gates obtained a single plant among offspring of rubrinervis in which the sepals were red throughout, and to this he gave the name rubricalyx. When selfed this plant gave rise to both rubricalyx and rubrinervis, and in the second generation when the rubricalyx was selfed again the numbers of the two were approximately 3 to 1. Rubricalyx is therefore a dominant heterozygote, and this fact was further confirmed in the third generation when a selfed plant gave 200 offspring all rubricalyx, the mother plant having evidently been homozygous for the red character. In this case, therefore, we have what Bateson was seeking, the origin of a new dominant character under observation, the original mutation having arisen in a single gamete of the zygote which gave rise to the plant. It is claimed by mutationists that mutations are not new combinations or separations of Mendelian unit characters already present, but are themselves new characters, though not always necessarily, as in the case of rubricalyx, new unit characters in the Mendelian sense. 
Perhaps the most interesting of the researches on the phenomena of mutation are those concerning the relation of the characters to the chromosomes of the cell, in which Gates has been a pioneer and one of the most industrious and successful investigators. The behaviour of the chromosomes in meiosis or reduction division both in the pollen mother-cells and in the megaspore mother-cells which give rise to the so-called embryo-sac are fully described by Gates. Here it is only necessary to refer to the abnormalities in the reduction division which are related to mutation, and the results of these abnormalities in the number of chromosomes. The original number of chromosomes in Enothera is 14. In the mutation lata this has become 15, and also in another mutation called semilata. The chromosomes before the reduction division are arranged in pairs, each pair consisting, it is believed, of one paternal and one maternal chromosome. One of each pair goes into one daughter-cell and the other into the other, but not all maternal into one and all paternal into the other. Thus each daughter-cell after the first or heterotypic division in normal cases contains 7 chromosomes. A second homotypic division takes place in which each chromosome splits into two as in somatic divisions, and thus we have 4 gametes with 7 chromosomes each. Now when lata is produced it is believed that in the heterotypic division one pair passes into one daughter-cell instead of one chromosome of the pair into each daughter-cell, the other pairs segregating in the usual way. We thus have one daughter-cell with 8 chromosomes and the other with 6 . This $6+8$ distribution has actually been observed in the pollen mother-cell in rubrinervis. 
When a gamete with 8 chromosomes unites in fertilisation with a normal gamete with 7 the zygote has 15. The lata mutants having an odd chromosome are almost completely male-sterile, and their seed production is also much reduced: but this partial sterility cannot be attributed entirely to the odd chromosome because semilata, which has also 15 chromosomes, does not show the same degree of sterility.

Other cases occur in which the number of chromosomes in the somatic cells is double the ordinary number - namely, 28 - and others in which the number is 21 . The normal number in the gamete, 7 , is considered the simple or haploid number, and therefore the number 28 is called tetraploid. This doubling of the somatic number of chromosomes is now known in a number of plants and animals. It occurs in the Enothera mutant gigas. The origin of it has not been clearly made out, but it must result either from the splitting of each chromosome or from the omission of the chromosome reduction. In many cases the more numerous chromosomes are individually as large as those in normal plants, and consequently the nucleus is larger, the cell is larger, and the whole plant is larger in every part. But giantism may occur without tetraploidy, and vice versa. In the Enothera gigas the rosette leaves are broadly lanceolate with obtuse or rounded tips, more crinkled than in Lamarckiana, petioles shorter. The stem-leaves are also larger, broader, thicker, more obtuse, and more crinkled than in Lamarckiana. The stem is much stouter, almost double as thick, but not taller because the upper internodes are shorter and less numerous. It is difficult to avoid 
the conclusion that the stouter character of the organs in this plant is causally connected with the increased number of chromosomes. Where the number of cells formed is approximately similar, as in two allied forms of plant in this case, the greater size of the cells would naturally give a stouter habit, but it is clear that large cells do not necessarily mean greater size. The cells of Salamander and Proteus are the largest found among Vertebrates, but those Amphibia are not the largest Vertebrates. It is curious to note how different are these discoveries concerning differences in the number of chromosomes from the conception of Morgan that a mutation depends on a factor situated in a part of one chromosome.

More copious details concerning mutations will be found in the publications cited. The question to be considered here is how far the claim is justified that the facts of this kind hitherto discovered afford an explanation of the process of evolution. It seems probable that mutations are of different kinds, as exemplified in Enothera by gigas and rubricalyx respectively, the former producing only sterile hybrids, the latter behaving exactly like a Mendelian unit. There can be little doubt that, as Bateson states, numerous forms recognised as species or varieties in nature differ in the same way as the races or breeds of cultivated organisms which differ by factors independently inherited. There are facts, however, which prove that all species are not sterile inter se, and that their characters when they are hybridised do not always segregate in Mendelian fashion. John C. Phillips, ${ }^{1}$ for example, crossed

1 Journ. Exper. Zool., vol. xviii., 1915. 
three wild species of duck, Anas boscas (the Mallard) with Dafila acuta (the Pintail) and with Anas tristis. In the former cross he states that except for one or two characters there seemed to be no more tendency to variation in the $F_{2}$ generation than in the $F_{1}$. An $F_{1}$ Pintail-Mallard o was mated with a wild Pintail $\delta$. According to Mendelian expectation the offspring of this mating should have been half Pintail and half Pintail-Mallard hybrids, but Phillips states that on casual inspection the plumage of all the males appeared pure Pintail although the shape was distinctly Mallard-like. The statement is, however, open to criticism. The question is, what were the unit characters in the parent species? If the unit characters were very small and numerous, an individual in which all the characters of the Pintail existed together among the offspring of the hybrid mated with pure Pintail would be rare in proportion to the individuals presenting other combinations. Of the $\mathrm{F}_{2}$ 's obtained from crossing Anas tristis of with Anas boscas o, Phillips obtained 23 females and 16 males. The females were all alike and similar to $F_{1}$ females. Of the males one was a variate specially marked, about half-way between the $F_{1}$ type and the Mallard parent. This, according to Phillips, was a segregate. The rest showed a range of variation but no distinct segregation.

It is somewhat surprising that Mendelian experts, who seem to believe that species are distinguished by Mendelian characters, have not made systematic experiments on the crossing of species in order to prove or disprove their belief.

For my own part I cannot help thinking that the origin of varieties in species in a domesticated or 
cultivated state is in a sense pathological. Such variation doubtless occurs in nature, but not with such luxuriance. The breeds of domestic fowls differ so greatly that Bateson and others refuse to believe that they have all arisen from the single species Gallus bankiva. It seems to me from the evidence that there cannot be any doubt that they have so arisen. One fact that impresses my mind is that if we consider colour variations in domesticated animals, we find that a similar set of colours has arisen in the most diverse kinds of animals with sometimes certain markings or colours peculiar to one group, e.g. dappling in horses, wing bars in pigeons. Thus in various kinds of Mammals and Birds we have white and black, red or yellow, chocolate with various degrees of dilution, and piebald combinations. Why should forms originally so different, as the cat with its striped markings and the rabbit with no markings at all, give rise to the same colour varieties? It seems probable that the reason is that the original form had the small number of pigments which occur mixed together in very small particles, and that in the descendants the single pigments have separated out, with increase or decrease in different cases. It is true that historical evidence tends to show that the greatest variations, such as albinism in one direction or excess of pigment in the other in the Sweet Pea, were the first to arise (see Bateson, Presidential Address to British Association, Australia, 1914, Part I.), and the splitting appears often to be intentionally produced by crossing these extreme variations with the original form, but the possibility remains that the conditions of domestication, abundant food, security and reduced 
activity, lead to irregularity in the process of heredity. In any case the mere separation among different individuals of factors originally inherited together in one complex does not account for the origin of the complex or of the factors. This is somewhat the same idea as that of Bateson when he states that it is easy to understand the origin of a recessive character but difficult to conceive the origin of a dominant.

The point, however, which I desire most to emphasise is that the investigations we have been discussing are concerned with variations which have no relation whatever to adaptation, and afford no explanation of the evolution of adaptations. These variations perform no function in the life of the individual, have no relation to external conditions, either in the sense of being caused by special conditions or fitting the individual to live in special conditions. A still more important fact is that they do not explain the origin of metamorphosis. They do not arise by a metamorphosis : in the case of the rose comb of fowls the chick is not hatched with a single comb which gradually changes into a rose comb, but the rose comb develops directly from the beginning. Mutationists and Mendelians do not seem in the least to appreciate the importance of metamorphosis or of development generally in considering the relation of the mutations or factors which they study to evolution in general, because they have not grasped the fact that there are two kinds of characters to be explained, adaptational and non-adaptational. T. H. Morgan, for example, ${ }^{1}$

1 A Critique of the Theory of Evolution, p. 67 (Princeton, U.S.A., and London, 1916). 
describes a mutation in Drosophila consisting in the loss of the eyes, and triumphantly remarks: 'Formerly we were taught that eyeless animals arose in caves. This case shows that they may also arise suddenly in glass milk-bottles by a change in a single factor.' As it stands the statement is perfectly true, but it is obvious that the writer does not believe that the darkness of caves ever had anything to do with the loss of eyes. It is almost as though a man should discover that blindness in a certain case was due to a congenital, i.e. gametic, defect, and should then scoff at the idea that any person could become blind by disease. Some of those who specialise in the investigation of genetics seem to give inadequate consideration to other branches of biology. It is a well-established fact that in the mole, in Proteus, and in Amblyopsis (the blind fish of the Kentucky caves), the eyes develop in the embryo up to a certain stage in a perfectly normal way and degenerate afterwards, and that they are much better developed in the very young animal than in the adult. Does this metamorphosis take place in the blind Drosophila of the milk-bottle? The larva of the fly is, I believe, eyeless like the larvae of other Diptera, but Morgan says nothing of the eye being developed in the imago or pupa and then degenerating. There is therefore no relation or connexion between the mutation he describes and the evolution of blindness in cave animals. It is a truth, too often insufficiently appreciated by biologists, that sound reasoning is quite as important in science as fact or experiment. Loeb ${ }^{1}$ also endeavours to prove that the blindness of cave animals is no

1 The Organism as a Whole, p. 319 (New York and London, 1916). 
evidence of the influence of darkness in causing degeneration of the eyes. He refers to experiments by Uhlenhuth, who transplanted eyes of young Salamanders into different parts of their bodies where they were no longer connected with the optic nerves. These eyes underwent a degeneration which was followed by a complete regeneration. He showed that this regeneration took place in complete darkness, and that the transplanted eyes remained normal when the Salamanders were kept in the dark for fifteen months. Hence the development of the eyes does not depend on the influence of light or on the functional action of the organs. But it must be obvious to any biologist who has thoroughly considered the problem, that this experiment has little to do with the question of the cause of blindness in cave animals. No one ever supposed that cave fishes became blind in fifteen months, or in fifteen years. The experiment cited merely proves that in the individual the embryonic or young eye will continue developing by heredity even after it is transplanted and in the absence of light. But the eye of the Mammal normally develops in the uterus in the absence of light.

In his remarks concerning Typhlogobius, a blind fish on the coast of southern California, Loeb seems to be mistaken with regard to the facts. He states that this fish lives 'in the open, in shallow water under rocks, in holes occupied by shrimps.' According to Professor Eigenmann the same species of shrimp is found all over the Bay of San Diego, and is accompanied by other genera of goby, such as Clevelandia and Gillichthys, which have eyes: but these fishes live outside the holes, and only retreat 
into them when frightened, while the blind species is found only at Point Loma, and never leaves the burrows of the shrimp. It would appear, therefore, that Typhlogobius lives in almost if not quite complete darkness, instead of being, as Loeb states, 'blind in spite of exposure to light,' while the closely allied forms which are exposed to light are not blind.

Loeb states, on the authority of Eigenmann, that all those forms which live in caves were adapted to life in the dark before they entered the cave, because they are all negatively heliotropic and positively stereotropic, and with these tropisms would be forced to enter a cave whenever they were put at the entrance. Even those among the Amblyopsidae which live in the open have the tropisms of the cave dweller. But these latter are not blind, and the argument only tends to show that the blind fish Amblyopsis entered the caves before it was blind. Nocturnal animals generally must be said to be negatively heliotropic, but these usually have larger and more sensitive eyes than the diurnal.

It is said, however, that Chologaster agassizii, which is not blind, lives in the underground streams of Kentucky and Tennessee, but I think it is open to doubt whether it is a species entirely confined to darkness.

Another point which Loeb omits to mention is the absence of pigment in cave animals, especially Vertebrates such as Amblyopsis and Proteus. If absence of light is not the cause of blindness in these cases, how is it that the blindness is always associated with absence of pigment, since we know that the latter in Fishes and Amphibia is due to the 
absence of light? It has been shown that Proteus when kept in the light develops some amount of pigment, although it does not become pigmented to the same degree as ordinary Amphibia. We have here, I think, an example of the essential difference between mutations and somatic modifications. Absence of the gametic factor or factors for pigmentation results in albinism, and no amount of exposure to light produces pigmentation in albinos, e.g. albino Axolotls which are well known in captivity. Absence of light, on the other hand, prevents the development of pigment. The question therefore is whether the somatic modification is inherited. The fact that Proteus does not rapidly become as deeply coloured when exposed to light as ordinary Amphibia shows that the gametic factors for pigmentation have been modified as well as the somatic tissues.

Loeb attributes the blindness of cave fishes to a disturbance in the circulation and mutation of the eyes originally occurring as a mutation. But how could an explanation of this kind be applied to the case of Anableps tetrophthalmus, in which each eye is divided by a partition of the cornea and lens into an upper half adapted for vision in air and a lower half for vision in water? This fish lives in the smooth water of estuaries in Central America, and swims habitually with the horizontal partition of the lens level with the surface of the water. It is impossible to understand in this case, firstly, how a mutation could cause the eyes to be divided and doubly adapted to two different optic conditions, and, secondly, how at the same time a convenient 'tropism' should occur which caused the animal 
to swim with its eyes half in and half out of water. Are we to suppose that the upper half of the body or eye had a positive heliotropism and the lower half a negative heliotropism? The fact is that the fish swims at the surface in order to watch for and feed on floating particles. The tropism concerned is the food tropism, but what is gained by calling the search for food common to all active animals a tropism, and how is the search for food before the food is perceptible to the senses, before it can act as a stimulus on a food-sensitive substance in the body, to be compared to a tropism at all ?

Loeb undertakes to prove that the organism as a whole acts automatically according to physicochemical laws. But he misses the question of evolution altogether. For example, he quotes Gudernatsch as having proved that legs can be induced to grow in tadpoles at any time, even in very young specimens, by feeding them with thyroid gland. Loeb writes: 'The earlier writers explained the growth of the legs in the tadpole as a case of an adaptation to life on land. We know through Gudernatsch that the growth of the legs can be produced at any time by feeding the animal with the thyroid gland.' Obviously he thinks that these two propositions are contradictory to each other, whereas there is no contradiction between them at all. Loeb actually supposes that the thyroid is the cause of the development of the legs. Logically, if this were the case it would follow that if we fed an eel or a snake with thyroid it would develop legs like those of a frog, and if a man were injected with extract of the testes of a stag he would develop antlers on his forehead. It will be obvious to most 


\section{ORIGIN OF NON-SEXUAL CHARACTERS}

biologists that the thyroid, whether that of the tadpole itself or that which is supplied as food, only causes the development of legs because the hereditary power to develop legs is already present. The question is how this hereditary power was evolved. Legs are an adaptation to life on land. What we have to consider and to investigate is whether the legs arose as a gametic mutation or as a direct result of locomotion on land.

The general result of clinical and experimental evidence is to show that the hormone of the thyroid is necessary to normal development. The arrest of development in cretinous children is due to some deficiency of thyroid secretion, and is counteracted by the administration of thyroid extract. Excess of the secretion produces a state of restlessness and excitement associated with an abnormally rapid rate of metabolism and protrusion of the eye-balls (Graves' disease). The physiological text-books, however, say nothing of precocity of development in children as a result of hyperthyroidism. This, however, is undoubtedly what occurs in the case of tadpoles. The legs would naturally develop at some time or other, after a prolonged period of larval life. Feeding with thyroid causes them to develop at once. I have repeated Gudernatsch's experiment with the following results:-

This year I had a considerable number of tadpoles of the common English frog, which were hatched between March 26 and March 29. On April 12, when they had all passed the stage of external gills and developed internal gills and opercula, I divided them into two lots, one in a shallow pie-dish, the other in a glass cylinder. To one lot I gave a 
portion of rabbit's thyroid, to the other a piece of rabbit's liver. They fed eagerly on both. Afterwards I obtained at intervals of a week or so the thyroid of a sheep. I have seen no precise details of Gudernatsch's method of feeding tadpoles, but my own method was simply to put a piece of thyroid into the water containing the tadpoles and leave it there for several days, then to take it out and put in another piece, changing the water when it seemed to be getting foul.

April 22. Noticed that the non-thyroid tadpoles were larger than those fed on thyroid. Changed the former into the pie-dish and the latter into the glass jar, to make sure that the difference in size was not due to larger space.

May 3. Only eighteen of the non-thyroid tadpoles surviving, owing to the water having become foul, but these are three times as large as those fed on thyroid. In the latter no trace of hind-legs was visible, but the abdominal region was much emaciated and contracted, while the head region was broader.

May 4. Noticed minute white buds of hind-legs in the thyroid-fed tadpoles.

May 6. A number of the thyroid-fed were dying, and the skin and opercular membranes were swollen out away from the tissues beneath.

Largest normal tadpole, . . $2 \cdot 7 \mathrm{~cm}$. long.

$$
\begin{gathered}
\text { body, } 1 \cdot 0 \quad, \\
\text { tail, } 1 \cdot 7 \quad,
\end{gathered}
$$

Largest thyroid-fed tadpole, $1 \cdot 1 \mathrm{~cm}$. long.

body, $0.5 \quad$,
tail, $0.6 \quad$,

May 10. A great number of the thyroid-fed dead 


\section{ORIGIN OF NON-SEXUAL CHARACTERS}

and the rest dying, lying at the bottom motionless. They now had the tail much shorter, and the fore-legs showing as well as the hind, but the latter not very long, and without joints or toes.

Period from first feeding with thyroid, thirty days. I now decided to feed the controls with thyroid, expecting that as they were large and vigorous they would have strength enough to complete the metamorphosis and become frogs.

May 15. Fed the controls with thyroid for first time.

The smallest of them was in total length $1 \cdot 7 \mathrm{~cm}$.

$$
\begin{gathered}
\text { body, } 0.7, \\
\text { tail, } 1 \cdot 0,
\end{gathered}
$$

The largest measured was in total length $2 \cdot 2$, body, 0.8 , tail, $1 \cdot 4$,

May 25. All but two of the tadpoles dead. The tails were only half the original length, all had welldeveloped hind-legs, some with toes, but the fore-legs were beneath the opercula, not projecting from the surface.

Smallest total length, $1.2 \mathrm{~cm}$.
body, 0.5,
tail, 0.7,
Largest total length, 1.8,
body, 0.7,
tail, 1.1,

These last measurements were made after the tadpoles had been preserved in spirit, and were therefore doubtless somewhat less than in the fresh condition. Making allowance for this it is evident that the tails had undergone reduction as part of the 
metamorphosis, but the body was also shorter. There is some reason therefore for concluding that actual reduction in size of body occurs as the result of metamorphosis induced by thyroid feeding. As in the other case the skin and opercular membranes were distended by liquid beneath them.

The total period of the change in this second experiment was ten days.

I conclude that the amount of thyroid eaten was so excessive as to cause pathological conditions as well as precocious metamorphosis, so that the animals died without completing the process.

On June $10 \mathrm{I}$ still had four tadpoles which had never had thyroid, but only pieces of meat, earthworm, or fish. These were very much larger than any of the others, were active and vigorous, and the largest one showed small rudiments of hind-legs, the others none at all. 


\section{CHAPTER VII}

\section{METAMORPHOSIS AND RECAPITULATION}

As one of the most remarkable examples of metamorphosis and recapitulation in connexion with adaptation we will consider once more the case of the Flat-fishes which I have already mentioned in an earlier chapter. These fishes offer perhaps the best example of the difference between gametogenic mutations and adaptive modifications. In several species specimens occur occasionally in which the asymmetry is not fully developed. ${ }^{1}$ These abnormalities are most frequent in the Turbot, Brill, Flounder, and Plaice. The chief abnormal features are pigmentation of the lower side as well as of the upper, the eye of the lower side, left or right according to the species, on the edge of the head instead of the upper side, and the dorsal fin with its attachment ceasing behind this eye, the end of the fin projecting freely forwards over the eye in the form of a hook. Such specimens have been called ambicolorate, but it is an important fact that they are also ambiarmate-that is to say, the scales or tubercles which in the normal Flat-fish are considerably reduced or absent on the lower side, in these abnormal specimens are developed on the lower side almost as much as on the upper. Minor

${ }^{1}$ See 'Coloration of Skins of Fishes, especially of Pleuronectidae,' Phil. Trans. Royal. Soc., 1894. 
degrees of the abnormality occur: in Turbot with the hook-like projection of the dorsal fin the lower side of the head is often without pigment, while the rest of the lower side is pigmented. Less degrees of pigmentation of the lower side occur without structural abnormality of the eye and dorsal fin.

There is no evidence that these abnormalities are due to abnormal conditions of life. One specimen of Plaice of this type was kept alive in the aquarium, and it lay on its side, buried itself in the sand, and when disturbed swam horizontally, like a normal specimen. The abnormalities are undoubtedly mutations of gametic origin. The development of one of these abnormal specimens from the egg has not to my knowledge been traced, but there is no reason to suppose that the fish develops first into the normal asymmetrical condition and then changes gradually to the abnormal condition described. On the contrary, everything points to the conclusion that the abnormality is an arrest or incomplete occurrence of the normal process of development, i.e. of the normal metamorphosis. T. H. Morgan, in a volume published some years ago, ${ }^{1}$ put forward the extraordinary view that the Pleuronectidae arose from symmetrical fishes by a mutation which was entirely gametogenetic and entirely independent of habits or external conditions, and then finding itself with two eyes on one side of its head, and no airbladder, adopted the new mode of life, the new habit of lying on the ground on one side in order to make better use of its asymmetrically placed eyes. According to this view habits have been adapted to structure, not structure to habits. We are thus to

1 Evolution and Adaptation. 
believe that Amphibia came out of the water and breathed air because by an accidental mutation they possessed lungs and a pulmonary circulation capable of atmospheric respiration. Such is the result of applying conclusions derived from phenomena of one kind to phenomena of a totally different kind. One of the chief differences between structural features and correlations which are adaptive from those which are not is the process of metamorphosis, where we see the structure changing in the individual life history as the mode of life changes. The egg of the Flat-fish develops into a symmetrical pelagic larva similar to that of many other marine fishes. The larva has an eye on each side of its head and swims with its plane of symmetry in a vertical position: it has also colour on both sides equally. When the skeleton begins to develop the transformation takes place: the eye of one side, left in some species, right in others, moves gradually to the edge of the head and then on to the other side. The dorsal fin extends forward, preserving its original direction, and so passes between the eye that has changed its position and the lower side of the fish, on which that eye was originally situated. In some cases this extension of the fin takes place earlier and the eye passes beneath the base of the fin to reach the other side. Any one who takes the trouble to make himself acquainted with the facts will see that the three chief features of the Pleuronectid-namely, the position of the eyes, the extension of the dorsal and ventral fins, and the absence of pigment from the lower side-are not structurally correlated with one another at all as changes in different parts of the organism in a mutation are said to be, but are all 
closely related to their functions in the new position of the body. A mutation consisting in general asymmetry would be comprehensible, but the head of the Pleuronectid is not asymmetrical in a general sense, but only so far as to allow of the changed position of the eyes. The posterior end of the skull is as symmetrical as in any other fish, and in some cases the mouth and jaws are also symmetrical, entirely unaffected by the change in the position of the eyes. In other cases the jaws are asymmetrical in a direction opposite to that of the eyes, there is no change of position but a much greater development of the lower half of the jaws, reduction, with absence of teeth, of the upper half. In the latter case the fish feeds on worms and molluscs living on the ground and seized with the lower half of the jaws, in the former the food consists of small fish swimming above the Flat-fish and seized with the whole of the jaws (Turbot, Halibut, etc.).

I contend, then, that the mode in which the normal Flat-fish develops is quite different from that in which mutations arise. T. H. Morgan ${ }^{1}$ states that a variation arising in the germ-plasm, no matter what its cause, may affect any stage in the development of the next individuals that arise from it. In certain cases this is true, that is to say, when there are very distinct stages already. For example, a green caterpillar becomes a white butterfly with black spots. A mutation might affect the black spots, an individual might be produced which had two spots on each wing instead of one, and no sign of this mutation would be evident in the caterpillar. But my contention is that when this mutation

1 A Critique of the Theory of Evolution (1916), p. 18. 
occurred, the original condition of one spot would not be first developed and then gradually split into two. Morgan proceeds to state clearly what I wish to insist upon concerning mutations. He writes that in recent times the idea that variations are discontinuous has become current. Actual experience, he tells us, shows that new characters do not add themselves to the line of existing characters, but if they affect the adult characters, they change them without as it were passing through and beyond them.

Now in the case of the ancestors of the Flat-fish the adult and the larva must have had the same symmetry with regard to eyes and colour and the dorsal fin terminated behind the level of the eyes. Thus the variations which gave rise to the Flat-fish were not discontinuous but continuous. In each individual development now, not merely hypothetically in the ancestor, the condition of the adult arises by an absolutely continuous change of the eyes, fins, and colour. Such a continuous change cannot be explained by a discontinuous variation, i.e. a mutation. The abnormalities above mentioned on the other hand, although they doubtless arise from the same kind of symmetrical larva as the normal Flat-fish, and develop by a gradual and continuous process, do not presumably pass through the condition of the normal adult Flat-fish and then change gradually into the condition we find in them. As compared with the normal Flat-fish they arise by a discontinuous variation, they are mutations, whereas the normal Flat-fish as compared with its symmetrical ancestor arises by a continuous change.

In order to make my meaning clear I must point out that $I$ have been using the word continuous in a 
different sense from that in which it is used by other biologists, Bateson for example. The word has been applied previously to variations which form a continuous series in a large number of individuals, each of which differs only slightly from those most similar to it. No two individuals are exactly alike, and thus such continuous variations are universal. According to the theory of natural selection the course of evolutionary change in any organ or character would form a similar continuous series, the mean of each generation differing only by a small difference from that of the preceding. According to the modern mutationists such small differences are to be called fluctuations, and have no effect on evolution at all, are not even hereditary, are not due to genetic factors in the gametes. Discontinuous variations, on the other hand, are as a rule differences in an individual from the normal type and from its parents of considerable degree, and are conspicuous : these are what are called mutations.

The mutationists and Mendelians have not shown how the essential characteristics of mutations are to be reconciled with the facts of metamorphosis, or with recapitulation in development which is so often associated with metamorphosis. T. H. Morgan is the only mutationist, so far as my reading has gone, who has attempted to do this, and he seems to me to have failed to understand the difficulties or even the nature of the problem. He points out that the embryos of Birds and Mammals have gill slits representing the same structures as those of the adult Fish, but the young stage of the Fish also possessed gill slits, therefore it is " more probable that the Mammal and Bird possess this stage in their de- 
velopment simply because it has never been lost.' He concludes therefore that the gill slits of the embryo Pird represent the gill slits of the embryo Fish, and not the adult gill slits of the Fish, which have been in some mysterious way pushed back into the embryo of the Bird.

Morgan evidently does not realise that the Birds and Reptiles must have been derived from Amphibia, and that the embryo Reptile or Bird with gill slits and gill arches is merely a tadpole enclosed in an egg shell. The Frog in its adult state differs much from a Fish, while the larva in its gill arches and gill slits resembles a Fish. Morgan contends that the new characters do not add themselves to the end of the line of already existing characters. But in the case of the Frog this is exactly what they have done. The existing characters were in this case the gill arches and slits. Those who believe in recapitulation do not suppose that the animal had to live a second life added on to the life of its ancestors and that the new characters appeared in the second life. They believe that in the ancestor a certain character or general structure of body when developed persisted without change throughout life like the gill arches and slits in a Fish. At some stage of life before maturity this character underwent a change, and in the descendants the development of the original character and the change were repeated by heredity. There is no 'mysterious pushing back of adult characters into the embryo,' although it is possible or even probable that in some cases the change gradually became earlier in the life history: it is the new character which is pushed back, not the adult character of the ancestor. 
It is perfectly true, as Morgan says, that new characters which arise as discontinuous variations -in other words, those kinds of variation which are called mutations-do not add themselves to the line of already existing characters, but 'change the adult characters without as it were passing through and beyond them.' The mutations which Morgan describes in his own experiments on Drosophila illustrate this in every case. In no case is the original organ or character, e.g. wings, of the normal Fly first developed and then changed by a gradual continuous process into the new character. It might perhaps be said that this took place in the pupa, but that seems impossible, for the complete wing is not fully developed in the pupa. The same truth is equally apparent in the mutations described in Enothera. It follows, therefore, that none of the evolutionary changes which have produced what are called recapitulations can have been due to changes of that kind which is known as mutation.

The abnormalities in Pleuronectidae to which I have referred are of the kind usually regarded as due to arrested development. But closer consideration gives rise to doubt concerning the validity of this explanation. It might be supposed that the attached base of the dorsal fin is unable to extend forward because the eye on the edge of the head is in the way, but if the metamorphosis is arrested, why should the fin grow forward in a free projection? I have described a very abnormal specimen of Turbot in a paper communicated to the Zoological Society of London, ${ }^{1}$ and in that paper have discussed other possible explanations of these mutations. In the

1 Proc. Zool. Soc., 1907. 
specimen to which I refer the pigmentation instead of being present on both sides was reversed: the lower side was pigmented from the posterior end to the edge of the operculum (Plate II., fig. 2), while the upper side was unpigmented excepting a scattering of minute black specks and a little pigment on the head (Plate II., fig. 1). I have suggested that the explanation here is that in the zygote the primordia of a normal body and a reversed head have been united together. We may suppose that different parts of the body are represented in the gametes by different determinants or factors, and therefore it is possible that these factors may be separated. In the specimen we are considering the body is normal or nearly so, with the pigmentation on the left side, which is normal for the Turbot, while the head has both eyes with some pigment on the right side and the left side unpigmented. Reversed specimens occasionally occur in many species of Pleuronectidae, and if the determinants for a reversed head and a normal body were united in one zygote, the curious abnormality observed might be the result. It is just a possibility that if this fish which was only $4.4 \mathrm{~cm}$. long had lived to adult size, the upper side would have become pigmented under the influence of light, while the strong hereditary influence would have prevented the disappearance of the pigment from the lower side. In that case the adult condition would have been similar to that of ordinary ambicolorate specimens, but reversed, with eyes on the right side instead of the left. Other explanations of the more frequent ambicolorate mutation are possible: the body may consist of two left sides instead of a left and right, joined on to a normal 

PLATE II.

FIG. I UPPER SIDE, FIG. 2 LOWER SIDE OF AN ABNORMAL SPECIMEN OF THE TURBOT (RHOMBUS MAXIMUS). THE SPECIMEN WAS 4.4 CM. IN LENGTH, AND WAS CAPTURED ALIVE AT PADSTOW ON THE COAST OF CORNWALL. REPRODUCED BY PERMISSION OF THE COUNCIL FROM THE PROCLEDINGS OF THE ZOOLOGICAL SOCIETY. 


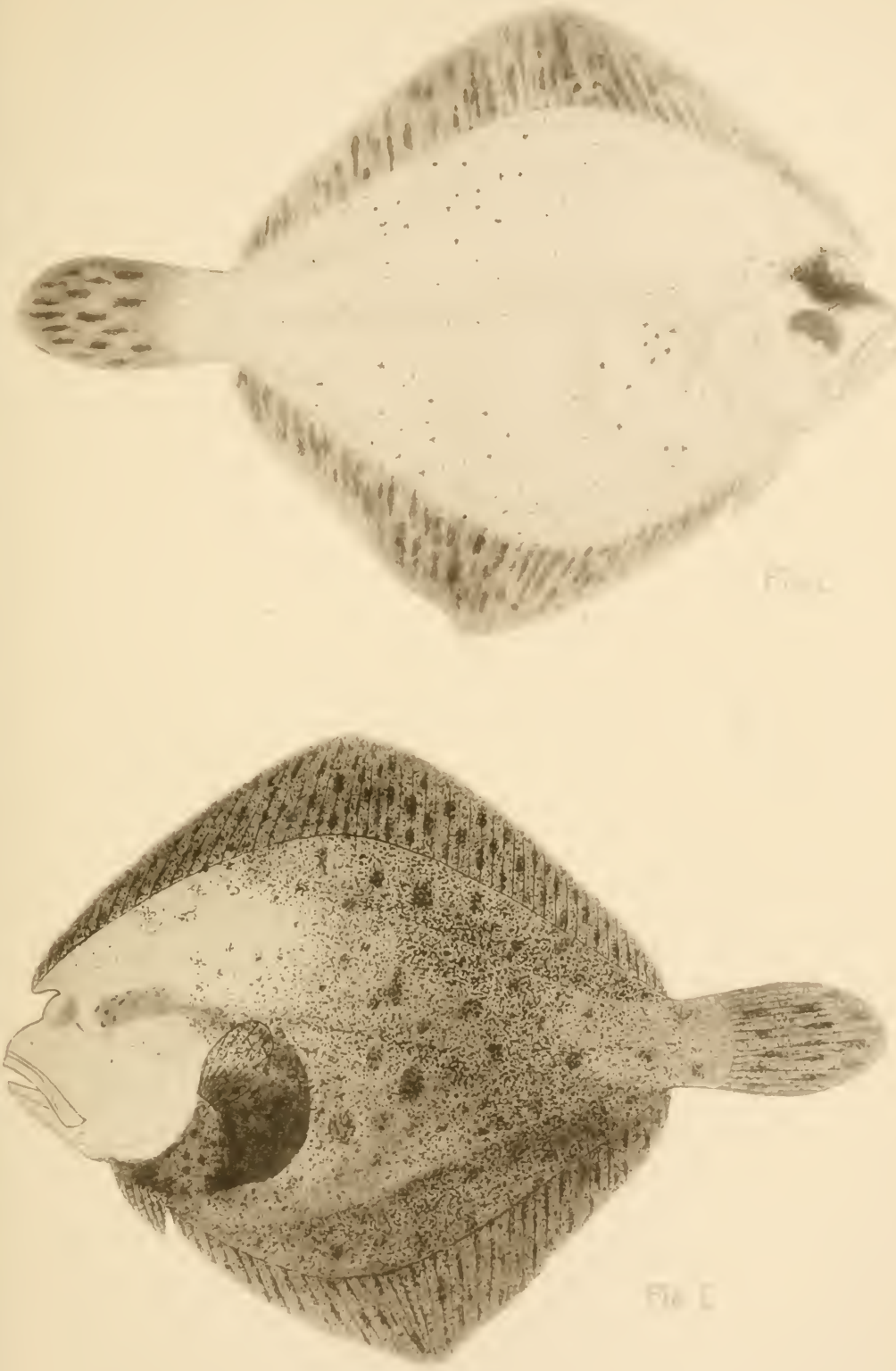



head. But the first suggestion seems the more probable, as two rights or two lefts would not be symmetrical. Supposing the head and body not properly to belong to each other, one being reversed and one normal, we can in a way understand why the dorsal fin does not form the usual connexion with the edge of the head, because the determinants would not be in the normal intimate relation to each other. In thus writing of reversed and normal it must be understood that the former word does not mean merely turned over, for in that case right side of the body would be joined to the left side of the head, and the dorsal fin would be next to the ventral side of the head, which is not the case. What is meant is that a left side of the body which is normally pigmented is joined to a left side of the head which instead of having both eyes has neither, the two eyes being on the right side of the head which is joined to the right side of the body, and this is normal and unpigmented. The dorsal fin belonging to the normal sinistral body would therefore have a congenital tendency in the metamorphosis to unite with the head on the outer side of the original lower or right eye after it has moved to the left side. Actually, however, in this abnormal specimen it finds itself on the outer side of the left eye which has passed to the right side, and it has no tendency to unite with this part of the head. At the same time it has no tendency to bend over at an angle to reach the outer side of the right eye, and therefore it grows directly forward without attachment to the head at all.

It will be seen, therefore, that what is changed in relative position in these mutations is not the actual parts of the body, but merely the characters of those 
parts. In a sinistral Flat-fish, whether it is normally sinistral like the Turbot or abnormally like a ' reversed' Flounder, the viscera are in the same position as in a dextral specimen : the liver is on the left side, the coils of the intestine on the right. Thus in a reversed or sinistral Flounder, which is normally dextral, the left side which is uppermost is still the left side, but it has colour and two eyes, whereas in the normal specimen the right side has these characters and not the left. Thus we are forced to conceive of the determinants in the chromosomes of the fertilised ovum which correspond to the two sides of the body, as entirely distinct from the determinants which cause the condition or 'characters' of the two sides, unless indeed we suppose that determinants of right side with eyes and colour occur in some gametes and of right side without eyes and colour in others, and vice versa, and that homozygous and heterozygous combinations occur in fertilisation. On this last hypothesis the mutation here considered might be a heterozygous specimen, with the dextral condition dominant in the head and the sinistral in the body. Or it might be somehow due to what Morgan and his colleagues have called crossing over in the segregation of heterozygous chromosomes, so that a part corresponding to a sinistral body is united with a part corresponding to a dextral head.

My conclusion from the evidence is that any process of congenital development may in particular zygotes exhibit a mutation, a departure from the normal. We need not use the term heredity at all, or if we do, must remember that in the present argument it does not refer to any transmission from 
the parent. The factors in the gametes of the normal Flat-fish egg cause the normal metamorphosis to take place after the larval symmetry has lasted a certain time. In occasional individuals the factors whatever they are, portions of the chromosomes or arrangement of the chromosomes or anything else, are different from those of the normal egg, and in consequence the abnormalities above described are developed. But the chicf fact which I cannot too strongly emphasise is that the development of the abnormality from the symmetrical larva is direct, whether it is merely an arrest of development or an abnormal combination of reversed and normal parts. The abnormal development is not due to a change occurring after the normal asymmetry has been developed. These abnormalities are true mutations.

The evolution of the normal Flat-fish, on the other hand, was obviously due to a change of a different kind. Here we are dealing with the change from a symmetrical fish to the asymmetrical. Judging from what takes place in other mutations, it was quite possible for asymmetry to have developed directly from the egg, in consequence of some difference in the chromosomes of the nucleus. It has been shown that placing a fish egg for a short time in $\mathrm{MgCl}_{2}{ }^{1}$ causes a cyclopean monstrosity to be developed in which the two eyes are united into one: but the two eyes do not develop separately first and then gradually approach each other and unite, the development of the optic cups is different from the first. In the normal Flat-fish the evolution that has occurred is the original development of the symmetrical fish, and the subsequent continuous gradual

1 Stockard, Arch. Eut. Mech., xxiii. (1907). 
change in eyes, fin, and colour to the adult Flat-fish as we see it. All the evidence accumulated by the experiments and observations of mutationists and Mendelians goes to prove that this change is of an entirely different kind from those variations which are described as mutations, or as loss or addition of genetic factors.

This being the case, we have to inquire what is the explanation of the evolution of the normal metamorphosis.

The important fact is that the original symmetrical structure of the larva and the asymmetrical structure of the adult Flat-fish correspond to the different positions of the body of the fish in relation to the vertical, the horizontal ground at the bottom of the water, and incidence of light. The larva swims with its plane of symmetry vertical like most other fishes; its locomotion requires symmetrical development of muscles and fins; the two sides being equally exposed to light, it requires an eye on each side, and the pigment on each side is also related to the equal exposure to light. The adult lying with one side on the ground has its original plane of symmetry horizontal and parallel to the ground, and only the other side exposed to light, and on this side only eyes and colour, i.e. pigment. The change of structure corresponds with the change of habit. It consists in the change of position of the lower eye, the extension of the dorsal fin forwards, and the disappearance of pigment from the lower side. In the actual metamorphosis these changes take place as the skeleton develops, before the hard bones are fully formed, while the fish is still small, but the young Turbot reaches a much larger size before 
metamorphosis is complete, namely, about one inch in length, than the young Plaice or Flounder. It is of little importance to consider whether at the beginning of the evolution the change of position occurred late or early in life. It may have become earlier in the course of the evolution. The important matter is to consider the evidence in support of the conclusion that the relation to external conditions has been the cause of the evolutionary change. We have already seen that the nature of the change and the relation of the change of structure to the change of conditions necessarily tend to the inference that the latter is the cause of the former. But we have to consider the particular changes in detail.

To take first the loss of pigmentation from the lower side. I have shown experimentally that exposure of the lower sides of Flounders to light reflected upwards from below causes development of pigment on the lower side. At the same time the experiments proved that the loss of pigment in the fish in the natural state and the development of it under exposure to light were not merely direct results of the presence or absence of light in the individual, for in some cases the young fish were placed in the apparatus before the pigment had entirely disappeared from the lower side, and the metamorphosis went on, the lower side becoming quite white, and the pigment only developed gradually after long exposure to the light. In the principal experiment four specimens were placed in the apparatus on September 17, 1890, when about six months old and 7 to $9 \mathrm{~cm}$. in length. One of these died on July 1, 1891, and had no pigment on 
the lower side. The other three all developed pigment on that side. In one it was first noticed in April 1891, and in the following November the fish was $22 \mathrm{~cm}$. long and had pigmentation over the greater part of the lower side (Plate III.). Microscopically examined, the pigmentation was found to consist of black and orange chromatophores exactly similar to those of the upper side. Some hundreds of young Flounders were reared at the same time under ordinary conditions and none of them developed pigment.

It is clear, therefore, that exposure of the lower side to light and reduction of the amount of light falling on the upper side (for the tops of the aquaria used were covered with opaque material) does not cause the two sides to behave in the same way in respect of pigment, as they would if the normal condition of the fish was merely due to the difference in the exposure to light of the two sides in the individual life. There is a very strong congenital or hereditary tendency to the disappearance of pigment from the lower side, and this is only overcome after long exposure to the light. On the other hand, if the disappearance of the pigment were due to a mutation, were gametogenic and entirely independent of external conditions, there would be no development of pigment after the longest exposure. To prove that an inherited character is an acquired character is quite as good evidence as to show that an acquired character is inherited. The latter kind of evidence is very difficult to get, for the effect of conditions in a single lifetime is but slight, and is not likely to show a perceptible inherited effect. The theory that adaptations are due to the heredity of the effects of 

PLATE III.

PIGNENTATION OF THE LOWER SIINE OF A FLOUNDER (PLEURONECTES FLESUS) WHICH WAS EXPOSED TO DAYLIGHT REFLECTED FROM A MIRROR, FROM SEPT. I89O TO YOV. I89I. THE SPECIMEN WAS ABOUT SIX MONTHS OLD AT THE BEGINNING OF THE EXPERIMENT, AND THEN HAD NO PIGMENT ON THE LOWER SIDE. REPRODUCED BY PERMISSION OF THE ROYAL SOCIETY FROM PHIL. TRANS. I893. B. 


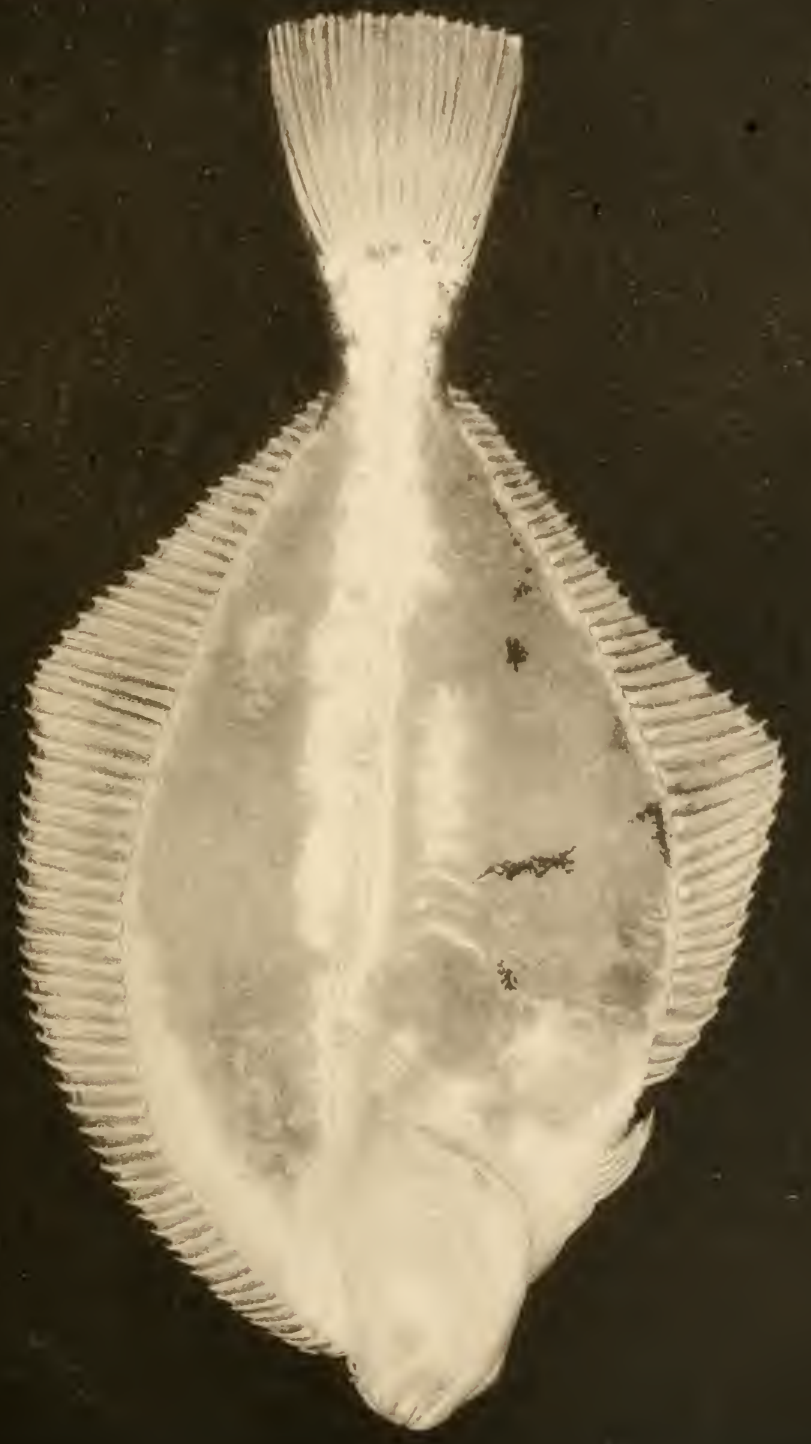



stimulation assumes that the same stimulus has been acting for many generations.

It is necessary, however, to consider how far the conclusions drawn from these experiments are contradicted by the mutations occurring in nature, some of which have already been mentioned. We will consider first ambicolorate specimens. If the absence of pigment from the lower side in normal Flat-fishes is due to the absence of light, how is it that the pigmentation persists on the lower side of ambicolorate specimens, which is no more exposed to light than in normal specimens? The answer is that in the mutants the determinants for pigmentation are united with the determinants for the lower side of the fish. My view is that the differentiation of these determinants for the two sides was due in the course of evolution to the different exposure to light, was of somatic origin, but once the congenital factors or determinants were in existence they were liable to mutation, and thus in the ambicolorate specimens there is a congenital tendency to pigmentation on the lower side, which would only be overcome by exclusion of light for another series of generations.

Mutations also occur in which part or whole of the upper side is white and unpigmented. Several such specimens are mentioned in the memoir by myself and Dr. MacMunn in the Phil. Trans. already cited, one being a Sole which was entirely white on the lower side, and also on the upper, which was pigmented only over the head region from the free edge of the operculum forwards. Since the upper sides in these specimens are fully exposed to light in the natural state and yet remain unpigmented, it 
would appear impossible to believe that the action of light was the cause of the development of pigment on the lower sides of normal specimens in my experiments. To some it may be so, but in my own opinion the one fact is as certain as the other. I believe the two facts can be reconciled. I had one specimen of Plaice in the living condition which had the middle third of its upper surface white, and the whole of the lower side white as usual. This specimen was kept for $4 \frac{1}{2}$ months with its lower surface exposed to light and the upper side shaded. At the end of that period there were numerous small patches of pigment scattered over the lower side principally in the regions of the interspinous bones, above and below the lateral line. In the area of the upper side, which was originally unpigmented, there were also numerous small pigment spots. I believe, therefore, that in this case there were determinants for absence of pigment not only on the lower side but on part of the upper side also, and that so long as light was excluded from the lower side the patch on the upper side remained unpigmented in sympathy. When the congenital tendency of the determinants on the lower side was overcome by the action of light, the white patch on the upper side also began to develop pigment.

Lastly, I may refer again to the specially abnormal Turbot mentioned above. In this case the lower side was over the greater part pigmented and the upper side white, and this would appear to contradict the conclusion just drawn coneerning the piebald Plaice. But this Turbot was only $4 \cdot 4 \mathrm{~cm}$. long, and is the only case known to me where so much of the lower side was pigmented with the upper side almost 
entirely white. The theory of sympathy or correlation might apply here since the lower side of the head was unpigmented, but from the small size of the specimen and the amount of pigment on the lower side, it seems to me most probable that if the specimen had lived to be adult the upper side would have developed pigment under the action of light and the specimen would have become ambicolorate.

When we compare the results reached by the mutationists with those obtained by the Mendelians we find that they tend to two different conceptions of the relation between the gametes and the organism developed from them. The effect of a change in the determinants of the gametes according to the mutationists is evident in every part of the plant. A factor in Mendelian experiments usually affects only one organ or one part of the organism. The factor for double hallux in fowls, for instance, may coexist with single comb or rose comb. The general impression produced on the mind by study of Mendelian phenomena is that the organism is a mosaic of which every element corresponds to a separate element in the chromosomes. Thus we know that what we call a single factor may cause the whole plumage of a fowl to have the detached barbs, which constitutes the Silky character, but we also know that an animal may be piebald, strongly pigmented in one part and white or unpigmented in another. So we find in these Flat-fish mutations mosaic-like forms which evidently result from mosaic-like factors in the gametes, or in the chromosomes of the gametes.

Experimental evidence concerning the movement 
of the lower eye to the upper side and of the forward extension of the dorsal fin has not been obtained, though years ago I made some attempts, at the suggestion of Mr. G. J. Romanes, to obtain such evidence with regard to the eye by keeping young Flounders, already partially metamorphosed, in a reversed position. I did not succeed in devising apparatus which would keep the young fish alive in the reversed position for a sufficiently long time. We can only consider, therefore, whether those other changes can reasonably be attributed to the conditions of life. Anatomical investigation shows that the bony interorbital septum composed principally of the frontal bones, which in symmetrical fish passes between the eyes, is still between the eyes in the Flatfish, but has been bent round through an angle of 90 degrees on the upper side, while in the lower side a new bony connexion has been formed on the outer side of the eye which has moved from the lower side. This connexion is due to a growth from the prefrontal backwards to join a process of the frontal, and is entirely absent in symmetrical fishes. It is along this bony bridge that the dorsal fin extends. The origin of the eye muscles and of the optic nerves is morphologically the same as in symmetrical fishes. On the theory of modification by external stimuli we must naturally attribute the dislocation of the eye of the lower side to the muscular effort of the fish to direct this eye to the dorsal edge, but something may also be due to the pressure of the flat ground on the eye-ball. There is little difficulty in attributing the bending of the interorbital septum to pressure of the lower eye-ball against it, pressure which is probably due partly if not chiefly to the action of the 
eye muscles. The formation of the bony bridge outside the dislocated eye is more difficult to explain, as I have never had the opportunity to study the relation of this bridge to the muscles. It is worth mentioning that in the actual development of Turbot and Brill the metamorphosis takes place to a considerable degree while the young fish is pelagic, before the habit of lying on the ground is assumed, but of course this is no evidence that the change was not originally caused by the habit of lying on the ground.

With regard to the extension of the dorsal fin there is no difficulty in discovering a stimulus which would account for it. Symmetrical fishes propel themselves chiefly by the tail; in shiffling over the ground or swimming a little above it, Flat-fishes move by means of undulations of the dorsal and ventral fins. Increased movement produces hypertrophy, and according to the theory here maintained, not merely enlargement of parts existing, but phylogenetic increase in the number of such parts, here fin rays and their muscles. In Flat-fishes the dorsal and ventral fins extend along the whole length of the dorsal and ventral edges: the dorsal from the head, in some cases from a point anterior to the eyes, to the base of the tail, the ventral from the anus, which is pushed very far forward, to the base of the tail, and in some species of Solidae these fins are confluent with the caudal fin.

Formerly it was dogmatically maintained that the effect of an external stimulus on somatic organs or tissues could have no influence on the determinants in the chromosomes of the gametes to which the hereditary characters of the organism were due. 
As we have tried to show, this dogma is no longer credible in face of the discoveries concerning hormones. The hormone theory supposes that the somatic modifications due to external stimuli-in the case of the Flat-fish the disappearance of pigment from the lower side, the torsion of the orbital region of the skull, and the extension of the dorsal finmodify the hormones given off by these parts, increasing some and decreasing others, and that these changes in the hormones affect the determinants, whatever they are, in the gametocytes within the body.

Here arises an interesting question-namely, how does the hormone theory explain the phenomenon of metamorphosis any better than the mutation theory? It might be agreed that if the determinants are stimulated or deprived of stimulation, the effect of the change should logically show itself from the beginning of development, and that therefore the process of metamorphosis or indirect development does not support the hormone theory any more than the theory of gametogenic mutations. This objection may be answered in the following way. The reason why the determinants give rise to the original structure first and then change it into the new structure is probably the same as that which causes secondary sexual characters to develop only at the stage of puberty. By the hypothesis the new habits and new stimuli begin to act at some stage after the complete development of the original structure of the body. The differences in the original hormones of the modified parts are therefore acting simultaneously with the hormones, that is, the chemical substances derived from all other parts of the body in its fully 
developed condition. It is very probable that in the early stages of development the metabolism of the body would be considerably different from that of the adult stage, and the same combination of hormones would not be present. We may suppose, therefore, that the determinants of the zygote have acquired a tendency to produce the increases and decreases of tissue which constitute a certain modification, e.g. the change in the position of the eyes in a Flat-fish, but the stimulus which caused this tendency has always acted when the adult combination of hormones was present. In consequence of this the developed tissues do not undergo the inherited modification until the adult combination is again present. In this way we can form a definite conception of the reason why an adaptive modification is inherited at the same stage in which it was produced, just as the antlers of a stag are only developed when the hormone of the mature testis is present. At the same time it is probable that the age at which the inherited development takes place tends to become earlier in later generations, to occur in fact as soon as the necessary hormone medium is present.

The diagnostic characters of some of the species of Pleuronectidae have been mentioned in an earlier part of this volume, in order to point out that they have no relation to differences of habit or external conditions. Here it is to be pointed out that there is no evidence that they arise by metamorphosis. The scales, for example, afford distinct and constant diagnostic characters both of species and genera, but their peculiarities have not been found to arise by modification of a primitive form. The rough 
tubercles of the Flounder, and the scattered thornlike tubercles of the Turbot, develop directly, not by the continuous modification of imbricated scales. There is, however, one scale-character among the Pleuronectidae which appears to stand in direct contradiction to the conclusions drawn by me concerning scales in general. It not only develops by a gradual change, but it is a secondary sexual character developing in the males only at maturity. The character was described by E. W. L. Holt in specimens of the Baltic variety of the Plaice, Pleuronectes platessa, ${ }^{1}$ and consists in the spinulation of the posterior edges of the scales, especially on the upper side, in mature males. The same condition, but to a much slighter degree, was afterwards shown by myself to occur constantly in Plaice from the English Channel and North Sea. ${ }^{2}$ It occurs also in $P$. glacialis, the representative of the Plaice in more northern seas. I have shown that the spinules develop in the mature males not as a modification of the scale, but as separate calcareous deposits the bases of which afterwards become united to the scale. It would seem that the development of this character is dependent on the hormone from the mature testis, and in order to conform with the arguments used by me in other cases, the spinulation should have some definite function in relation to the habits of the sexes, and this function should involve some kind of external stimulation restricted to the mature male. So far, however, no evidence whatever of such function or such stimulation has been discovered. It is possible that the case differs from

1 Journ. Mar. Biol Assn,, vol. iii. (Plymouth, 1893-95).

2 Ibid., vol. iv. p. 323. 
other secondary sexual characters such as the antlers of stags in one respeet, namely, that since the Dab (P. limanda), the Sole, and other species of Solea, and several other Pleuronectidae have what are called ctenoid scales-that is, scales furnished with spines on the posterior edge-and since the ordinary scales of the Plaice are reduced, the spinulation of scales in the mature male Plaice is not a new character but the retention of a primitive character. Then the question would remain why the scales in the mature female and immature male have degenerated, or rather why the primitive character develops only in the mature stage of the male.

There is one point in which this sexual dimorphism in the Plaice appears to differ from typical cases, and which suggests that the greater spinulation of scales in the males has no function at all in the relations of the sexes, and is therefore not subject to any external stimulation. This point is the remarkable way in which the degree of development of spiny armature differs in different regions and in local races, and seems to correspond to different climatic conditions. Both Plaice and Flounders in the Baltic are much more spiny than in the North Sea, although in the Flounder no sexual difference in this respect has been noted. On the east coast of North America occurs $P$. glacialis, in which the scales of the male are strongly spinulate and those of the female smooth. On the coast of Alaska females of this species seem to be more spinulate than elsewhere. The Flounder does not occur in the Arctic, but on the west coast of North America occurs a local form called $P$. stellatus, scarcely distinct as a species, which has a strong development of spiny tubercles all over the upper 
side. The Flounders of the Mediterranean are much less spinous than those of the North Sea or Channel. The Dab ( $P$. limanda) occurs on the American coast in a local form called Limanda ferruginea, and in the North Pacific there is a rougher form called $L$. aspera. In these three species therefore, apart from mutations, the northern forms all show a greater development of spines on the scales. Whether this is an effect of colder temperature it is difficult to say. It is possible that the difference is due to external conditions, of which lower temperature of the water is the most obvious, and it may be that these conditions have a greater effect on the male than on the female in the Plaice.

Sexual differences in scales, which have a function in the relations of the sexes, occur in a few other fishes, and these can be attributed with good reason to mechanical stimulation. For example, in the Rajidae among Elasmobranchs the males possess on each 'wing' or pectoral two series of large, recurved, hooked spines. It has been stated, ${ }^{1}$ apparently by Yarrell, that these spines are developed only in the breeding season. It is doubtful if there is any marked breeding season in these fishes, but it is probable that the spines are absent in the immature male, as it is known that in Raia clavata the adult male has sharp pointed teeth, while the young male and the female at all ages have broad flat teeth. It is supposed that the spines and perhaps the sharp teeth are used for holding the female, but it seems equally probable that these structures are really used by the males in fighting with each other. The habits of these marine fish have not been much

1 Darwin, Descent of Man (2nd edit., 1885), p. 331. 
observed, but there is little reason to doubt that these differences in scales and teeth correspond with differences of mechanical stimulation. This does not at all imply that the scales and teeth themselves have been produced by mechanical stimulation, or that the difference between the dermal denticles of Elasmobranchs and the scales of Teleosteans correspond to differences of stimulation. But the degree of development of a structure whose presence is due to gametic factors may very probably be modified by external stimulation, and the modification may become hereditary. If the views here advocated are true, the two processes mutation and modification must be always acting together and affecting the development not only of the individual but of any organ or structure. Thus the peculiarities of antlers in stags, it seems to me, prove that the mechanical stimulation due to fighting was the cause of the evolution of antlers, that without the habit of fighting in the males antlers would not exist. At the same time each species of the Cervidae has its special characters in the antlers, in shape and branching, and it would be impossible to attribute these to differences in mode of fighting: they are due to mutation.

In connexion with the metamorphosis of Amphibia the case of the Axolotl has always been of very great interest. In the few small lakes near the city of Mexico where it occurs it has never been known to undergo metamorphosis but is aquatic throughout its life and breeds in that condition. Yet in captivity by reducing the quantity of water in which it is placed the young Axolotl can be forced to breathe air, and then it undergoes complete metamorphosis to the abranchiate con- 
dition. The same species in other parts of North America normally goes through the metamorphosis, like other species of the Urodela. It is evident, therefore, that the Mexican Axolotls, although they have been perennibranchiate for a great number of generations, have not lost the hereditary tendency to the metamorphosis which changes the larvae of Amblystoma elsewhere into an air-breathing terrestrial animal. This may be regarded as evidence that the conditions of life which prevent the metamorphosis in the Mexican Axolotl have produced no hereditary effect. The fact, however, that Axolotls require special treatment to induce metamorphosis seems to show that they have distinctly less congenital tendency to metamorphosis than larvae of the same species, Amblystoma tigrinum, in other parts of North America, and this difference must be attributed to the inherited effect of the conditions. The most important of these conditions seems to be abundance of oxygen in solution in the water, and the next in importance abundance of food in the water. Recently it has been shown that the metamorphosis may be induced by feeding Axolotls on thyroid gland. But there is no reason to suppose that a congenital defect of thyroid arising as a mutation was the original cause of the neoteny, i.e. the persistence of the larval or aquatic, branchiate condition. Such a supposition would imply that the association between Axolotls and the peculiar Mexican lakes, supplied with oxygenated water by springs at the bottom, was purely accidental. Moreover, there is no evidence that there is any deficiency of thyroid in the Axolotl. The secretion of the thyroid gland is necessary for the normal 
growth and development of all Vertebrates, and we are only beginning to understand the effects of defect or excess of this secretion. There is nothing very surprising in the fact that excess in the case of the Axolotl causes the occurrence of the metamorphosis which had already in numerous experiments been produced by forcing the animals to breathe air.

Metamorphosis, as in the development of gill arches and gill slits in the embryos of Birds, Reptiles, and Mammals, exhibits a recapitulation of the stages of evolution of certain organs. But in the case of other organs the absence of recapitulation is remarkable by contrast. If, as I believe, the development of lungs and disappearance of gills was directly due to the necessity of breathing air, it is difficult to avoid the conclusion that the terrestrial legs were originally evolved from some type of fishes' fins by the use of the fins for terrestrial locomotion. Yet neither the amphibian larva nor the embryo of higher Vertebrates develops anything closely similar to a fin. There is no gradual change of a finlike limb into a leg, but the leg develops directly from a simple bud of tissue. The larva of the Urodela is probably more primitive than the tadpole of the Frogs and Toads, and in the former the legs develop while the external gills are still large, long before the animal leaves the water.

It is possible that the limbs were transformed to the terrestrial type before the animal itself became terrestrial, the habit of swimming having been partly abandoned for that of crawling or walking at the bottom of the water, and the tail being used merely for swimming to the surface to obtain air. 
But the condition of the Dipnoi, which possess lungs but do not walk on land, does not support this supposition, for they possess fins which are either filamentous or fin-like, having a central axis with rays on each side. There can be little doubt that the digits of the terrestrial limb are homologous with endoskeletal fin-rays, but the evolution of the axis of the limb is not to be ascertained either from development or palæontology. The absence of metamorphosis here may perhaps be due to the fact that the lateral fins ceased to function in the earlier aquatic stages, only the caudal fin being used for swimming. If this were the case the absence of metamorphosis in the legs is itself an adaptation, the disuse of the paired limbs in the larva having caused the earlier fin-like stages of these limbs to disappear, while the terrestrial leg was developed later by heredity, just as the legs have disappeared in the larvae of many insects, though fully developed in the adult.

Metamorphosis of structure in Amphibia and in Flat-fishes corresponds to the change of conditions of life in the free-living animal. In the case of the eyes of the Cave-fishes the conditions in respect of absence of light are constant throughout life, and we find only an embryonic development of the eye taking place by heredity. The question arises whether, when there is no embryonic recapitulation, it must be concluded that apparent adaptations are due to mutation and not to function or external conditions. One case of this kind is that of the limbs of Snakes, where, if we except the vestiges of hind limbs in the Pythons, there is no trace of limbs either in the embryo or after hatching. There are several similar cases among Reptiles and Amphibia. 
The Slow-worm (Anguis fragilis) is limbless, and so are the members of the sub-class Apoda among the Amphibia. In these also rudiments of limbs are entirely absent in the embryos or larval stages. Considering the recent evolution of Snakes as compared with the origin of lungs and loss of gills and gill slits in terrestrial Vertebrates in general, we have here a remarkable contrast which shows in the first place the difference resulting when the change in habits and conditions in the one case takes place from one stage of life to another, and in the other case the new habits are constant throughout life from the moment of hatching. It seems to me that in the present state of our knowledge we cannot form a decisive opinion on the question whether the absence of limbs in such cases is the result of mutation or of disuse-that is, absence of functional stimulation.

The power of flight is an excellent example of adaptation. It has been evolved independently in Pterodactyls, Bats, and Birds. In the two first groups, and to a slight degree in the third, the expanse of the wing is formed by an extension of the skin into a thin membrane, supported by the fore-limbs. It is not necessary to argue in detail that the evolution of this membrane and of the modifications of bones and muscles by which it is supported and moved, can be satisfactorily explained on the theory that modifications due to mechanical and functional stimulation are ultimately inherited. In birds, however, the surface of the wing is supplied chiefly by feathers, and consideration of the matter affords no reason for supposing that the evolution of feathers was due to any external or functional stimulation. It is often 
stated that the feathers of birds are a modification of the epidermic scales of reptiles, but investigation does not fully confirm this statement. The reptilian scales are retained on the tarso-metatarsal region of the leg in the majority of birds, and it would be expected, if the view just quoted were correct, that a transition from scales to feathers would be visible at the ankle-joint. This, however, is not the case. In fowls some breeds have scaly shanks and others feathered. In those with scaly legs I have found cases in which, in the chicks, there were two or three very minute feathers, and I have examined these microscopically by means of sections of the skin. The result was to show that the minute feathers were not a prolongation of the tips or edges of the scales, but arose from follicles between the scales. The scale is flat and is a fold of the epidermis not arising from an invaginated follicle. The feather, on the other hand, is a tubular structure arising from a papilla at the base of a deep follicle extending inwards from the surface of the skin. As the feather grows the papilla grows with it. This papilla consists of vascular dermal, i.e. mesodermic tissue, and if the feather is pulled out during growth bleeding occurs. The epidermic horny tube splits posteriorly towards the apex of the feather, and is divided into rachis and barbs, and thus the dermal tissue within, by this time dead and dry, is exposed and is shed. Every feather is in fact an open wound, and is perhaps the only other case, in addition to that of the antlers of stags, in which vascular mesodermic tissue is normally shed in such considerable quantities. When the development of the feather is complete, growth gradually ceases, 
the proximal part of the feather remains tubular and does not split, and the vascular tissue within dies, shrivels, and dries up, forming the pith of the quill. When the papilla recommences to grow the old feather is pushed out, and this process causes the moult. It would appear, therefore, that the feather must have been evolved, not by a continuous modification from the scale but by a development of a new kind between the scales. I have been unable to discover hitherto any evidence suggesting an external stimulus which could cause this remarkable process of development in feathers, or indicating that the function of flight would involve such a stimulus. For the present, therefore, we must conclude that feathers are not an adaptation, and not due to somatogenic modification, but must be the result of a gametogenic mutation.

Feathers, having been evolved, served in the wings and tail as important organs of flight. There is reason to believe that, once present, the size and growth of feathers was modified greatly by the degree of stimulation applied to the papillae at their roots by the movement and bending strain of the feathers. The modification of the bones and muscles of the wing, shoulders, and sternum by the functional stimuli involved in flying are obviously adaptations, and in my opinion are only to be explained as the hereditary effects of functional stimulation, like all skeleto-muscular adaptations. The strains produced in bones by muscular contraction produce hypertrophy of the part of the bone to which the muscles are attached, and thus we can understand the origin of the carina of the sternum in flying birds, and its absence in flightless forms. In bats and in ptero- 
dactyls also the sternum is produced into a carina along the median line. The reduction of the digits of the wing in birds to three, with the bones firmly united together, would follow from their use in flight and their disuse as digits, and it would seem, from the fact that the flight-feathers must have been always on the posterior edge of the wing, and that the ulna is larger than the radius, that the three digits which have persisted are the $3 \mathrm{rd}, 4 \mathrm{th}$, and $5 \mathrm{th}$, and not the 1st, 2nd, and 3rd as usually taught. A comparison of the hind-limbs of birds with those of bats and pterodactyls suggests strongly that the patagium flyers have arisen from arboreal or climbing animals, while the birds arose from terrestrial forms which acquired the bipedal habit, as certain reptiles have. An arboreal animal would necessarily use all four limbs, as climbing animals actually do. The wings of birds, on the other hand, would have arisen from the endeavour to increase speed by movements of the fore-limbs. The perching birds would therefore have arisen by later adaptations after the power of flight had been evolved.

Complete recapitulation does not occur in the development of the digits of the wing. Only a rudiment of a fourth digit has been found in the embryonic wing, not, as might be expected, rudiments of five digits of which two disappear. The metacarpals are free, not united as in the adult, and there are separate distal carpals, which in the adult are united with the metacarpals. In other respects the modifications of wings and sternum are so obviously adaptive that it is difficult to believe that the reduction of digits was not due to disuse. This is 
another of those cases in which the function to which structure is adapted is constant from the beginning of independent life to the end, and there is some ground for believing that in course of time in such cases embryonic recapitulation may be much diminished or disappear. The period of time since birds were first evolved is in all probability immensely greater than that which has elapsed since the blind fish, Amblyopsis, was modified by cavelife, so that we can understand why the eye is developed to a certain stage in the embryo of the blind fish, although it lives in darkness all its life, while embryonic recapitulation in the wing of the bird is very incomplete.

In another class of adaptations the embryonic or larval stage is adapted to new conditions, while the adult condition is either less changed or not changed at all. One of the most obvious examples of this is the allantois in the Amniota. The embryos of Reptiles, Birds, and Mammals all develop two embryonic or fœtal membranes, the amnion and the allantois. Of the function or origin of the amnion little is known : to state that it is protective affords little explanation. It seems possible that it is merely the mechanical result of the weight of the embryo and the development of the allantois. The latter is a precocious hypertrophy of the cloacal bladder found in Amphibia, with the function of embryonic respiration. In the water the amphibian larva respires by means of gills and gill slits. In adaptation to terrestrial life it is necessary, if the free aquatic larval stage is to be eliminated, that the embryo should be able to breathe air before hatching. Various Amphibia show how this requirement was 
met in various ways. In the South American treefrogs of the genus Nototrema the eggs are developed in a dorsal pouch of the skin of the female, and within this pouch the respiration of the embryo is carried on by a membranous expansion of the second and third external gills on each side. In the Reptilia the bladder is expanded for the same function, and absorbs oxygen and gives off carbon dioxide through the pores of the shell. It is impossible to reconcile the conception of mutation with the adaptive relation between this allantois and the expulsion of the egg enclosed in a shell on land. The transition probably came about gradually from the deposition of the eggs in moist places but not in water. In the midwife toad (Alytes obstetricans) the male carries the eggs about attached to his legs, respiration is effected by enlarged external gills, and the larvae are hatched in water. In the ancestral reptiles external gills may have helped at first, until by the enlargement of the bladder they were rendered unnecessary. In all such cases the absorption of oxygen must be regarded as the stimulus which caused the enlargement of the respiratory membrane. As the allantois could not be absorbed or retracted again into the abdomen, the umbilicus was evolved-that is to say, the scar formed by the union of the folded edge between the body wall and amnion surrounding the stalk of the allantois. It would be difficult for a mutationist to explain how a mutation should affect the development of the cloacal bladder to such an enormous degree, just when it was required for embryonic respiration, and cause the sides of the body to unite ventrally at the time of hatching, cutting off the allantois and the amnion. 


\section{RECAPITULATION}

T. H. Morgan ${ }^{1}$ states that a mutation of gametic origin may affect any stage in the development of the individual. This may be true when there are already distinct stages in the life history. The more important question is whether distinct stages can be caused by mutation. It is true that in heterozygous individuals characters may develop more fully in the adult stage than in the young. But when we find different stages evidently adapted to different modes of life, it is impossible to explain them by mutations affecting different stages of life. In such cases as the larval stages of Insects we find that the larvae have become adapted to new habits while the adults have remained unchanged, or have evolved quite independent adaptations. For example, the adults in the chief orders of Insects have the typical three pairs of legs, while the maggots or grubs of the Diptera or Hymenoptera have no legs at all, the caterpillars of Lepidoptera have evolved pseudolegs on the abdomen, and the larvae of Coleoptera have the ordinary legs and no more. This is the reverse of recapitulation: in the case of legless maggots, and caterpillars with pro-legs, the adult is more similar to the ancestor than the larva. But the same principle holds, that where functions and habits are different, there organs are different. No mutationist has yet produced by breeding experiments a caterpillar without the three pairs of thoracic legs and yet developing into a moth that had the normal three pairs. Morgan, with all his mutations of the adult Drosophila, says nothing of larval mutants possessing legs. The only rational conclusion is that legless larvae have lost the legs through

1 a Critique of the Theory of Evolution, p. 18. 
disuse, since those larvae which are destitute of legs do not go in search of food but either live in the midst of it or are fed by others, and that the pro-legs of the caterpillar have been developed by the muscular action of the insect in clinging to leaves. Here again the hormone theory, although we cannot pretend to understand the matter completely, helps us to form a conception of the process of heredity and evolution. The disuse of legs in the larva affects the determinants, so that they remain inactive in the presence of the hormones produced in the body generally in this stage. In the adult stage activity of the legs produces hormones which influence the same determinants in the gametes to develop legs, but again in the presence of the different hormones which are present in the body generally in the adult stage. As the habits of larva and adult became more specialised and contrasted, the change became less and less gradual, and the intermediate stage, not being adapted to any transitional mode of life, became an inactive pupa in which the adult organs develop.

In conclusion I will briefly consider the attempts which have been made to prove the influence of somatic modifications or characters on the gametes by direct experiment. The method of Kammerer of inducing changes of habit or structure by conditions, and then showing that the change is in some degree inherited, has already been mentioned. One obvious criticism of this evidence is that it seems to prove too much, for it is difficult to believe that a change produced in individuals would show so much hereditary effect in their immediate offspring. Two other methods are conceivable by which the 
influence of somatic hormones might be made evident. One of these is to graft ovaries or testes from one animal into another which possesses a certain somatic character, and then to see if the offspring produced from these gonads shows any trace of the character of the foreign soma in which it was nourished. C. C. Guthrie ${ }^{1}$ claimed to have done this in his experiments on hens. He grafted the ovaries of two Black Leghorn pullets into two White pullets of the same breed, and vice versa. The black and the white birds bred true when mated to cocks of their own colour. The black hen with white ovary mated with black cock produced four black chicks and two black chicks with white legs, the white hen with black ovary mated with white cock produced some white chicks, some black and some white with black spots. This is held to prove that the transplanted ovaries were functional, because they produced evidence of the character originally belonging to them. On the other hand, the black hen with white ovary mated with white cock produced nine white chicks, and eleven chicks which were white spotted with black, and the white hen with black ovary mated with black cock produced not black chicks but white chicks spotted with black. This was held to prove that the somatic characters of the 'foster mothers' were transmitted.

Davenport repeated Guthrie's experiments on different fowls, grafting the ovary from a cinnamoncoloured hen into a white hen, and mating her with a cinnamon-coloured cock. The chicks were exactly similar to those obtained from crossing such a cock 
with a normal white hen, and Davenport concludes that the engrafted ovary was not functional but had degenerated. It is known to be almost if not quite impossible to remove the ovary completely from a hen, owing to its close attachment over the great post-caval vein. At the same time it is difficult to see how Guthrie could have obtained black and spotted chicks from a white hen mated with a white cock if the grafted ovary from a black hen had not been functional. One point which Guthrie does not mention, and of which apparently he was not aware, is that the white of the White Leghorn is dominant to colour, the heterozygotes not being pure white but white with spots. Thus when he mated a black cock with a white hen with grafted ovary and obtained spotted chicks, this would have been the result if the original white ovary was functional. None of his results prove conclusively the influence of the soma of the hen into which ovaries were grafted, but would all be explained if some eggs were derived from the part of the original ovary not removed in the operation, and others from the grafted ovary.

The grafting of ovaries in Mammals has often been tried, but very rarely with success. The introduced ovary usually dies and is absorbed. C. Foa ${ }^{1}$ states that he made bilateral grafts of ovaries from newborn rabbits into adult rabbits, and two months after the operation one of the operated females was fecundated and produced five normal young. In other cases he placed ovaries from new-born young in positions far from the normal position, such as the space between the uterus and bladder, and in one case the female so treated became pregnant, and

1 Arch. Ital. de Biol. (1901), Tome xxxv. 
when killed had a single embryo in one uterus and no trace of the original ovaries in the normal position. But Foa was not investigating the influence of somatic characters on ova in the grafted ovaries, and does not even mention the characters or breed of the rabbits he used or of the young which were produced from the grafted ovaries. Castle ${ }^{1}$ carried out seventy-four transplantations of ovaries principally in guinea-pigs. Out of all these only one grafted female produced young. In this case the ovaries of two different black guinea-pigs about one month old were grafted into an albino female about five months old. After recovery the grafted female was kept with an albino male. She produced six young in three pregnancies, first two, then one, and lastly died with three fotus in the uteri. All these were black, with some red hairs among the black. One of the first two young had a white forefoot. In this case black is dominant, and therefore there is nothing extraordinary in the offspring from a black grafted ovary being black. The presence of red hairs and a white foot is no evidence of the influence of the foster soma, but is due to imperfect dominance. When the same male was mated with a normal black female the offspring were black with red hairs interspersed.

All these experiments are open to the following criticism. It has been the main argument of this volume that there are two distinct kinds of characters in all organisms-namely, those of somatogenic origin and those of gametogenic origin. Theory supposes that somatic modifications by means of

1 W. E. Castle and J. C. Phillips, On Germinal 'T'ransplantation in Vertebrates, Pub. Carnegie Institution in Washington (1911), No. 144. 
hormones affect the determinants in the gametes. But it is obvious that the black and white of Leghorn fowls and of guinea-pigs are gametogenic characters, and are strongly established in the gametes of their respective varieties. It is not even certain that the black or white hair or feathers are giving off special hormones which would or could influence the gametes. The hormone theory only postulates such influence from hormones issuing from tissues modified by external stimuli. It is quite certain that the black colour in Leghorns or guinea-pigs is not due to any external stimulus or influence. The experiments therefore are entirely irrelevant to what has been called the inheritance of acquired characters. All that they can be said to prove is that an albino soma does not convert ingrafted ova of black race into ova carrying the albino character.

It is probably impossible to prove experimentally the influence of a modified soma in one generation. I have endeavoured to find a case which would not be open to the above criticism-that is, to find a character which could be considered somatogenic and which was absent in a closely allied variety. Most of the characters in domesticated varieties are obviously gametogenic mutations, but the lop-ear in rabbits may be, partly at least, somatogenic. Since many breeds have upright ears, we cannot say that disuse of the external ear has produced lop-ears in domesticated rabbits generally, but in lop-eared breeds the ears are much enlarged; and though this may be gametogenic, the increased weight may have been the cause of the loss of the power to erect the ears. I therefore tried grafting ovaries from straight-eared females into lop-eared individuals. 
The operation was perfectly successful in seven specimens-that is to say, they recovered completely and lived for many months, up to a year or more, afterwards, but none of them became pregnant. When killed no trace of ovary was found in any of them; in every case it had been completely absorbed, and the uteri and vagina were diminished in size, and anæmic. For grafting I used ovaries from young rabbits of various ages, from seven days to six weeks or more, but all were equally unsuccessful. Satisfactory evidence by direct experiment of the inheritance of somatogenic modifications due to external stimuli cannot be said to have been yet produced, and, as I have shown, such evidence from the nature of the case must be very difficult to obtain. The indirect evidence, however, which has been considered in this volume is too strong to be ignored-namely, the case of Japanese long-tailed fowls, that of colour on the lower sides of Flat-fishes, and the similarity of the congenital development of the antlers in stags, to the generally admitted effects of mechanical stimulation and injury on the skin and superficial bones of Mammals.

The general conclusions which are logically to be drawn from our present knowledge with regard to the problems of heredity and evolution in animals are in my opinion as follows :-

1. All attempts to explain adaptation by gametogenic mutations, or changes in gametic factors or 'genes,' have completely failed, as Bateson himself has admitted.

2. The facts discovered concerning mutations and Mendelian heredity harmonise with the nature of the majority of specific and varietal characters, and with 
the diagnostic characters of many larger divisions in classification.

3. Some of the most striking cases of adaptation, such as the organs of respiration and circulation in terrestrial Vertebrates, and the asymmetry of Flat-fishes, are developed in the individual by a metamorphosis which is generally regarded as a recapitulation of the ancestral evolution. No cases of mutation or gametogenic variation hitherto described exhibit a similar metamorphosis or recapitulation.

4. Secondary sexual characters, usually in the male sex, correspond in their development with the development of maturity and functional activity in the gonads, and it has been proved that the latter influence the former by means of 'hormones' or internal secretions. The evidence concerning sex and sex-linked characters and the localisation of their factors in the chromosomes of the gametes has no bearing on the action of hormones.

5. The facts concerning the action of hormones are beyond the scope of current conceptions of the action of factors or genes localised in the gametes and particularly in the chromosomes. According to these conceptions, characters are determined entirely by the genes in the chromosomes, whereas in certain cases the development of organs or characters depends on a chemical substance secreted in some distant part of the body.

6. It was formerly stated that no process was known or could be conceived by which modifications produced in the soma by external stimuli could affect the determinants in the gametes in such a way that the modifications would be inherited. The 
knowledge now obtained concerning the nature and action of hormones shows that such a process actually exists, and in modern theory real substances of the nature of special chemical compounds take the place of the imaginary gemmules of Darwin's theory of pangenesis or the 'constitutional units' of Spencer.

7. The theory of the heredity of somatogenic modifications by means of hormones harmonises with and goes far to explain the facts of metamorphosis and recapitulation in adaptive characters, and also the origin of secondary sexual characters, their correlation with the periodical changes in the gonads and the effects of castration. At the same time there are some somatic sex-characters, e.g. in insects and birds, which do not appear to be correlated with changes in the gonads, and which are probably gametogenic, not somatogenic in origin.

8. The theory of the heredity of somatogenic modifications is not in opposition to the mutation theory. The author's view is that there are two kinds of variation in evolution, one somatogenic and due to external stimuli, acting either directly on passive tissues or indirectly through function, and the other gametogenic and due to changes in the chromosomes of the gametes which are spontaneous and not in any way due to modifications of the soma. Adaptations are due to somatogenic modifications, non-adaptive diagnostic characters to gametogenic mutations. It is a mistake to attempt to explain all the results of evolution by a single principle. There are two kinds of congenital, constitutional or hereditary characters in all organisms, namely, the adaptive and the non-adaptive, and every distinct 
type in classification exhibits a combination of the two. To assert that all characters are adaptive is as erroneous as to state that all characters are blastogenic mutations, and therefore in their origin nonadaptive.

9. Finally it may be urged, although the question has not been directly discussed in this volume, that no biologist is justified in the present state of knowledge in dogmatically teaching the lay public that gametogenic characters are alone worthy of attention in questions of eugenics and sociology. Hereditary or constitutional factors are of course of the highest importance, but there exists very good evidence that modifications due to external stimulus do not perish with the individual, but are in some degree handed on to succeeding generations, and that good qualities and improvement of the race are not exclusively due to mutations which are entirely independent of external stimuli and functional activity. It is important to produce good stock, but it is also necessary to exercise and develop the moral, mental, and physical qualities of that stock, not merely for the benefit of the individual, but for the benefit of succeeding generations and to prevent degeneration. 


\section{N D E X}

Abraxas grossulariata and lacticolor, 108.

Adaptations, origin of, 7, 21 ; evolution of, 188.

Agonus cataphractus, 28.

Albinism, 187.

Allantois, 231.

Allurements, 70 .

Alytes obstetricans, 232.

Amblyopsis, eyes of, 159 .

Amblystoma tigrinum, 224.

Amnion, 231.

Anableps tetrophthalmus, 192.

Anas boscas, 84; crosses of, 186. tristis, crosses, 186.

Ancel and Bouin, 92.

Anguis fragilis, 227.

Antilocapra, 165 .

Antirrhinum, crossing of, 173 .

Antlers of stags, 71, 122 .

Ants, heredity of sex in, 55 .

Aphidae, heredity of sex in, 56 .

Apoda, 227.

Axolotl, albino, 192 ; metamorphosis, 223 ; influence of thyroid feeding, 224.

Barred plumage in fowls, 115.

Basch, 99.

Bateson, 17, 44, 171.

Bees, heredity of sex in, 55 .

Bernard, Claude, 91.

Berthold, A. A., 91.

Biedl, 145 ; and Königstein, 98.

Bionomics, 3.

Blindness in cave animals, 189.

Bombyx mori, 158.

Boring, Miss, 95.

Born and Fränkel, 103, 145.

Brachydactyly, 171.

Bresslau, 135.

Brown-Séquard, 91.

Bühler, 143.

Cambarus, males of, 73 .

Capons, 74.

Castle, experiments in grafting, 237 ; on sex, 58.
Castration, 73 ; in ducks, 81 ; of frog, 163 ; of Lepidoptera, 159 .

Cats, heredity of colour in, 117 .

Cave animals, absence of pigment, 191.

Cephalopoda, 2 .

Cetacea, absence of scrotum, 150.

Chelonia, 36.

Chologaster agassizii, 191.

Chromosomes, 41; in mutations, 183.

Clevelandia, 190.

Colaptes, 18.

Colour-blindness, 113 ; heredity of, 108.

Colours, origin of, in domesticated breeds, 187.

Comb of fowls, uselessness of, 133.

Corpora lutea, evolution of, 139 ; in viviparous lower vertebrates, 143 ; origin of, 9S, 100.

Corystes cassivelaunus, 2.

Courtship, organs of, 70 .

Criss-cross inheritance, 112.

Crossing over, 176.

Cryptorchidism, 94, 152.

Cuttle-fishes, 2.

Cyclostomes, absence of corpora lutea in, 143.

Cytology, 65.

Cytoplasm, in heredity, 43.

Dafila acuta, crosses, 186.

Daphnia, heredity of sex in, 56 .

Darwin, 6, 14.

Dasyurus, 146 ; corpora lutea, 144; lactation, 95, 101, 138.

Davenport, 235.

Determinants, 43.

Determination of sex, 120 .

Dipnoi, fins, 226 .

Dog-fishes, oviparous and viviparous, 4.

Dominant characters, origin of, 44 , 171.

Doncaster, 110 ; on heredity in cats, 117. 
Drosophila, blind mutation, 189 ; Inachus scorpio, 166. heredity of sex, 61, 112; muta- Insects, heredity of sex in, 57. tions, 175.

Ducks, crosses of, 186.

Dutch rabbit, 173.

Earthworis, sex in, 64.

Eclipse plumage, 82.

Eigenmann, 190, 191.

Eimer, 181.

Elasmobranchs, 35 ; corpus luteum in, 143.

Elephants, testes, 151.

Eugenics, 242.

Eunuch, 73.

Evolution, evidence of, 6 .

FActors, origin of, 44.

Feathers, 36 ; evolution of, 227.

Flat-fishes, 21, 22, 33; mutations of, 198-203.

Flight, evolution of, 227.

Flounder, 25.

Foa, on lactation, 98 ; on grafting ovaries, 236.

Foges, 76.

Fowls, castration of, 74 ; origin of breeds, 187.

Fractionation of Mendelian factors, 50.

Fränkel, 103.

Frog, thumb-pad, 163.

Gallus bankiva, 45, 46, 187.

Gates, Dr. R. Ruggles, 177.

Geddes and Thomson, 65.

Gemmules, 241.

Genital ducts, 69.

Gigas, Enothera, 184.

Gillichthys, 190.

Gipsy moth, 158.

Goltz and Ewald, 97.

Gonads, hormones of, 91, 92.

Goodale, H. D., 81.

Grafting, of ovaries or testes, 235.

Groves' disease, 194.

Gudernatsch, 193.

Guthrie, C. C., 235.

Gynandromorphism, 154, 159.

Haemophilia, 115.

Hanau, 76.

Hegner, 42.

Herdwick sheep, castration in, 93.

Heredity, 41 ; and sex, 88.

Hermaphroditism, 64.

Hill, J. P., 102.

Horns, 128.

Houssaye, 35.

Interstitial cells, 94 .

Intromittent organs, 69.

JAPANESE long-tailed fowls, 129 ; artificial treatment of, 132.

KAMMERER, 234.

Kellog, 158.

Kopeč, 159.

Lactation, dependence on stimulation, 137 ; in males, 138 ; regulation of, 97.

Laevifolia, Enothera, 182.

Lamarck, 11.

Lamarckian theory, 133.

Lane-Claypon, Miss, 95 ; and Starling, on ovaries of rabbit, 102.

Larvae of insects, 233.

Lata, Enothera, 184.

Leghorn, White, 172.

Lemon-dab, 26.

Leopold and Ravana, 145.

Lepidoptera, castration in, 158.

Leptinotarsa, 42.

Limantria dispar, 158.

Limon, 100.

Linnæus, 14.

Lode, 76.

Loeb, on blind fish, 190, 191; on blindness in cave animals, 189; on tadpoles and thyroid, 193.

Lop-eared rabbits, grafting experiments, 238.

Lotsy, Professor, 45; on crossing, 173.

Lutein, of corpora lutea, 140.

MALE characters in female, 87.

Mallard crosses, 186.

Mammary glands, 8 ; origin of, 134 ; rudimentary in male, 90 .

Marshall, 142 ; and Jolly, 99.

Marsupials, relation of fœtus to pouch, 144 ; scrotum of, 150.

Masked crab, 2.

Meisenheimer, 158; thumb-pad of frog, 165.

Mendel's Principles of Heredity, 20, 107.

Mendelism, 17, 20, 43; and castra. tion, 89.

Menstruation, 145.

Metamorphosis, 188; in Flat-fishes, 200 ; causes of, 212-217; and hor. mones, 218 ; and diagnostic charac. ters, 219. 
Michaux, 180.

Midwife toad, 232 .

Milk glands, 96 .

Mole, eyes of, 189.

Monotremata, origin of milk glands, 136.

Morgan, T. H., 21, 233; on blindness in cave animals, 189 ; on mutations, 174,175 ; on sex, 60 ; on sex-linked heredity, 112 ; on sexual dimorphism in Drosophila, 120 ; on variation, 201.

Mutations, 174; in antlers, 128.

Nateral selection, $6,15,37$.

Nuptial plumage, 83.

Nussbaum, 163.

Nyssia zonaria, 161.

O'Donoghee, 98, 101 ; development of milk glands, 135 .

Enothera, mutations, 180 ; grandiflora, 180; lata, 178, 181; La. marckiana, 178-181.

Onagra, species of, 180.

Origin of Species, Darwin's, 6.

Ornithorhynchus, corpus luteum, 142.

Orthogenesis, 181.

Otariidae, scrotum, 151.

Oraries, position of, 151 .

Ovary, in birds, 183 .

Ovulation, 145.

Pangenesis, 241.

Parthenogenesis, 56.

Parturition, 146.

Pearson, Karl, 40.

Pheasant, male, 83 ; gynandromorphism in, 155.

Phillips, John C., 185.

Philosophie Zoologique, 11.

Phocidae, testes, 151.

Physiology of Reproduction, 142.

Picotee Sweet Pea, 50, 173.

Pigeons, 46.

Pigment, absence in cave animals, 191.

Pile fowls, 47.

Pintail duck, crosses, 186.

Plaice, 25.

Pleuronectes flesus, 25 ; glacialis, 27 ; platessa, 25.

Plymouth Rock fowl, 115.

Pole-dab, 26.

Poll, 156.

Preformation, 174.

Problems of Genetics, 17.

Prong-buck, 165.
Pro-œstrus, 146.

Proteus, 185 ; eyes of, 159,

Prototheria, milk glands in, 136 .

RabBITs, lactation in, 97 .

Recapitulation, absence of, 225 ; and mutations, 203.

Reptiles, corpora lutea in, 143.

Reversal, in Flat-fishes, 206.

Rhinoderma duruinii, 70 .

Ribbert, 97.

Rieger, 76 .

Rodents, testes, 152.

Romanes, 17.

Röntgen rays, effect on testes, 95 .

Rose comb, in fowls, 43.

Rotifers, heredity of sex in, 56 .

Rubricalyx, Enothera, 182.

Rubrinervis, Enothera, 152.

Sacculina, 166.

Salamanders, transplantation of eye. 190.

Sandes, 144.

Schuster, Edgar, 163.

Scrotum, origin of, 147 .

Sea-horse, 28.

Secondary sexual characters, 67 .

Selheim, 76.

Semilata, Enothera, 183.

Sertoli's cells, 93 .

Sex, 37; chromosomes, 59 ; Mendelian theory of, 53 .

Sex-linked heredity, 108.

Sexual Dimorphism, 68.

Sexual dimorphism, 119 ; in Rajidae, 222 ; in Plaice, $220,221$.

Shattock and Seligmann, 75, 156.

Silkworm, 158.

Silky fowl, 44, 46; ; plumage of, 178 .

Sirenia, absence of scrotum, 150.

Slow-worm, 227.

Smith, Geoffrey, 163, 166-168.

Snakes, absence of limbs, 226.

Sociology, 242.

Somatic sexual characters, 67,68 .

Species, conception of, 9 ; origin of, $11,14,21$; characters of, 37 : sterility and hybridism, 185.

Spermatogenesis, in man, 115.

Starling and Lane-Claypon, on lactation, 97.

Steinach, 104; heredity of milk glands, 136.

Sternum, carina of, 229.

Swallows, 3ij.

Sweet Pea, 187.

Swifts, 36 . 
TADPoles, effect of thyroid in, 193. $\mid$ Vries, De, 177.

197.

Tandler and Gross, 95.

Taxonomics, 1.

Teleosteans, 35 ; corpora lutea in, 143 ; ovarian follicles, 101.

Testes, descent of, 147.

Tetraploidy, 184.

Thayer, 33.

Thumb-pad of frog, 69 .

Thyroid-gland feeding, 193-197.

Tortoise-shell colour in cats, 117.

Tosa fowls, Japanese, 129.

Transplantation of gonads, 104.

Typhlogobius, 190, 191.

UHLENHUTH, 190.

Urodela, larva, 225.

Variations, 41.

Vespa vulgaris, 19 ; germanica, 19.

WALLART, 100.

IVasps, 18; heredity of sex in, 55.

Weapons, organs used as, 70 .

Weismann, 16.

Whale, paddle of, 8 .

White Leghorn, crosses, 49.

IVilson, E. B., 58, 61.

Wing, development of, $\{230$.

Winiwarter, von, 115.

Witch, 26.

Wood, T. B., on crossing of sheep, 107 .

Woodland, IT., 149.

Woodpecker, 8, 18.

$X$ chromosome, 58.

Zeugopterus, 29, 34.

Zoaea, 4.

\section{PTOBERTY LIRRARY N. C. State College}






$$
\begin{aligned}
& \text { Heckman Pundery in } \\
& \text { FEB. } 65
\end{aligned}
$$


21920

s.

36033

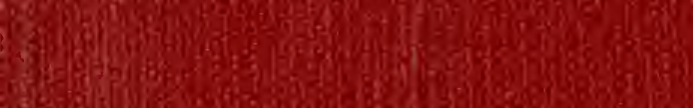

19.5.

ate

1950

for

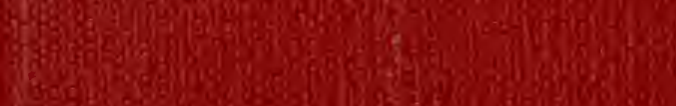

bogitic

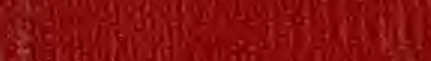

23.

81.

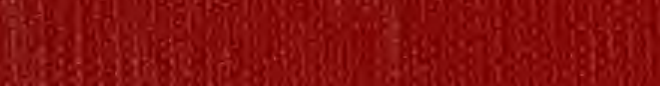

250250830

20365

Cols

ofis

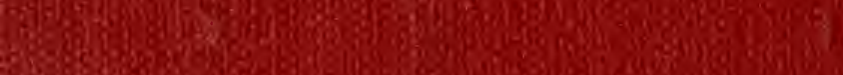

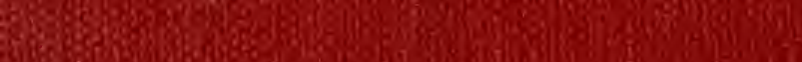

Aleses.

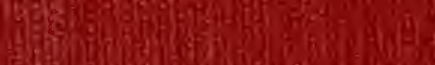

Foik

ogingen

6.

39.

2010

ESt

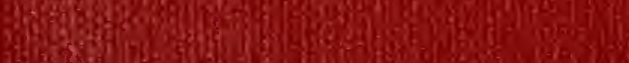

S.

thas

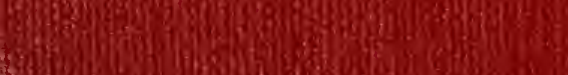

